\title{
Validation Status of the Vargow Oil Reservoir Model
}

D. W. Mayer

E. M. Arnold

W. M. Bowen

P. J. Gutknecht

October 1980

Prepared for the U.S. Geological Survey under a Related Services Agreement with the U.S. Department of Energy

Contract DE-AC06-76RLO 1830

Pacific Northwest Laboratory Operated for the U.S. Department of Energy by Battelle Memorial Institute 


\title{
NOTICE
}

This report was prepared as an account of work sponsored by the United States Government. Neither the United States nor the Department of Energy, nor any of their employees, nor any of their contractors, subcontractors, or their employees, makes any warranty, express or implied, or assumes any legal liability or responsibility for the accuracy, completeness or usefulness of any information, apparatus, product or process disclosed, or represents that its use would not infringe privately owned rights.

The views, opinions and conclusions contained in this report are those of the contractor and do not necessarily represent those of the United States Government or the United States Department of Energy.

\author{
PACIFIC NORTHWEST LABORATORY \\ operated by \\ BATTELLE \\ for the \\ UNITED STATES DEPARTMENT OF ENERGY \\ Under Contract DE-AC06-76RLO 1830
}

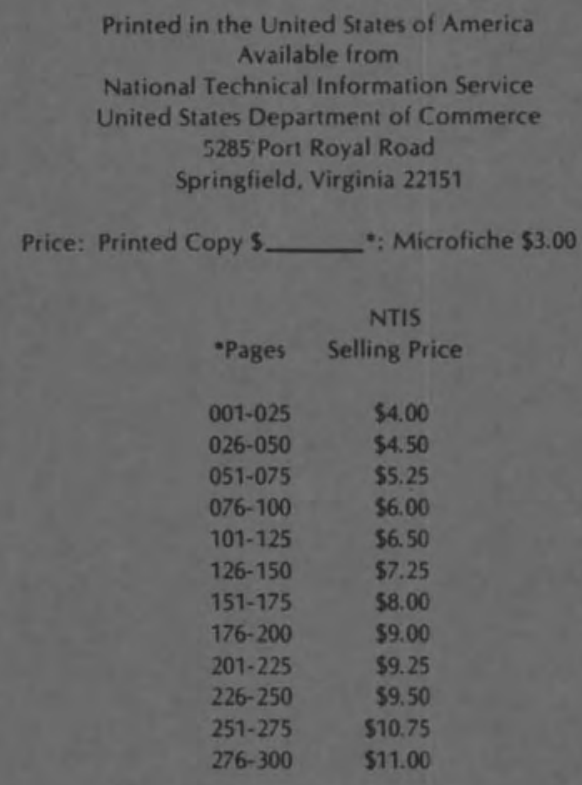




\title{
33679000553398
}

\section{VALIDATION STATUS OF THE VARGOW OIL RESERVOIR MODEL}

\author{
D. W. Mayer \\ E. M. Arnold \\ W. M. Bowen \\ P. J. Gutknecht
}

October 1980

\footnotetext{
Prepared for the U.S. Geological Survey under a Related Services Agreement with the U.S. Department of Energy Contract DE-AC06-76RLO 1830
}

Pacific Northwest Laboratory Richland, Washington 99352 
2

$\checkmark$ 


\section{SUMMARY}

VARGOW, a variable gas-oil-water reservoir model, was developed by the U.S. Geological Survey to provide recovery estimates suitable for assessing various reservoir production policies and regulations. The purpose of this study is to apply the model to actual reservoirs and to assess the model's ability to describe and predict reservoir behavior.

To this end, data were collected for a number of reservoirs. From this data base, three reservoirs approximating the model assumptions were selected for model testing purposes. Each of these reservoirs has been simulated by fixing as many of the input parameters as possible based on the data available. The remaining parameters have been estimated statistically. The ability of the VARGOW model to interpolate and predict certain observed reservoir data was used to assess the validation status of the model.

For all three reservoirs, it has been possible to simulate the observed pressures in both interpolative and extrapolative modes. Simulating the gas/ oil ratio (GOR) has not been as successful, however, even though reasonable matches with the observed data at the end of the history match period have been achieved. It has also been possible to extrapolate GOR's for a short period of time beyond the history match period.

The VARGOW model will predict physically unrealistic results if the reservoir being simulated is not initially at the bubble point pressure of the reservoir fluid. If the discovery pressure is slightly above the bubble point, adjustments to initial conditions can be made using a method that has been outlined in this report. If the discovery pressure is considerably above the bubble point, it is recommended that an undersaturated reservoir model be employed until the bubble point is reached. For simulating reservoirs whose discovery pressure is below the bubble point, the VARGOW model must be modified in a simple manner also identified in this paper. 


\section{CONTENTS}

SUMMARY

FIGURES

TABLES

NOMENCLATURE

INTRODUCTIO

CONCLUSIONS AND RECOMMENDATIONS

INITIAL GAS DERIVATIVE $\quad$ • $\quad$ • $\quad$ •

PARAMETER ESTIMATION METHODOLOGY $\quad$ • $\quad$ •

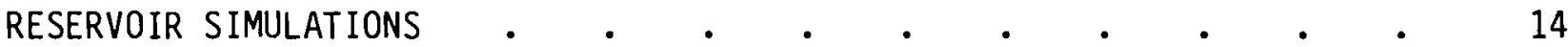

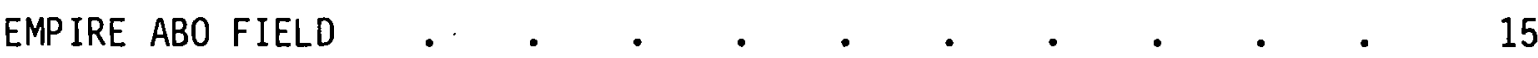

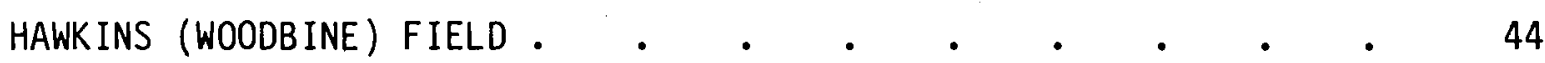

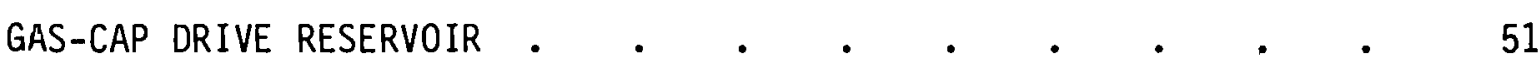

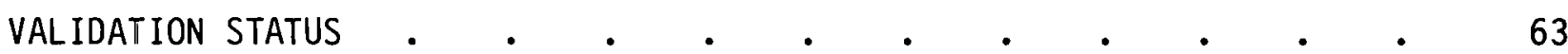

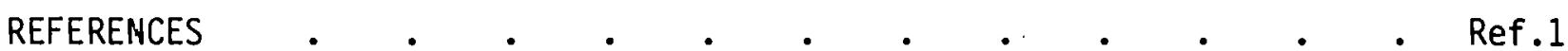

APPENDIX A - DERIVATION OF THE INITIAL GAS

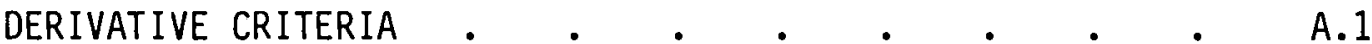

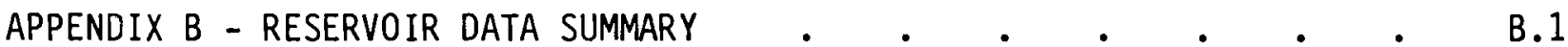




\section{FIGURES}

1 Empire Abo Pool - 0il Production Data Used for Sets . . $\quad 17$ 1,2 , and 3

2 Predicted and Observed Pressure, Set 2 (x Minimized . . . 19 for 7.6 Years)

3 Predicted and Observed GOR, Set 2 (x Minimized for . . . 20 7.6 Years)

4 Predicted and Observed Pressure, Set 3 (x Minimized . . . 25 for 15.6 Years)

5 Predicted and Observed GOR, Set 3 (x Minimized for . . . 26 15.6 Years)

6 Predicted and Observed Pressure, Set 3 (z Minimized . . . 27 for 15.6 Years)

7 Predicted and Observed GOR, Set 3 (z Minimized for . . $\quad 28$ 15.6 Years)

8 Empire Abo Pool - $0 i 1$ Production Rate Used for Set 4 . . . 29

9 Predicted and Observed Pressure $(C=2000)$, Set 4 . . . . 31 (z Minimized for First 10 Years)

10 Predicted and Observed GOR $(C=2000)$, Set 4 . . . . . 32 (z Minimized for First 10 Years)

11 Predicted and Observed Pressure $(C=12000)$, Set $4 . \quad$. . . 33 (z Minimized for First 10 Years)

12 Predicted and Observed GOR $(C=12000)$, Set 4 ( $z$ Minimized . . 34 for First 10 Years)

13 Predicted and Observed Pressure, Set $4(x$ and $y$. . . . 36 Minimized for First 10 Years)

14 Predicted and Observed GOR, Set 4 ( $x$ and y Minimized . . . 37 for First 10 Years)

15 Predicted and Observed Pressure, Set 4 (z Minimized for . . 40 15.6 Years)

16 Predicted and Observed GOR, Set 4 (z Minimized for . . . 41 15.6 Years) 
17 Predicted and Observed Pressure, Set 4 ( $x$ and $y \quad$. . . . . 42 Minimized for 15.6 Years)

18 Predicted and Observed GOR, Set 4 ( $x$ and $y$ Minimized . . . 43 for 15.6 Years)

19 Hawkins Field - $0 i l$ Production Rate $\quad . \quad$. $\quad . \quad$. $\quad . \quad 46$

20 Predicted and Observed Pressure (z Minimized for First . . . 49 21 Years)

21 Predicted and Observed GOR (z Minimized for First . . . . . 50 21 Years)

22 Predicted and Observed Pressure, $F=3$ ( $x$ Minimized for . . 52 First 21 Years)

23 Predicted and Observed GOR, $F=3$ ( $x$ Minimized for First . . 53 21 Years)

24 Predicted and Observed Pressure, $F=7$ ( $x$ Minimized for $\quad$. $\quad 54$ First 21 Years)

25 Predicted and Observed GOR, $F=7$ ( $x$ Minimized for First . . 55 21 Years)

26 Gas-Cap Drive Reservoir - 0il Production Rate _ . . . 56

27 Predicted and Observed Pressure (x Minimized for First . . . . 59 First 7 Years)

28 Predicted and Observed GOR (x Minimized for First 7 Years) . . 60

29 Predicted and Observed Pressure, $\mathrm{a}=-3 . \quad$. . . . . . 61

30 Predicted and Observed GOR, $\mathrm{a}=-3 . \quad$. $\quad . \quad$. . . . 62

\section{TABLES}

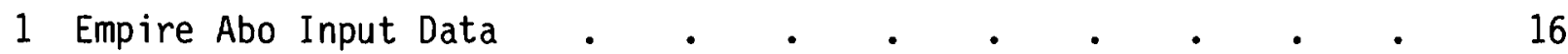

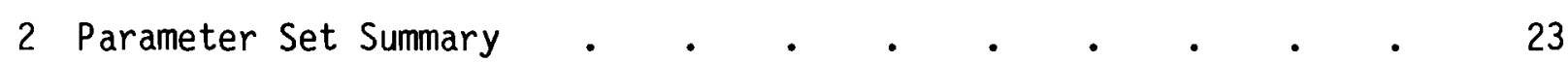

3 Hawkins Field Input Data . . . . . . . . . . 45

4 Gas-Cap Drive Reservoir Input Data . . . . . . . 57 
a Intercept of the relative permeability ratio function

API API gravity of the stock tank oil, OAPI

b Slope of the relative permeability ratio function

C Schilthuis water drive constant, $\mathrm{ft}^{3} /$ year/psia

D Segregation damping factor, years

F $0 i 1 /$ gas entrapment factor (entrapment by the invading water)

G Initial gas/oil ratio, lb-moles gas/lb-mole oil

$K_{R}$ Relative permeability ratio, $K_{R}=10(a+b \sigma)$

M Molecular weight

$\mathrm{N}$ Amount of a substance, 1b-moles

P Pressure, psia

$r \quad$ Rate of production, lb-moles/year

$R \quad$ Ideal gas constant, $19.3166 \frac{1 \mathrm{bf}-\mathrm{ft}^{3}}{\mathrm{in}^{2}-1 \mathrm{~b}-\mathrm{mole}-{ }^{0} \mathrm{~K}}$

S Gas segregation factor

$\mathrm{T} \quad$ Reservoir temperature, ${ }^{O_{K}}$

$v_{r} \quad 0 i l$ formation volume factor, RVB/STB

$v \quad$ Volume, $\mathrm{ft}^{3}$

$x \quad$ Average absolute pressure discrepancy, psi

y Average absolute weighted pressure discrepancy, psi/psi

$z \quad$ Gas deviation factor

or average abşolute GOR discrepancy, lb-mole/lb-mole

$\gamma \quad$ Specific gravity

$\theta \quad$ Time, years

$\sigma \quad$ Gas saturation, $\sigma=V_{F G} /\left(V_{F G}+V_{L}\right)$

$\Delta \quad$ Time constant in production mode1, 1/year 
B.1 Data Summary - Initial Conditions . . . . . . . . B.10

B.2 Data Summary - Reservoir Fluid Characteristics and . . . B.11 Performance History

B.3 Reservoir Agreement with Mode1 Assumptions . . . . . . B.12 
SUBSCRIPTS

DG Referring to dissolved gas

FG Referring to free gas

FGC Referring to free gas plus gas-cap gas

$L \quad$ Referring to reservoir liquid (oil plus dissolved gas)

OIL Referring to oil

$R$ Relative value

wt Weighted value

SUPERSCRIPTS

o Referring to time equal to zero. An initial condition.

- Indicates partial derivative with respect to pressure

- Indicates partial derivative with respect to time 


\section{VALIDATION STATUS OF THE VARGOW}

OIL RESERVOIR MODEL

D. W. Mayer, E. M. Arnold, W. M. Bowen, and P. J. Gutknecht

\section{INTRODUCTION}

The reservoir model discussed in the following report is a variable gasoil-water (VARGOW) reservoir per se model. This model has been developed by the U.S. Geological Survey (USGS 1976). "The purpose of the oil reservoir per se model was to make estimates of recovery from reservoirs suitable for quantitative assessments of policy alternatives related to production regulations" (Lohrenz and Monash 1979).

The term "reservoir per se" indicates that the model considers only the reservoir itself and does not consider individual wells drilled into the reservoir. The only influence that wells have on the reservoir is in determining the rate of production.

The VARGOW model is a zero-dimensional tank-piston model. "Zerodimensional" indicates that spatial variations are not considered. "Tankpiston" implies that the reservoir is modeled as a large tank with the inflowing aquifer water forming a piston that pressurizes the reservoir. The "piston" is modeled as a porous piston that allows entrapment of the reservoir material (oil and gas) by the inflowing water.

The purpose of the following report is to discuss the results obtained when the VARGOW model is used to simulate actual reservoirs. Three reservoirs have been simulated:

- Empire Abo Pool, New Mexico

- Hawkins (Woodbine) Field, Texas

- A gas-cap drive reservoir, probably in Texas. 
For each of these reservoirs, as many input parameters as possible were fixed using available reservoir data. The remaining parameters have been estimated statistically. The ability of the VARGOW model to predict certain observed reservoir data is used to determine the validation status of the model. 
The VARGOW model as currently formulated requires that a reservoir simulation be started at the bubble point pressure (the pressure at which gas starts to come out of solution) of the reservoir fluid. Most reservoirs upon discovery do not exhibit this characteristic, however: they either exceed or fall below the bubble point pressure. The model further assumes that all of the gas in the reservoir is in a dissolved phase - i.e., that neither gas-cap gas nor free gas (gas in the oil zone) is present. This, also, is not a realistic assumption unless the reservoir is at or above the bubble point pressure.

Whenever these two assumptions or conditions are not met, the model will erroneously calculate a negative value for the initial free-gas plus gas-cap gas derivitive $\dot{\mathrm{N}}_{\mathrm{FGC}}^{0}\left[\dot{\mathrm{N}}_{\mathrm{FGC}}^{0}=\mathrm{d}\left(\mathrm{N}_{\mathrm{FGC}}\right) /\left.\mathrm{dt}\right|_{t=0}\right]$. This is an unrealistic result if only dissolved gas is assumed to exist in the reservoir initially; therefore, the simulations for these cases are terminated.

For reservoirs at or above the bubble point pressure, it has been found that the following criterion must hold in order for the initial gas derivative to be positive:

$$
\mathrm{F}_{\mathrm{FGC}}<1
$$

where

$$
F_{F G C}=\frac{\frac{(1+G)^{2}}{G}\left(1-\frac{G}{1+G}\right)\left(1-\frac{1}{V_{r}}\right)+1}{N_{L}^{0} R T^{0} /\left(V_{L}^{0} P^{0}\right)}
$$


For reservoirs that are only slightly above the bubble point pressure, the above criterion can be used as a guide to adjust the initial conditions. If initially the reservoir is significantly above the bubble point, it is recommended that an undersaturated reservoir model be used to simulate the reservoir until the bubble point is reached. At that time the VARGOW model can be used to continue the simulation.

For reservoirs that are below the bubble point at discovery, the VARGOW mode 1 will also compute a negative value for $\dot{N}_{F G C}^{0}$. This occurs because the model assumes that initially there is no free gas or gas-cap gas present in the reservoir; this assumption eliminates terms from the equation for $\dot{N}_{F G C}^{0}$. To simulate these reservoirs properly, it is recommended that the feasibility of a model modification allowing for an initial amount of gas-cap gas be investigated. At this time, it appears that this modification will also necessitate the revision of the gas segregation equation. The proposed modification to the gas segregation equation is as follows:

$$
S_{E}=S_{1}^{0} e^{-D / \theta}+S_{2}^{0} e^{-\theta / D}
$$

where

$$
\begin{aligned}
& S_{1}^{0}=s_{2}^{0}=s^{0} \text { if } N_{G C}>0 \\
& S_{1}^{0}=s^{0}, S_{2}^{0}=0 \text { if } N_{G C}=0
\end{aligned}
$$

It has been found that when parameters that couldn't be determined from available data were estimated statistically using the observed pressure, the average absolute pressure discrepancy is around 40 psi. This is about $2 \%$ of the average observed pressure. When the parameters are estimated using the observed GOR, the average absolute GOR discrepancy is between 0.08 to 0.32 or between $7 \%$ and $22 \%$ of the average observed GOR. 
It is possible to fairly accurately match and predict observed pressures. This is especially true for parameters established using the observed pressures. Matching or predicting the observed GOR has been less successful probably because of discrepancies in the observed data for the Empire Abo Pool and problems in modeling an initial gas-cap for Hawkins Field and the gas-cap drive reservoir.

The model's ability to match and predict reservoir data has been considerably improved by modifying the code so as to allow simulations using the actual oil production rates.

Reservoir pressure may be extrapolated for a time span up to $50 \%$ of the history match time span; GOR's have been extrapolated for up to $20 \%$ of the same period.

Caution must be exercised when estimating certain parameters simultaneously. The concurrent estimation of $C$ and $F$ is a case in point: because $C$ and $F$ have a counteracting influence on the magnitude of the reservoir pressure, numerous parameter combinations may result in essentially the same predicted pressures, and lead to erroneous conclusions. A similar effect may be observed when $D$ and $S^{0}$ are estimated simultaneously. 


\section{INITIAL GAS DERIVATIVE}

Application of the VARGOW model to certain reservoirs results in the gas derivative (free gas plus gas-cap gas), $\dot{\mathrm{N}}_{\mathrm{FGC}}^{0}$, going negative at time equal to zero. The model assumes that initially there is no gas-cap gas or free gas (i.e., that the reservoir is in equilibrium at the bubble point pressure). As it is not physically possible to have a negative initial-gas derivitive, al1 simulations of this nature were terminated.

Subsequent investigation of this problem indicated that by adjusting certain parameters, $\dot{\mathrm{N}}_{\mathrm{FGC}}^{0}$ could be made positive. As it turns out, the parameters that influenced $\dot{N}_{\mathrm{FGC}}^{0}$ could be determined from the published reservoir data.

Parameters typically estimated by statistical techniques (a, b, C, F, D, $S^{0}$ ) seemed to have no influence on $\dot{N}_{F G C}^{0}$. The derivation of the mode 1 equations has been subsequently reviewed with special emphasis on the equation for $\dot{\mathrm{N}}_{\mathrm{FGC}}$. In the mode $1, \dot{\mathrm{N}}_{\mathrm{FGC}}$ is calculated as follows (USGS 1976):

$$
\dot{N}_{F G C}=\frac{b_{1}(\alpha \gamma-\beta \psi)-b_{2} \gamma+b_{3} \beta}{W}
$$

where

$$
\begin{aligned}
& b_{1}=-r_{\text {TOTAL }}-\frac{C F(1+n)\left(P^{0}-P\right)}{\alpha+\zeta n} \\
& b_{2}=-C(1+F)\left(P^{0}-P\right)
\end{aligned}
$$




$$
\begin{aligned}
& b_{3}=-\frac{C F(\psi+n)\left(P^{0}-P\right)}{\alpha+\zeta n}-\frac{\left(\psi+\frac{K_{R} v^{0} \phi}{\zeta}\right)}{\left(1+\frac{K_{R} v^{0} \phi}{\zeta}\right)} r_{T O T A L} \\
& \alpha=\frac{V_{L}^{0}}{N_{L}^{0}}\left[\frac{1}{v_{r}}+\left(1-\frac{1}{v_{r}}\right) \frac{P}{P^{0}}\right] \\
& \beta=\frac{V_{L}^{0}}{P^{0}}\left(1-\frac{1}{V_{r}}\right)-\frac{R T^{0}}{P^{2}} N_{F G C} \\
& \gamma=\frac{G P^{0} N_{L}}{\left(P^{0}+G P\right)^{2}} \\
& \psi=\frac{G P}{P^{0}+G P} \\
& W=\frac{R T^{0}}{P} \\
& W(1-\psi)+\gamma(\alpha-\zeta) \\
& \hline
\end{aligned}
$$

Now

$$
v^{0}=\frac{V_{L}^{0}}{N_{L}^{0}}
$$




$$
\begin{aligned}
& \phi=\frac{1}{v_{r}}+\left(1-\frac{1}{v_{r}}\right) \frac{p}{p^{0}} \\
& K_{R}=10^{(a+b \sigma)} \\
& \sigma=\frac{v_{F G}}{V_{F G}+V_{L}} \\
& r_{\text {TOTAL }}=r_{\text {OIL }} \frac{1+\left(K_{R} v^{0} \phi / \zeta\right)}{1-\psi}
\end{aligned}
$$

The other variables have been defined in the nomenclature section.

In conjunction with the assumption that initially gas-cap gas and free gas are not present in the reservoir (i.e., $N_{F G C}^{0}=0$ and $V_{F G}^{0}=0$ ), an analysis of Equation 1 (Appendix $A$ ) results in the following equation for $\dot{\mathrm{N}}_{\mathrm{FGC}}^{0}$ :

$\dot{N}_{F G C}^{0}=\left(\frac{r_{0 I L}^{0}}{1-\frac{G}{1+G}}\right) \frac{\left[\left(\frac{G}{1+G}-1\right)\left(1-\frac{1}{V_{r}}\right)\left(10^{a} \frac{V_{L}^{0} P^{0}}{N_{L}^{0} R T^{0}}\right)\right]-\left[\frac{G}{(1+G)^{2}}\left(1+10^{a} \frac{V_{L}^{0} P^{0}}{N_{L}^{0} R T^{0}}\right)\right]}{\left[\left(1-\frac{1}{v_{r}}\right)\left(1-\frac{G}{1+G}\right)+\frac{G}{(1+G)^{2}}\right]-\left[\frac{G}{(1+G)^{2}} \frac{N_{L}^{0} R T^{0}}{V_{L}^{0} P^{0}}\right]}$

Since $N_{L}^{0}, V_{L}^{0}, T^{0}, P^{0}, G$, and $r_{0 I L}^{0}$ are always positive, and $v_{r}$ is always greater than one, it is apparent that the numerator for Equation 16 is always negative. Therefore, to avoid a negative value for $\dot{\mathrm{N}}_{\mathrm{FGC}}^{0}$ and to avoid $\dot{\mathrm{N}}_{\mathrm{FGC}}^{\mathrm{O}}$ becoming infinite, the denominator must be less than zero. We can define a criterion as follows: 


$$
F_{F G C}=\frac{\frac{(1+G)^{2}}{G}\left(1-\frac{G}{1+G}\right)\left(1-\frac{1}{V_{r}}\right)+1}{\frac{N_{L}^{0} R T^{0}}{V_{L}^{0} P^{0}}}<1
$$

This criterion must be met if a negative value for $\dot{\mathrm{N}}_{\mathrm{FGC}}^{0}$ is to be avoided. Notice that $\mathrm{F}_{\mathrm{FGC}}$ is a function of parameters that are typically available or can be computed from data that are available for a given reservoir. This criterion has proven useful for investigating the cause of a negative initial-gas derivative.

Typically, reservoirs are not initially at the bubble point as assumed by the model. Therefore, certain adjustments to the initial conditions are necessary. If it is assumed that the values for $G$ and $V_{r}$ are reasonably close, then Equation (17) indicates that increasing $N_{L}^{0}$, increasing $T^{0}$, decreasing $V_{L}^{0}$, and/or decreasing $P^{0}$ are the proper adjustments to make if the criterion for $F_{F G C}$ is to be met.

If initially the reservoir is slightly undersaturated (i.e., if the discovery pressure is slightly above the bubble point pressure), then it will be necessary to adjust $N_{L}^{0}, T^{0}, V_{L}^{0}$, and/or $P^{0}$ if the reservoir is to be simulated. If initially the reservoir is below the bubble point pressure, free gas will have evolved and Equation 17 will no longer be valid. Experience with the VARGOW model indicates that $\dot{\mathrm{N}}_{\mathrm{FGC}}^{0}$ will still be negative for these conditions. This is not due to physical reasons, but due to the fact that terms are deleted from Equation 1 by the assumption that there is no free gas or gas-cap gas $\left(N_{F G C}^{0}\right.$ ) initialiy present (see Equation 6 ).

In summary, the initial-gas derivative can be negative if the reservoir is above or below the bubble point pressure. In the first case, a negative $N_{F G C}^{0}$ is physicaliy reasonable from the standpoint that, if gas were present under these conditions, it would be condensing. Consequently, the initial conditions need to be slightly adjusted using the criterion for $F_{F G C}$ as a guideline. The second case, however, causes $N_{F G C}^{0}$ to be negative since it is assumed that $N_{F G C}$ 
is initally zero. To overcome this problem, we have made a temporary change to the code that allows us to initialize $N_{F G C}$ at a value that corresponds to the original amount of gas in the gas cap. This change allows us to simulate certain kinds of reservoirs, at the cost of creating problems in the mode 1 development where the " $\mathrm{N}_{\mathrm{FGC}}^{\circ}$ equals zero" assumption has been used.

It would be desirable to couple the present VARGOW model with an undersaturated reservoir model. By doing this, initially undersaturated reservoirs could be simulated down to the point at which the pressure is equal to the bubble point pressure, at which time the present VARGOW model could be used to continue the simulation. Furthermore, it would be beneficial to slightly modify the model so that an initial amount of gas-cap gas and free gas can be accounted for. This modificaton is not expected to require extensive revision to the model derivation since the VARGOW model, as currently formulated, can account for the free gas and gas-cap gas at all times greater than zero. In other words, it should be possible to simulate reservoirs that have an initial amount of gas-cap gas and free gas if the model is changed such that the conditions at the start of the simulation correspond to the time (in the model as currently formulated) where the amount of free gas and gas-cap gas matches the actual data. 


\section{PARAMETER ESTIMATION METHODOLOGY}

When using the VARGOW model, one must describe the physical characteristics and rates associated with simulation of the reservoir. The purpose of the VARGOW statistical parameter estimation is to use statistical methodology to give optimal estimates of these parameters, which may include a, b, C, F, $D$, and $\mathrm{S}^{\mathrm{O}}$.

The basic strategy is to: 1) define a set of possible values for the unknown parameters; 2) to use this set of parameter values in the VARGOW model to predict the pressure and gas-oil ratio (GOR) for specific points in time; and 3) to then compare the predicted quantities with quantities actually observed for a given reservoir. The objective is to find a set of values for the unknown parameters that minimizes the discrepancies between the predicted and observed quantities.

The chosen measures of discrepancy between the predicted and observed quantities are given by:

$$
\begin{aligned}
& x=\sqrt{\sum_{t=1}^{n}\left(O P_{t}-P_{t}\right)^{2} / n} \\
& y=\sqrt{\sum_{t=1}^{n}\left(\frac{O P_{t}-P_{t}}{O P_{t}}\right)^{2} / n}
\end{aligned}
$$

and

$$
z=\sqrt{\sum_{t=1}^{n}\left(O G_{t}-G_{t}\right)^{2} / n}
$$


where the index $t$ ranges over $n$ specified times, and where

$$
\begin{aligned}
O P_{t} & =\text { observed pressure at time } t \\
P_{t} & =\text { predicted pressure at time } t \\
O G_{t} & =\text { observed gas-oil ratio at time } t \\
G_{t} & =\text { predicted gas-oil ratio at time } t .
\end{aligned}
$$

To conduct this search for a set of parameter values that will minimize $x, y$, and $z$, we used concepts from statistical response surface methodology. An excellent reference on this subject is Myers (1976).

This study was conducted using a six-step approach:

1. Value ranges were specified for the unknown parameters.

2. An orthogonal central composite design (Myers 1976, p. 127) was constructed based on five equally spaced levels of each unknown parameter spanning the ranges specified in Step 1. For example, this design defines 25 distinct combinations of values whenever four parameters are being estimated.

3. Each of the parameter value combinations was used in the VARGOW mode 1 to predict the pressure and GOR quantities for the specified times.

4. The results from Step 3 and the observed pressure and GOR quantities were used to compute $x, y$, and $z$ from Equations 18a, 18b, and 19 for each of the parameter value combinations.

5. A second-order response surface (i.e., a second-order polynomial regression model with linear, pure quadratic, and mixed quadratic terms) was fitted by letting $x, y$, or $z$ be the "response variable" and by letting the unknown parameters be the so-called "independent variables."

6. The fitted response surface was then analyzed via canonical analys is and ridge analysis (Myers 1976) to determine which parameter value combination(s) within the ranges specified in Step 1 will minimize $x, y$, or $z$.

The results of this analysis indicate that either: 
a. A stationary point exists on the fitted surface within the specified parameter ranges where $x, y$, or $z$ is an absolute minimum. This combination of parameter values, when used in the VARGOW model, will yield predicted pressure or GOR quantities that are closer to the observed quantities than the predicted quantities using any other parameter value combination on the present parameter ranges.

or

b. There is no stationary point of absolute minimum on the present range of parameter values. However, the analys is does identify the most promising region to explore next and, thus, gives guidance in respecifying ranges for the parameter values (see Step 1). The search continues by returning to Step 1 with this additional information.

These six steps are carried out repeatedly until no further decrease in $x$, $y$, or $z$ can be attained. The resulting parameter values are then retained as being the "best" set of values to use in the VARGOW model to predict the pressure or GOR. 


\section{RESERVOIR SIMULATIONS}

During the course of the research program, three reservoirs have been simulated. The reservoirs were selected on the basis of a Reservoir Data Summary that was performed during the early phases of research (Appendix A). Of the eleven reservoirs surveyed, the following three reservoirs were selected:

- Empire Abo Field, New Mexico

- Hawkins (Woodbine) Field, Texas

- a gas-cap drive reservoir, probably in Texas.

The selection of these reservoirs was based on the availability of sufficient data to perform a simulation and on reasonable agreement with the model assumptions. (For a listing of the model assumptions, see Appendix A.)

Preparation of the reservoir data for input to VARGOW frequently requires the conversion of volume-based units to mole-based units. Since information on the molecular weight and density is infrequently reported, the following relationships have been used to obtain the specific gravity $\left(\gamma_{0 I L}\right)$ and molecular weight $\left(M_{O I L}\right)$ of the stock tank oil:

$$
\begin{aligned}
& \gamma_{0 I L}=\frac{141.5}{A P I+131.5} \\
& M_{O I L}=\frac{6084}{A P I-5.9}
\end{aligned}
$$

where API is the API gravity of the stock tank oil (Craft and Hawkins 1959, p. 67). When information on the gas phase is required, the ideal gas law modified by the gas deviation factor $z$ has been used:

$$
P V=z n R T
$$


The gas deviation factor has been determined from pseudocritical temperature and pressure charts in conjunction with a compressibility factor chart (Craft and Hawkins 1959, pp. 19-21). The value $z$ has been assumed to be unity at standard conditions.

\section{EMPIRE ABO FIELD}

The Empire Abo pool is located in southeastern New Mexico and was discovered in November 1957. Upon discovery, this pool was slightly undersaturated; the discovery pressure was approximately $6 \%$ higher than the reservoir bubble point pressure of 2231 psia referenced to $-2264 \mathrm{ft}$. The data set for this reservoir is fairly extensive, having been compiled from reports by Killough and Foster (1979); Christianson (1977); and from the Annual Reports published by the New Mexico $0 i 1$ and Gas Engineering Committee (1958-1978). Based on the data contained in these reports, it has been possible to arrive at reasonable values for all of the model input parameters except for $C, F, D$, and $S^{0}$ (Table 1). Set No. 1 contains the data as originally developed for the simulation.

When the initial reservoir simulations were conducted with data set No. 1, it was discovered that the initial gas derivative, $\dot{\mathrm{N}}_{\mathrm{FGC}}^{0}$, was negative. Substitution of the appropriate values into Equation 17 indicates that:

$$
F_{F G C}=1.074 \nless 1 .
$$

Therefore, a negative value for $\dot{N}_{F G C}^{0}$ is expected. By reducing $V_{L}^{0}$ by $7 \%$, it was possible to perform the simulations. Therefore, Set No. 2 was adopted for the first parameter estimation series. For this set, the oil production curve designated by Mode $1=3$ (Figure 1 ) has been used. When Model $=3$, the instantaneous oil production is calculated by:

$$
r_{\text {OIL }}=r_{\text {OIL }}^{0}
$$


TABLE 1. Empire Abo Input Data

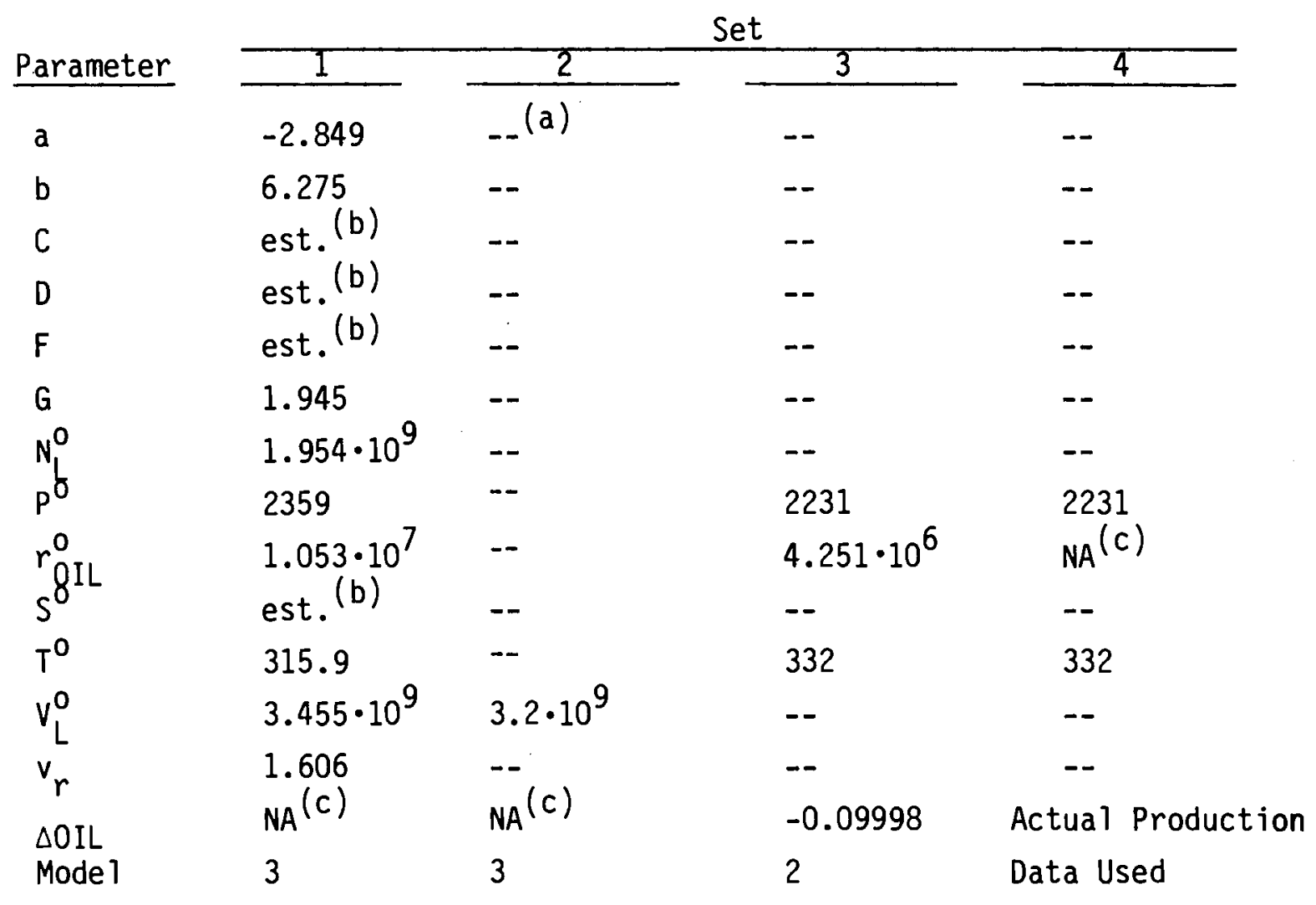

(a) All parameters the same as for Set 1 except for the indicated changes (b) These values estimated statistically

(c) Not applicable

This oil production curve was selected because the actual cumulative oil production matches the predicted cumulative oil production. The resulting oil production rate is too high initially and too low near the end of the simulation, however.

The parameters for Set 2 were estimated based on the observed pressure, using Equation 18a for the first 7.6 years of data. Since there are eight observed values, $n=8$ in Equation 18a. The parameter values which minimize $x$ are: 


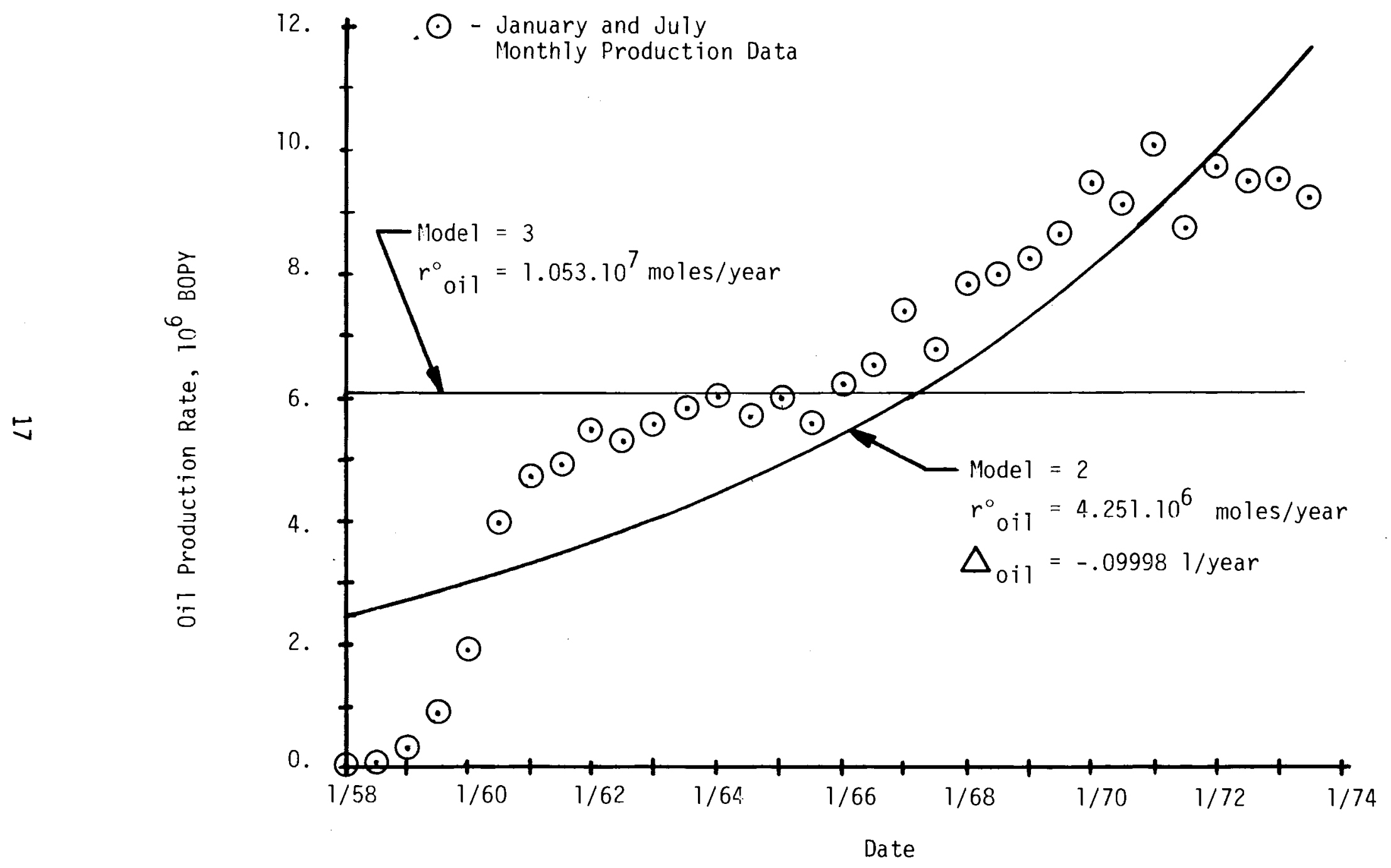

FIGURE 1. Empire Abo Pool - 0il Production Data Used for Sets 1,2 and 3 


$$
\begin{aligned}
C & =47500+2500 K \\
F & =2.75+0.75 K \\
D & =100 \\
S^{0} & =0.5
\end{aligned}
$$

where $-1 \leq K \leq 1$. The value of $x$ is 36 psi for any value of $k$ within the indicated range.

The predicted and observed pressures and GOR have been plotted in Figures 2 and 3 . The observed pressure is the average of observed pressures from individual wells, and the observed GOR is based on the annual oil and gas production (Annual Reports 1958-1978). In these and subsequent plots, the history match period is the time span over which the actual data have been used to statistically estimate certain parameters. The extrapolation region is the period of time following the history match. During this time, the parameters are fixed at the values indicated by the parameter estimation performed during the history match period.

Figure 2 shows that the predicted pressure curve matches the observed data very well at the end of the history match period. The predicted pressure curve has an initial slope that is too steep. This has caused the simulation to underpredict the pressure initially and to overpredict in the extrapolation region (time $>7.6$ years). This phenomenon was attributed to the constant oil production rate used for the simulation. Since the reservoir is overproduced initially, the predicted pressure will drop faster than the observed values. Conversely, near the end of the simulation the reservoir is being underproduced, causing the pressure to drop more slowly than the observed values. This explanation is verified by the results from Set 3, in which the $0 i 1$ production rate was modeled as an exponentially increasing function. Set 3 is discussed in detail later in this section.

Figure 3 is a plot of the observed and predicted GOR. The range of predicted and observed values appears reasonable, although they exhibit different trends. The observed data increase with time and then start to level off, while the predicted values decrease with time and then start to increase. 
MODEL TEST ON EMPIRE ABO POOL - JAN'58 TO JUL'73

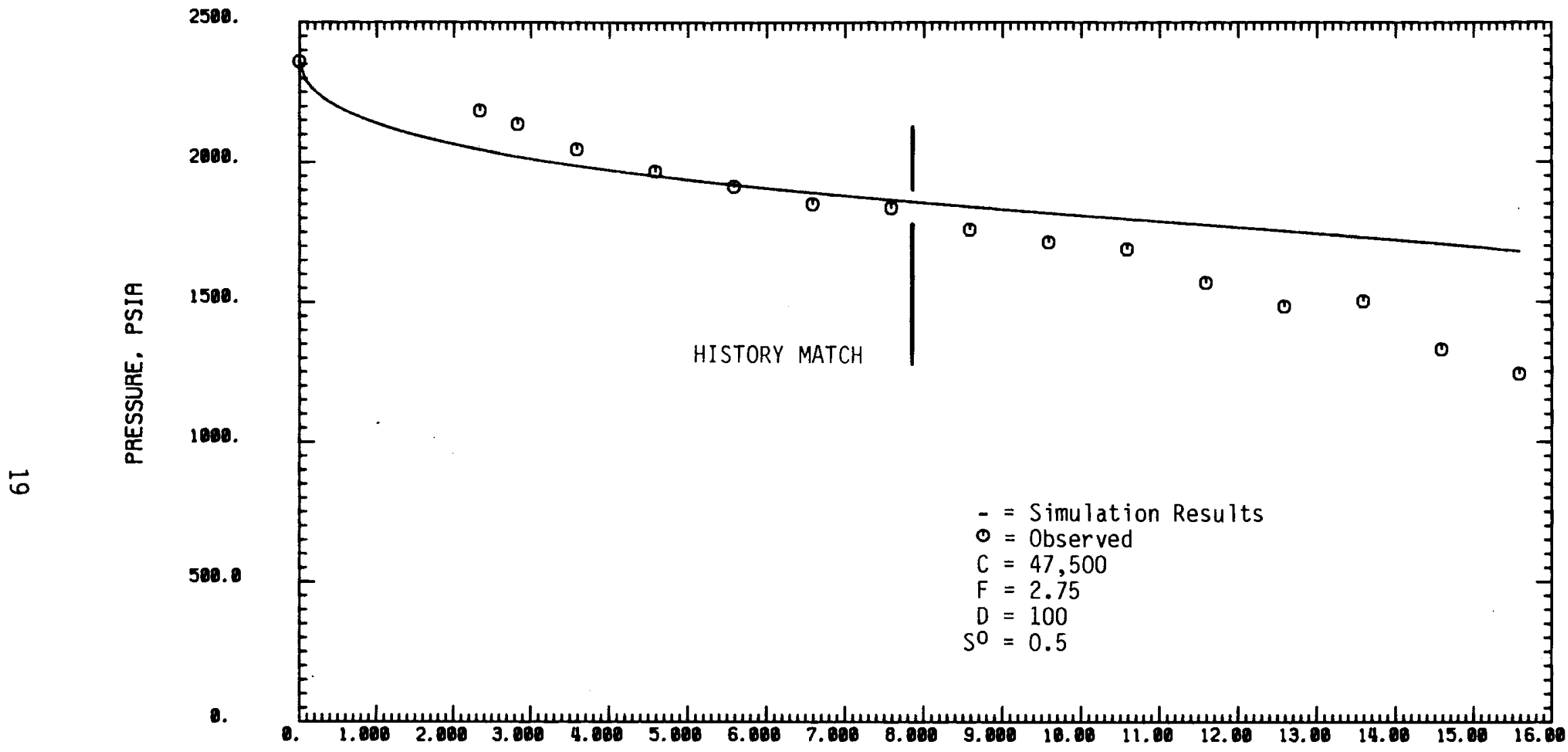

TIME = 14,19,59 DATE $=25-J U L-80$

TIME, YERRS

FIGURE 2. Predicted and Observed Pressure, Set 2 ( $x$ Minmized for 7.6 Years) 
MODEL TEST ON EMP:RE ABO POOL - JAN'58 TO JUL'73

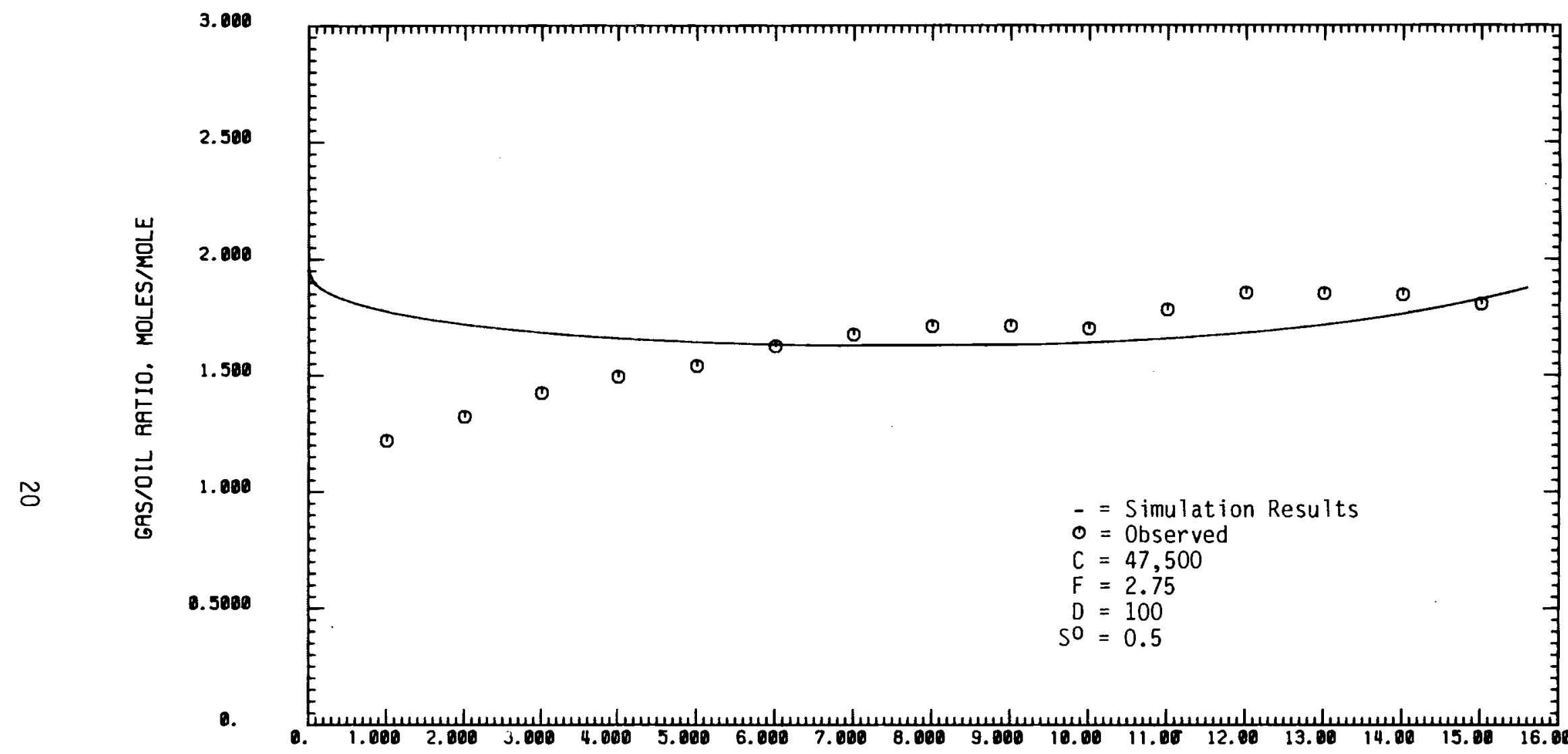

T:ME $=10 \cdot 22,05$ DATE $=31-\mathrm{JUL} \cdot 80$

T:ME, YEARS

FIGURE 3. Predicted and Observed GOR, Set 2 ( $x$ Minimized for 7.6 Years) 
The apparent discrepancy between the observed and predicted GOR can possibly be explained by one or all of the following:

- A laboratory analysis error may have been made in the initial measurement of the GOR

- The gas produced early in the reservoir's history may have been flared and consequently not reported

- Early gas production data may have been based on well test data and not metered until the gas plant came on line. Hence, the gas production data may not truly reflect the actual gas produced

- Strong gravity segregation may be causing the producing GOR to be less than is typical for the reservoir.

To test the hypothesis that the oil-production-rate model was contributing to the mismatch between the observed and predicted pressures, a new parameter estimation series was initiated. For this set (No. 3), it was decided that a more viable means of avoiding the problem, with $\dot{N}_{F G C}^{0}$ being negative, was to reduce the starting pressure to the bubble point value (one of the model assumptions is that the reservoir is initially at the bubble point), to use the original liquid volume as calculated, and to increase the reservoir temperature until $\dot{N}_{F G C}^{0}$ becomes positive. This action resulted in an increase of $\mathrm{T}^{0}$ by $5 \%$. In addition, the oil production rate model was modified to more qualitatively match the actual production history. An exponentially increasing oil rate curve was used. This curve (Figure 1 ) is designated by Model $=2$. The instantaneous oil rate, when Model $=2$, is given by:

$$
r_{O I L}=r_{O I L}^{0} e^{-\Delta_{0 I L} / \theta}
$$

The parameter estimation for this set has been carried out for the entire 15.6 years and is based on the pressure and on the GOR ratio. There were fifteen specified times, so that in Equations $18 \mathrm{a}$ and $19, n=15$. The starting ranges for the parameter values were based on the results of Set 2 . 
Looking first at the results for pressure, the parameter values which minimize $x$ (as given by Equation 18a) are:

$$
\begin{aligned}
C & =11,000 \\
F & =4.8 \\
D & =95 \\
S^{0} & =0.5
\end{aligned}
$$

The value of $x$ at this parameter combination is $95 \mathrm{psi}$. This means that the average absolute discrepancy between observed and predicted pressure quantities for the fifteen specified times will be $95 \mathrm{psi}$, if the parameter combination given by $(26)$ is used in the VARGOW model.

Looking now at the GOR results, the parameter values which minimize $z$ (as given by Equation 19) are:

$$
\begin{aligned}
C & =25,000 \\
F & =0.8 \\
D & =95 \\
S^{0} & =0.5
\end{aligned}
$$

The value of $z$ at this parameter combination is 0.2523 . In other words, the average absolute discrepancy between observed and predicted GOR quantities for the fifteen specified times will be 0.2523 if the parameter combination given by (27) is used in the VARGOW model.

In this case, there is no single combination of parameter values which minimizes both $x$ and $z$ simultaneously. Therefore, a compromise must be made. Table 2 summarizes the parameter sets given by (26) and (27), and the corresponding values of $x$ and $z$. Since $D=95$ and $S^{0}=0.5$ for both $(26)$ and (27), these values are not displayed. 


\section{TABLE 2. Parameter Set Summary}

\begin{tabular}{|c|c|c|c|c|}
\hline \multirow{2}{*}{$\begin{array}{c}\text { Value } \\
\text { Minimized }\end{array}$} & \multirow{2}{*}{$\frac{\text { Parameter }}{\mathrm{C}}$} & \multirow{2}{*}{$\frac{\text { Values }}{F}$} & \multicolumn{2}{|c|}{$\begin{array}{l}\text { Average Absolute } \\
\text { Discrepancies }\end{array}$} \\
\hline & & & $x$ & $z$ \\
\hline$x$ & 11,000 & 4.8 & 95 & 0.274 \\
\hline$z$ & 25,000 & 0.8 & 124 & 0.252 \\
\hline
\end{tabular}

At first glance, it would appear that the consequences of minimizing $z$ and ignoring $\mathrm{x}$ would be much more severe than if $\mathrm{x}$ were minimized and $\mathrm{z}$ were ignored. However, closer examination on a relative basis shows that the consequence of minimizing $x$ or $z$ is nearly the same.

The range of observed pressure quantities is:

$$
1243 \leq O P_{t} \leq 2184,
$$

while the range of observed GOR quantities is:

$$
1.2197 \leq O G_{t} \doteq 1.8067 .
$$

Thus, the observed pressure quantities are roughly 1000 times larger than the observed GOR quantities.

Looking at Table 2, the difference in the $x$ values for the two parameter combinations is $124-94=30$. Similarly, the difference in the $z$ values is $0.274-0.252=0.022$. Thus, the difference in the $x$ values for the two parameter combinations is roughly 1000 times larger than the difference in the $z$ values. Therefore, on a relative basis, either of the parameter sets in Table 2 could be used. The choice would depend entirely on whether it is more desirable to minimize $x$ or $z$. For this study, it was decided that the observed 
pressure quantities were more reliable than the observed GOR quantities, so that the parameter values given in (26) were the logical choice.

The simulation results using the parameter values in (26) are plotted in Figures 4 and 5 . If Figure 4 is compared with Figure 2, it is apparent that changing the oil production rate and estimating the parameters for the full 15.6 years leads to a better fit of the observed pressure data. The initial slope of the predicted pressure curve is not nearly as steep, and at points in time near the end of the simulation, the pressure curve tails down to better match the data. The GOR curve (Figure 5 ) has a more pronounced upsweep during the last few years of the simulation, however.

The results based on (27) are plotted in Figures 6 and 7. The pressure curve is essentially the same as that shown in Figure 4. The GOR curve, shown in Figure 7 , is a much better fit to the observed data than in Figure 5 . This is expected since this curve is based on a minimization of the GOR discrepancy.

Based on these results, it was felt that a better match with the observed data could be obtained if the VARGOW model was modified so that the actual monthly oil production rate data could be used. This modification has been completed. Now the production rate data can be input as a step function (i.e., at a constant rate until the time at which a new rate is in effect), or the rate will be linearly interpolated between rates specified at given points in time. Linearly-interpolated rates have been used for this study, because the code can run approximately three times faster than if step functions are used. In addition, the parameters have been estimated by minimizing the weighted pressure discrepancy, $y$ (Equation 18b), as well as the pressure and GOR discrepancy, $x$ and $z$. Data Set 4 (Table 1) has been used for this final series of parameter estimations on the Empire Abo Field. This data set is essentially the same as Set 3, except that the oil production rate is linearly interpolated between the actual data points. Figure 8 is a plot of the oil production rate used for this set.

The parameters are estimated using the first 10 years of observed data. The final 5.6 years of this case are used to test the model's extrapolative 
EMP:-RE RBO, PARAMETER'S EST. USING P, JAN'58 THRU JUL'73

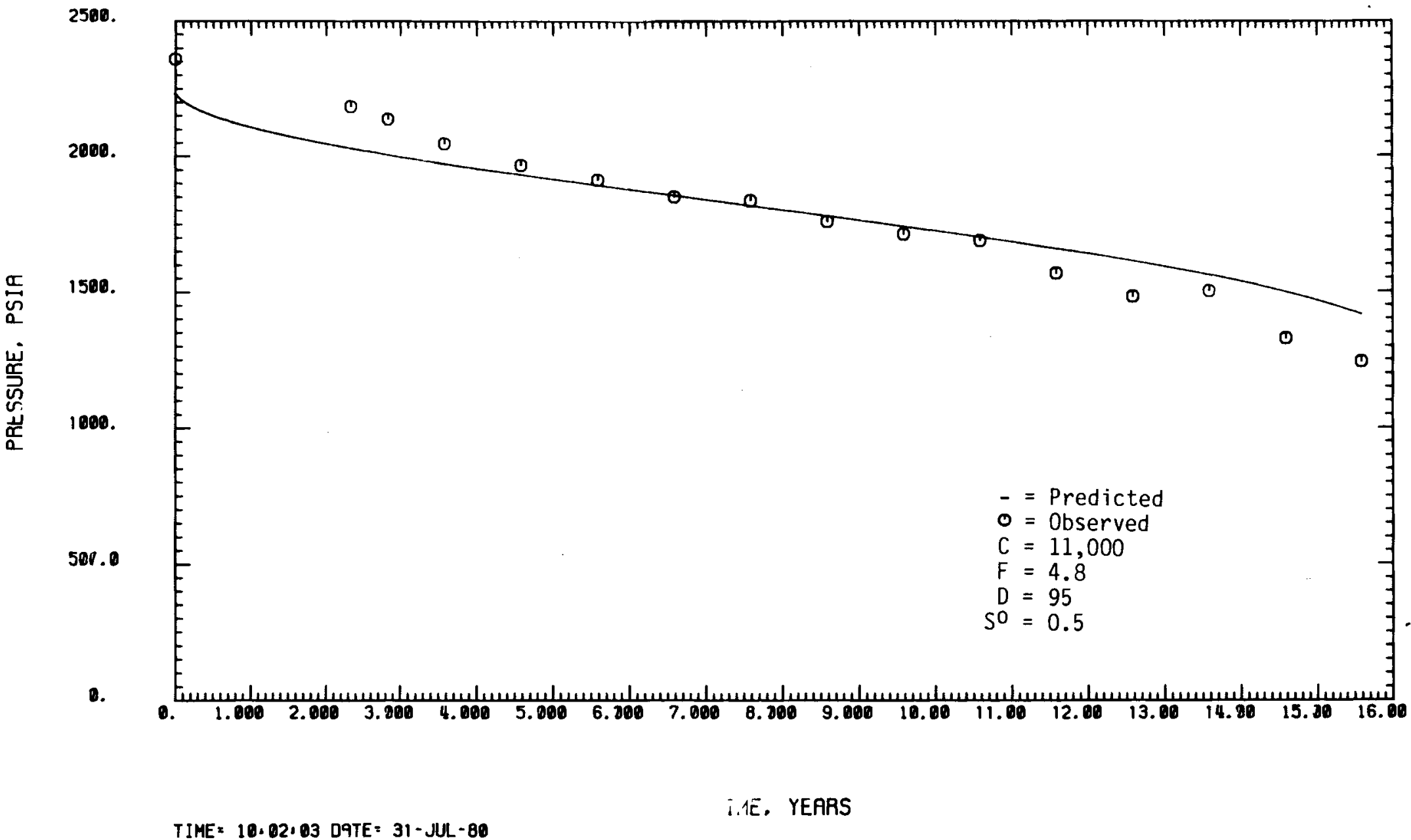

FIGURE 4. Predicted and Observed Pressure, Set 3 (x Minmized for 15.6 Years) 
EMP:RE ABO, PARAMETER'S EST. US:NG P, JAN'58 THRU JUL'73

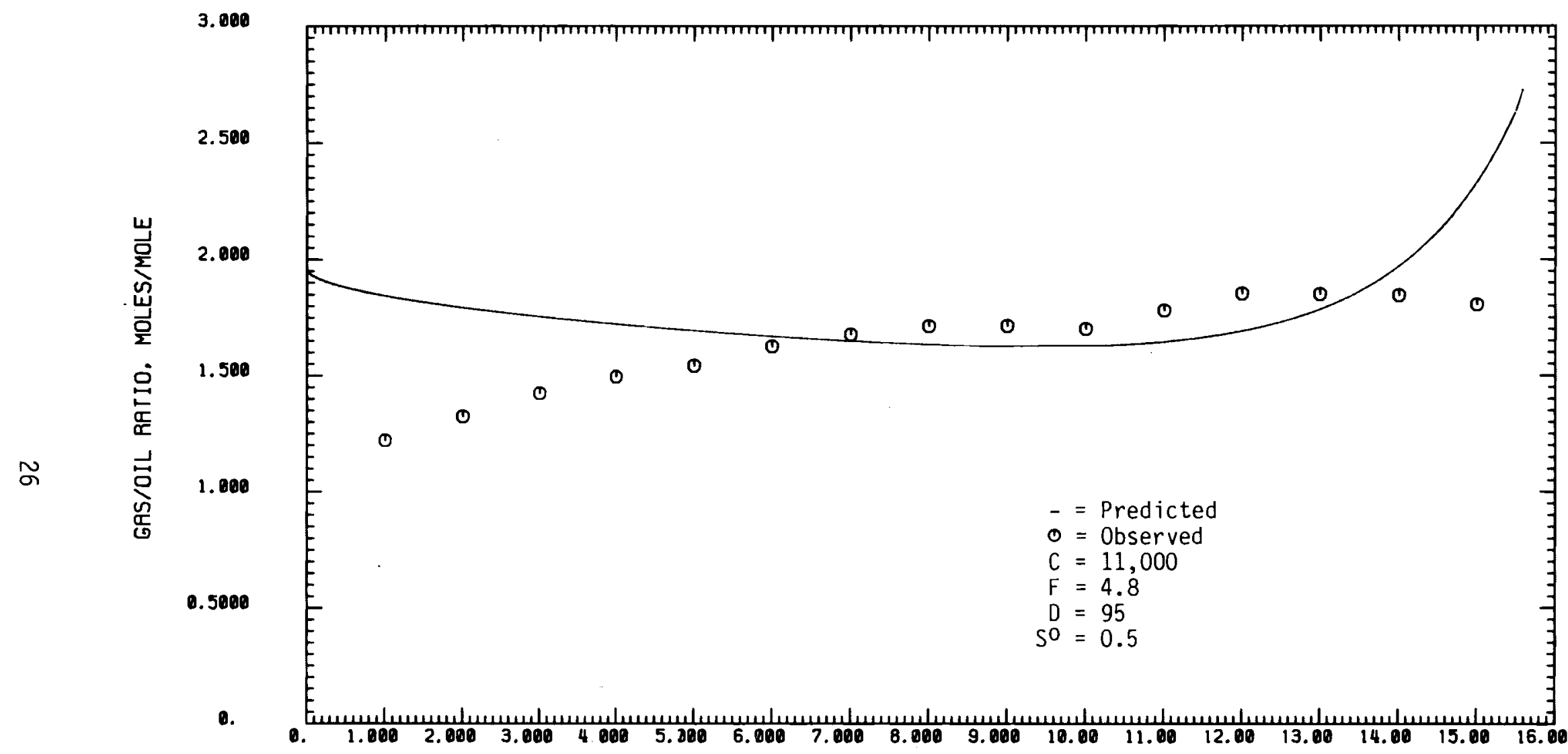

T:ME = 10:08:00 DATE = 31-JUL-80

TIME, YEARS

FIGURE 5. Predicted and Observed GOR, Set 3 (x Minimized for 15.6 Years) 
EMP:RE ABO, PARAMETER'S EST. USING G, JAN'58 THRU JUL'73

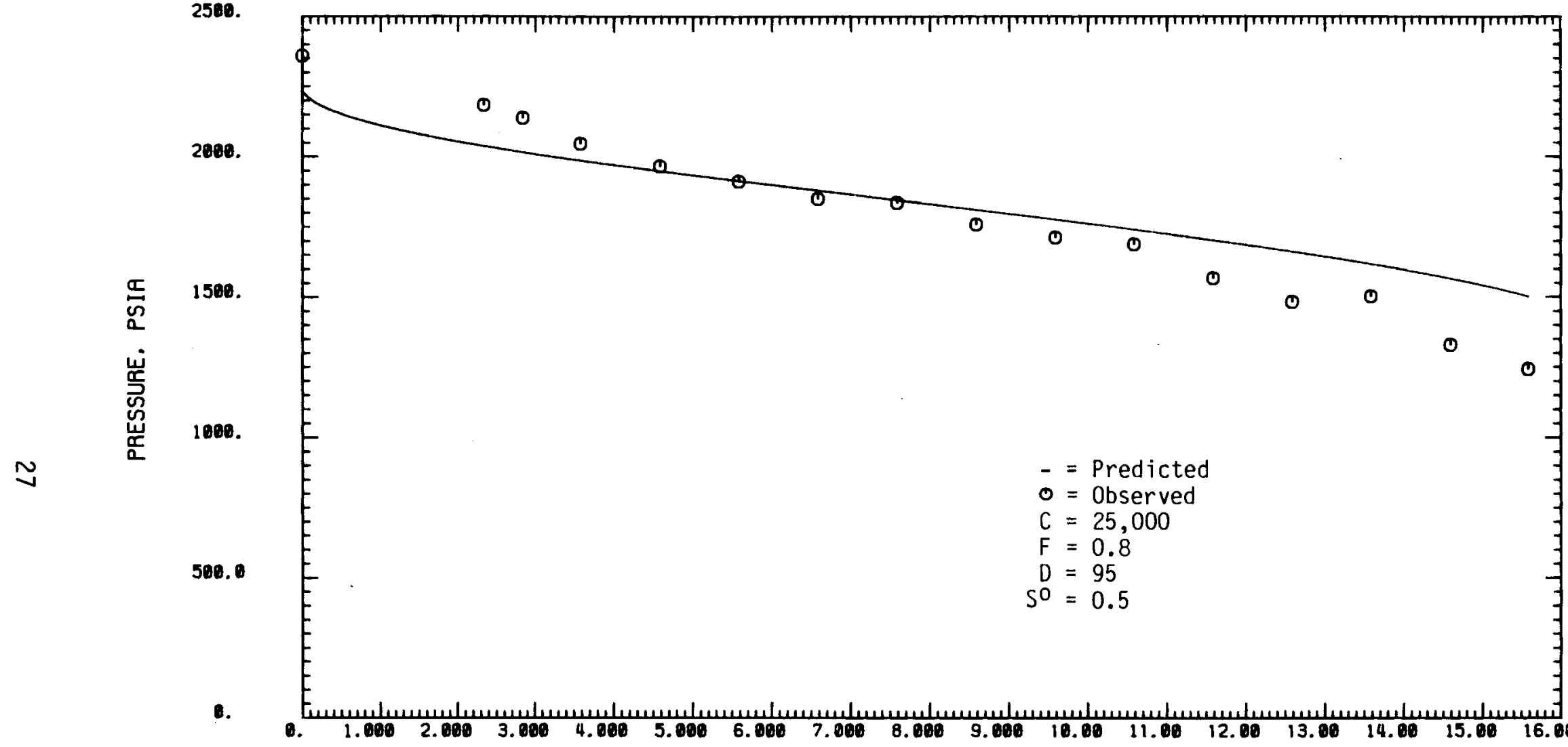

TIME $=10,15 \cdot 12$ DATE $=31-J U L-80$

TIME. YEARS

FIGURE 6. Predicted and Observed Pressure, Set 3 (z Minimized for 15.6 Years) 
EMP:PE ABD, PARAMETER'S EST. US'NG G. JAN'58 THRU JUL'73

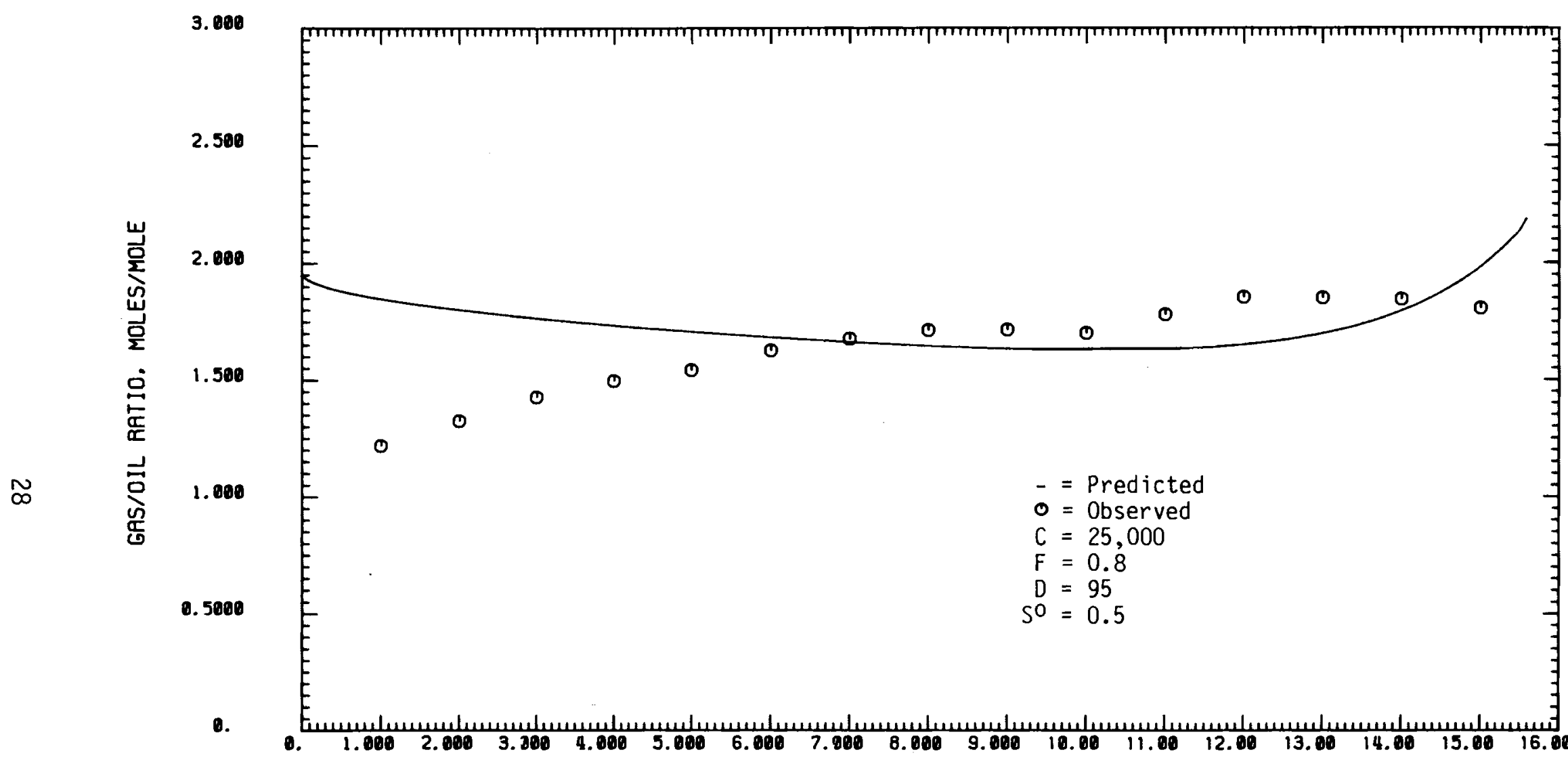

IIME $=10 \cdot 17 \cdot 11$ DATE $=31-J U L-80$

T:ME, YEARS

FIGURE 7. Predicted and Observed GOR, Set 3 ( $z$ Minimized for 15.6 Years) 
EMPIRE ABO POOL - OIL PRODUCTION RATE

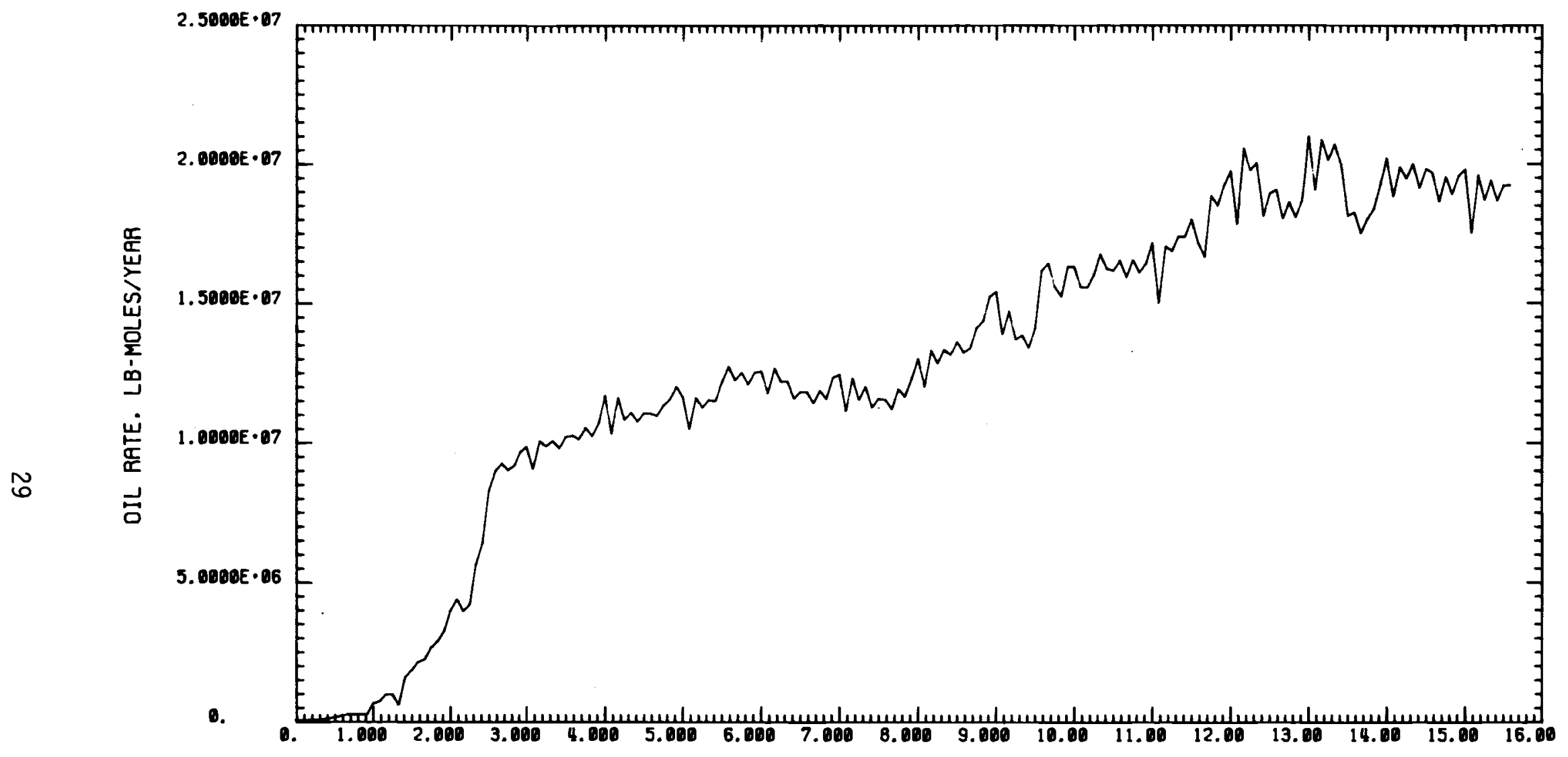

TIME $=20 \cdot 21: 47$ DATE $=26-$ AUG -80

TIME. YERRS

FIGURE 8. Empire Abo Pool - $0 i 1$ Production Rate Used for Set 4 
capabilities. The parameters are also estimated using the observed data for the entire 15.6 years to allow testing of the model's interpolative capabilities.

The results of the parameter estimation, when $z$ is minimized for the first 10 years of the reservoir data, are shown in Figures 9 through 12. When only the first 10 years are considered, the parameter values (which minimize $z$ ) are given by:

$$
\begin{aligned}
2000 \leq C & \leq 12000 \\
D & =81 \\
F & =2.2 \\
S^{0} & =0.5
\end{aligned}
$$

The value of $z$ for this set of parameters is 0.323 .

The parameter estimation indicated that $C$ could range between 2000 and 12,000 with negligible influence on $z$. The simulation results for $C=2000$ are shown in Figures 9 and 10 , and the results with $C=12,000$ are shown in Figures 11 and 12. By comparing Figure 9 with Figure 11 and Figure 10 with Figure 12 , it is apparent that varying $C$ has had only a minor influence on the predicted pressure and GOR curves.

Looking at the pressure results in Figures 9 and 11, it is apparent that the model matches the observed pressures quite well in both the history match region and in the extrapolation region. The GOR results (Figures 10 and 12) don't match as well. It should be remembered that the observed data, initially at least, may have been somewhat inaccurate. It appears that the initial value for $G$ used in the reservoir simulation is too large. This value is based on data reported by Christianson (1977) and Killough et al. (1979), while the observed values are based on the annual production data (Annual Reports 1958-1978). The initial value used for $G$ was felt to be more reliable than the initial values based on the production data. 
EMPIRE ABO POOL - BASED ON GOR FOR 10 YEARS.

2500.

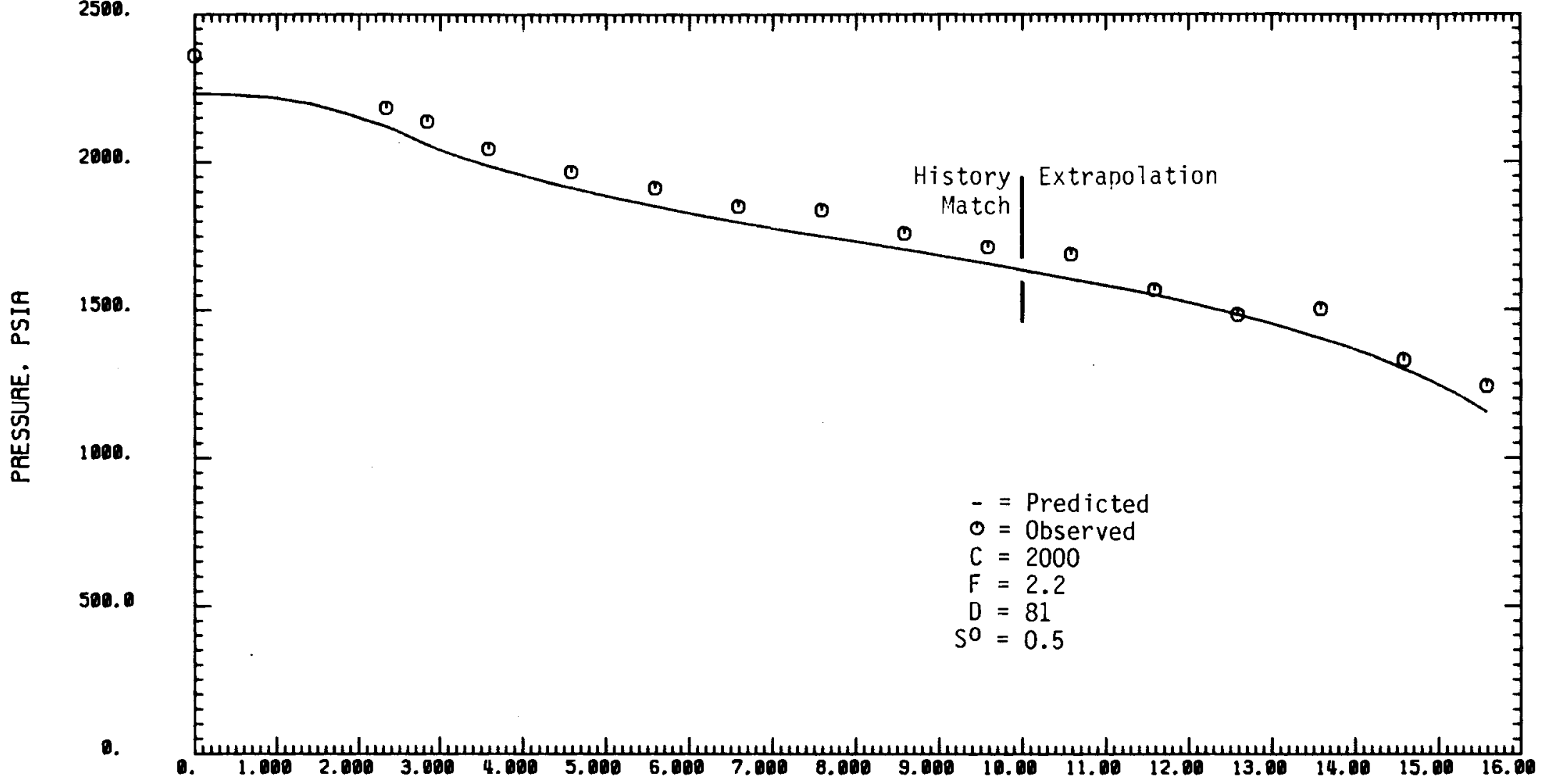

TIME = 20:32,06 DRTE $=26-$ RUG -80

TIME, YEARS

FIGURE 9. Predicted and Observed Pressure $(C=2000)$, Set 4 ( $z$ Minimized for First 10 Years) 
EMPIRE ABO POOL - BASED ON GOR FOR 10 YEARS.

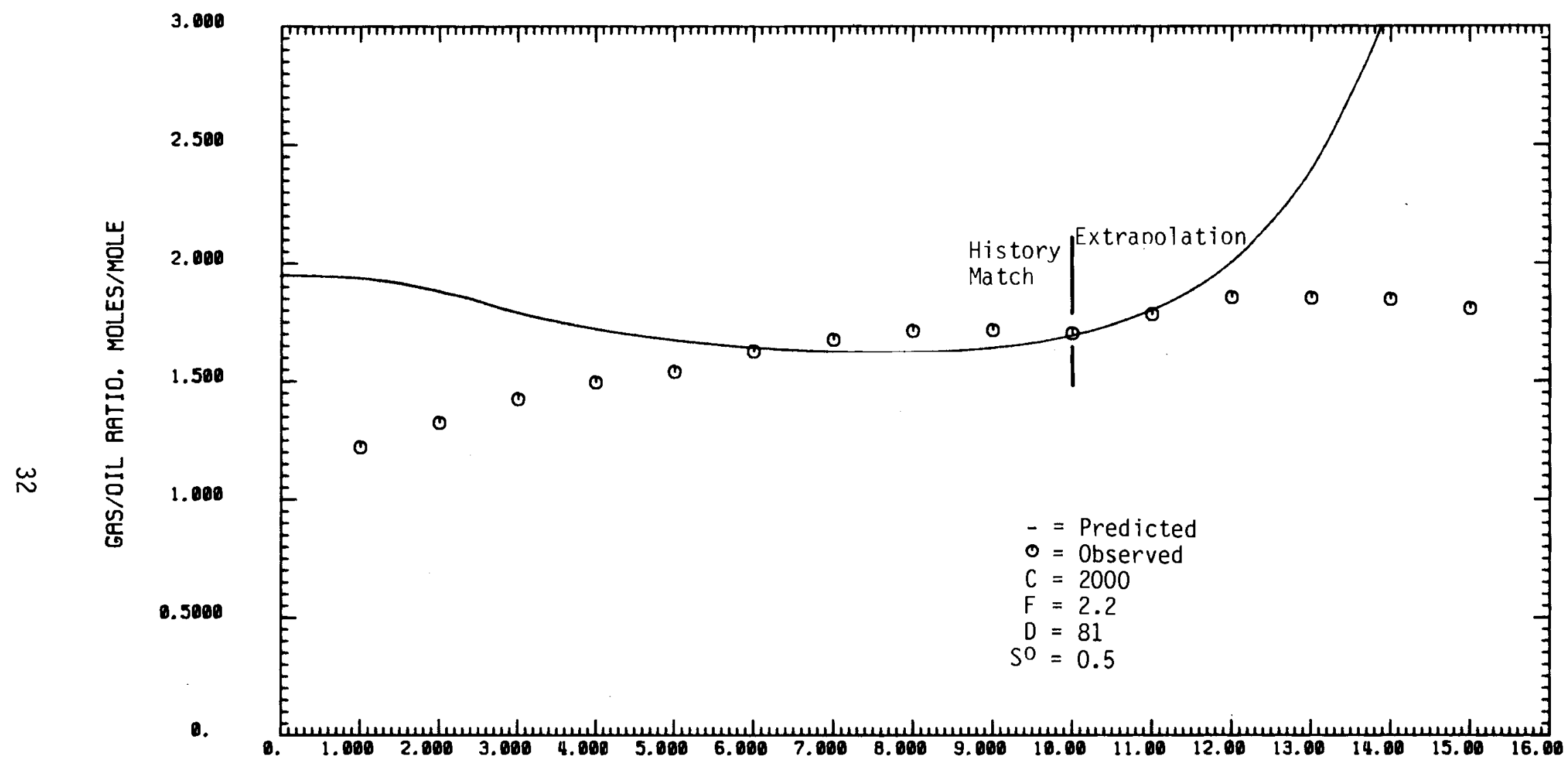

TIME $20: 54: 04$ DRTE $26-$ AUG-80

TIME, YEARS

FIGURE 10. Predicted and Observed GOR $(C=2000)$, Set 4 ( $z$ Minimized for First 10 Years) 
EMPIAE ABO POOL - BASED ON GOR FOR 10 YEARS.

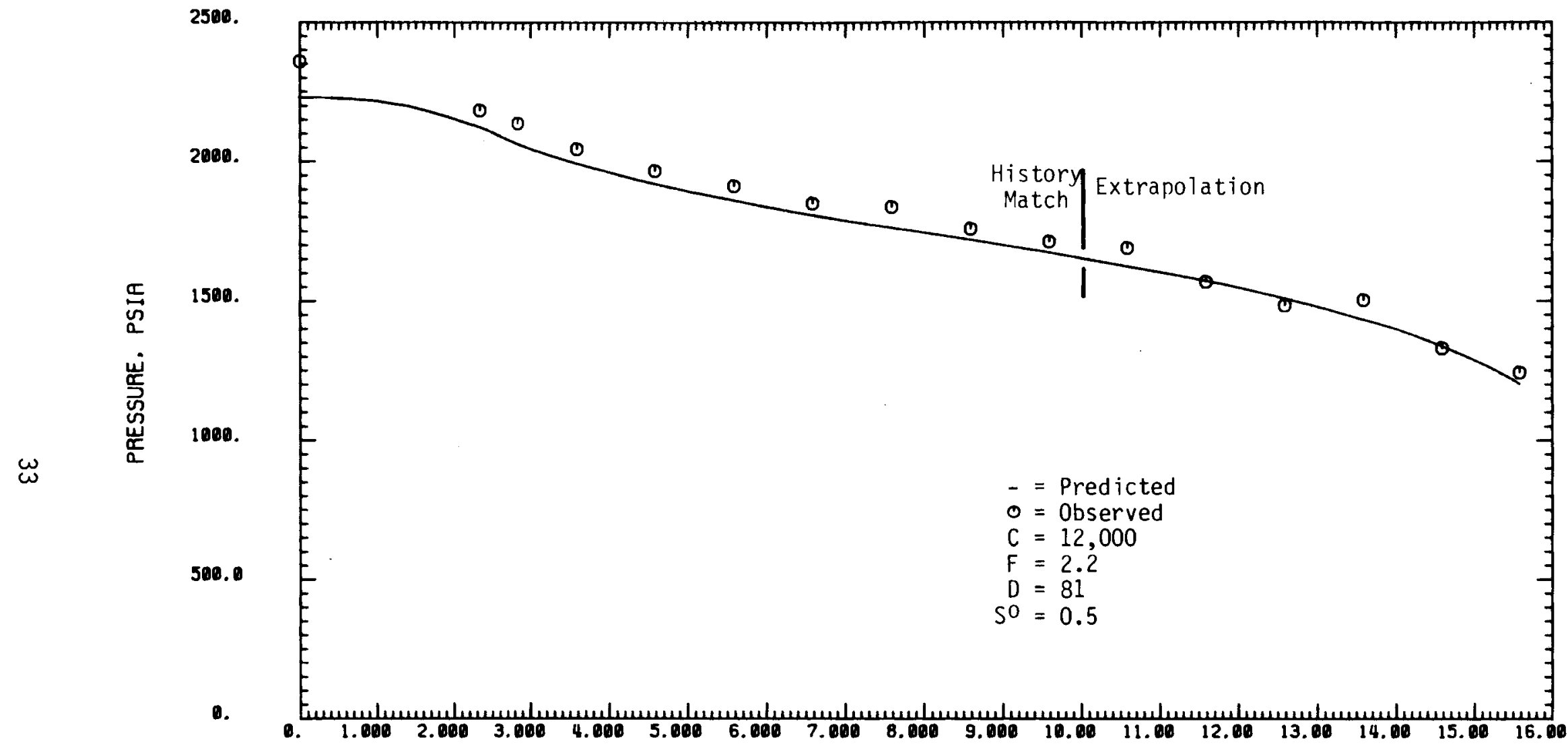

TIME = 20:32:36 DATE: $26-$ AUE -80

TIME, YEARS

FIGURE 11. Predicted and Observed Pressure $(C=12000)$, Set 4 ( $z$ Minimized for First 10 Years) 
EMPIRE ABO POOL - BASED ON GOR FOR 10 YEARS.

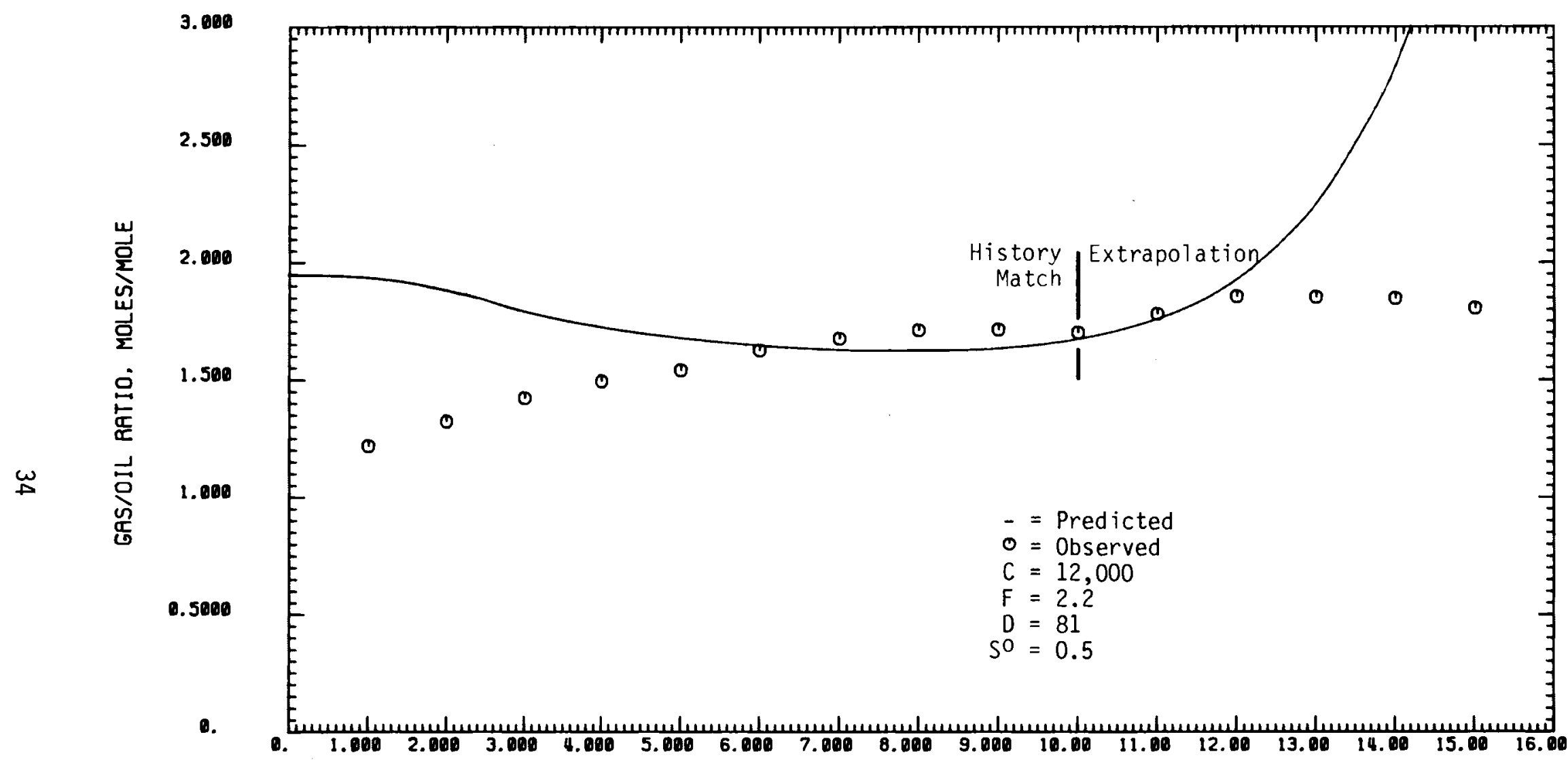

TIME $=20: 54: 33$ DATE $=26-$ AUG -80

TIME, YEARS

FIGURE 12. Predicted and Observed GOR $(C=12000)$, Set 4 (z Minimized for First 10 Years) 
The consequence of starting the simulation with $G$ higher than the observed values has been to force the simulated GOR to drop toward the observed data. This drop results in the predicted GOR slightly undershooting the observed data and then starting to climb. At the end of this history match, the predicted GOR matches the observed data quite we11. The curvature, however, is opposite that of the observed data and causes the extrapolation to deviate fairly rapidly from the observed values. The predicted value two years beyond the history match is still reasonably close to the observed value, which indicates that it may be possible to extrapolate GOR values for a time span that is roughly $20 \%$ of the history match period.

The next two plots, Figures 13 and 14, show the results of estimating the parameters by minimizng the pressure and weighted pressure discrepancy ( $x$ and $y)$ for the first 10 years of reservoir data. We attempted to weight the parameter estimation by dividing the pressure discrepancy by the observed pressure, as this should force the predicted curve to better match the lower pressure region. The effect of weighting is negligible, however, and the estimated values for the parameters are essentially the same. The set of parameter values which minimize $x$ and $y$ are:

$$
\begin{aligned}
C & =60,000 \\
D & =75 \\
F & =5.2 \\
S^{0} & =0.5
\end{aligned}
$$

The values for $x$ and $y$ for this set of parameters are 29.7 psi and 0.015 , respectively.

The predicted pressure matches the observed data quite well through the history match region (Figure 13). The extrapolated pressure, however, starts to deviate significantly after about 5 years. This indicates that it may not be advisable to extrapolate pressures for a period of time longer than $50 \%$ of the history match time. This is probably due to the high values estimated for $F$ in conjunction with the estimated value for $C$. Since $F$ and $C$ are large, the lower pressures will result in a large influx of water and a correspondingly large entrapment of reservoir liquids. This causes the reservoir to head 
EMPIRE ABO POOL' - BASED ON P AND WT. P FOR 10.0 YEARS.

2500
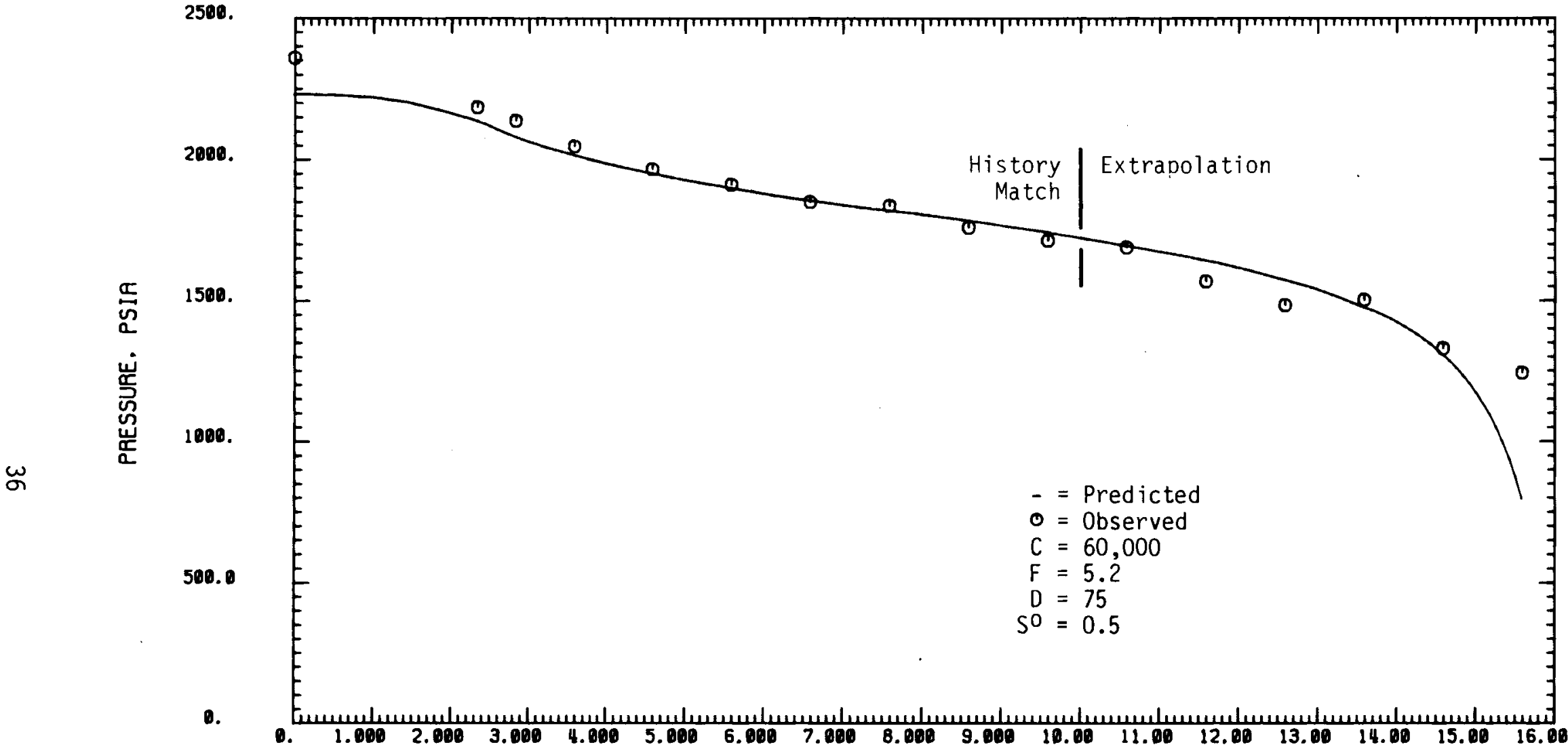

TIME $=21,57: 11$ DATE $=26-$ AUG -80

TIME. YEARS

FIGURE 13. Predicted and Observed Pressure, Set 4 ( $x$ and y Minimized for First 10 Years) 
EMPIRE ABO POOL - BASED ON P AND WT. P FOR 10.D YEARS.

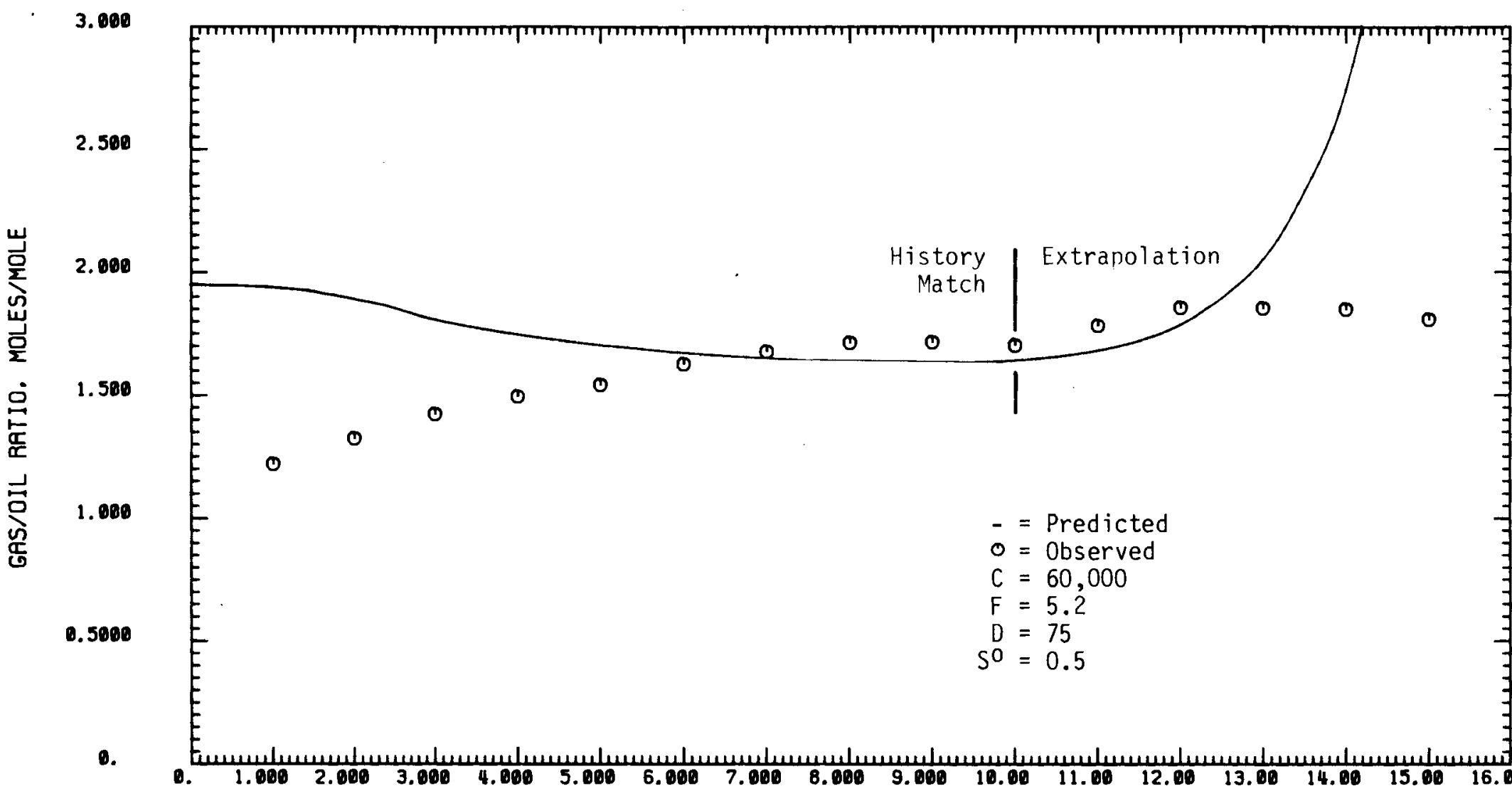

TIME * 22:00142 DATE: 26-AUG-80

TIME, YERRS

FIGURE 14. Predicted and Observed GOR, Set 4 ( $x$ and $y$ Minimized for First 10 Years) 
towards depletion at a fast rate, a phenomenon indicated by the large predicted GOR and by the steep negative slope of the predicted pressure curve at the end of the simulation.

An interesting phenomenon was noted during the estimation of this parameter set. It appeared that by increasing $C$ and $F$ simultaneously, the absolute discrepancy could be minimized further. Subsequent investigation indicated that if $C$ and $F$ were increased beyond the values indicated in Figures 13 and 14 , the value of $x$ and $y$ would be slightly decreased. This means that the fit of the data is improved during the history match. Problematically however, the pressure dives towards zero even sooner and the GOR increases even faster in the extrapolation region. This tendency points out a potential problem in estimating certain parameters simultaneously. In the case of $C$ and $F$, an increase in $C$ will cause the pressure to drop more slowly, while an increase in $F$ will tend to make the pressure drop more quickly. This indicates that it may not be possible to home in on reasonable values for $C$ and $F$.

For the Empire Abo Pool, Christianson (1977) found it was necessary to allow an average water influx rate of $1950 \mathrm{bbl/day}$ so that his numerical simulation would match the observed data. If it is assumed that this influx occurs at the median observed pressure of the present simulation, a value of $C$ equal to $\sim 7500 \mathrm{ft}^{3} / \mathrm{yr} / \mathrm{psi}$ is computed. This is roughly one order of magnitude smaller than the estimated value. In addition, a value of $F$ equal to five may be unreasonable. If $F$ is equal to five, then for every barrel of water that invades the reservoir, five barrels of the reservoir material (oil and gas) is trapped. This may be unreasonably high although no data have been located to determine a reasonable range for $F$. If a reasonable value or range of values can't be specified for either $F$ or $C$, then caution must be exercised when estimating these parameters. A similar phenomenon may occur when estimating $D$ and $S^{0}$ simultaneously. Larger values of $D$ result in slower migration of the free gas to the gas cap, while larger values of $s^{0}$ cause more of the available free gas to migrate toward the gas cap.

The final parameter estimation conducted on the Empire Abo Pool consists of minimizing $x, y$, and $z$ using all 15.6 years of available data. The purpose 
of this treatment is to test the model in a purely interpolative mode. The parameter values which minimize $z$, when all 15.6 years of data are considered, are given by:

$$
\begin{aligned}
C & =26,000 \\
D & =13 \\
F & =1.5 \\
S^{0} & =0.5
\end{aligned}
$$

The value of $z$ for this set of parameters is 0.287 .

The parameter values which minimize $x$ and $y$ when all 15.6 years of data are considered, are given by:

$$
\begin{aligned}
& C=34,077 \\
& 78 \leq D \leq 88 \\
& F=3.34 \\
& S^{0}=0.5
\end{aligned}
$$

The value of $x$ for this set of parameters is $39 \mathrm{psi}$, and the value of $y$ is 0.023. Figures 15 and 16 show the results when $z$ is minimized, and Figures 17 and 18 are the results when $x$ and $y$ are minimized. As in the previous parameter estimation, weighting the pressure discrepancy has had a negligable influence.

Looking at Figures 15 and 17 , it is apparent that the interpolative capabilities of the code for pressure are quite good. It seems to make little difference on the predicted pressure curve whether the parameters are estimated by minimizing $x$ and $y$ or by minimizing $z$. As expected, when $x$ and $y$ are minimized, the predicted pressures match the data slightly better.

The interpolative capabilities for GOR are not as good. Figure 16 is the best possible fit to the GOR data. The predicted GOR still exhibits the characteristic undershoot followed by an overshoot. As previously mentioned, this is probably due to the initial discrepancy between the observed data and the 
EMPIRE ABO POOL - BASED ON GOR FOR 15.6 YEARS.
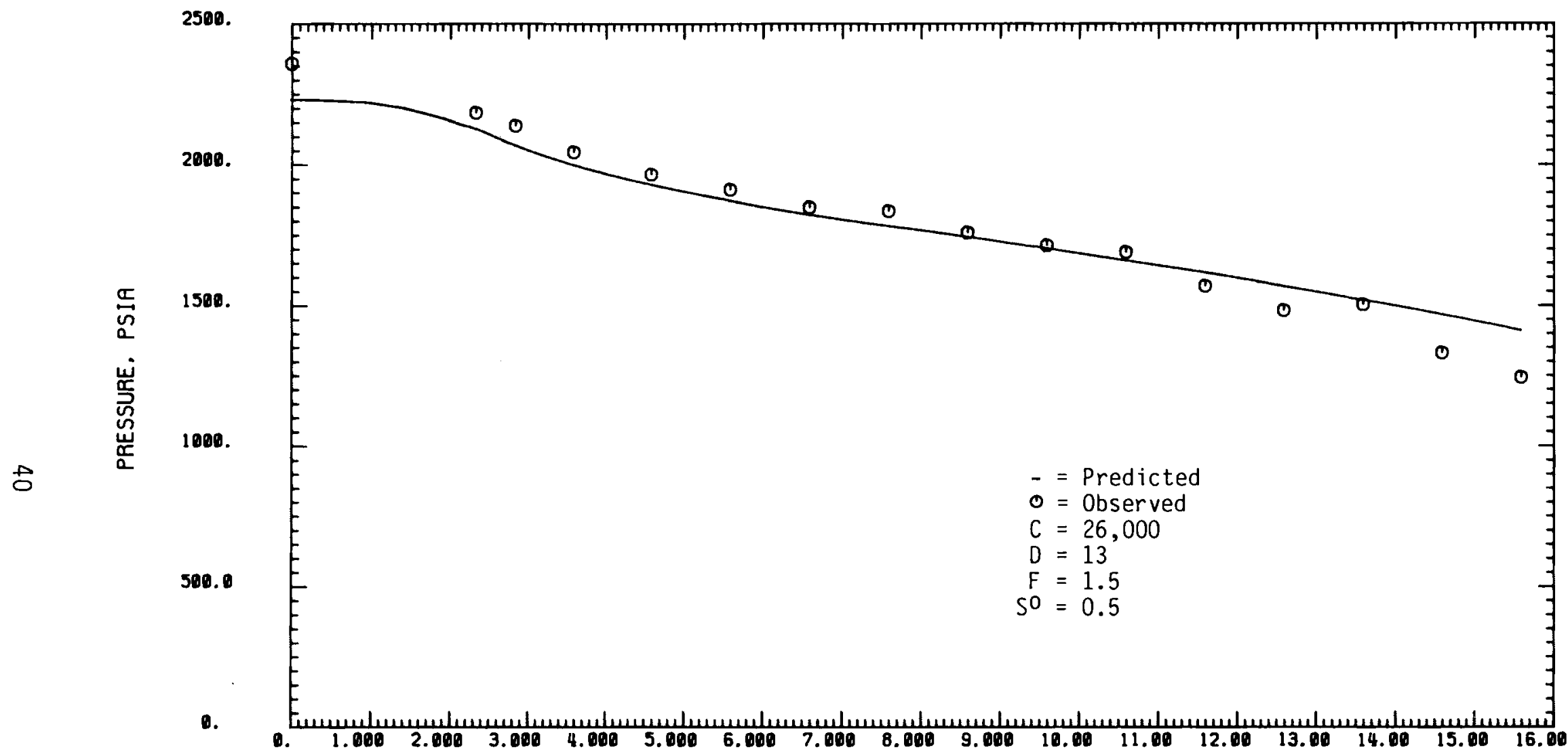

TIME $=20 \cdot 33 \cdot 07$ DATE $=26-$ RUG -80

TIME, YEARS

FIGURE 15. Predicted and Observed Pressure, Set 4 (z Minimized for 15.6 Years) 
EMPIRE ABO POOL - BASED ON GOR FOR 15.6 YEARS.

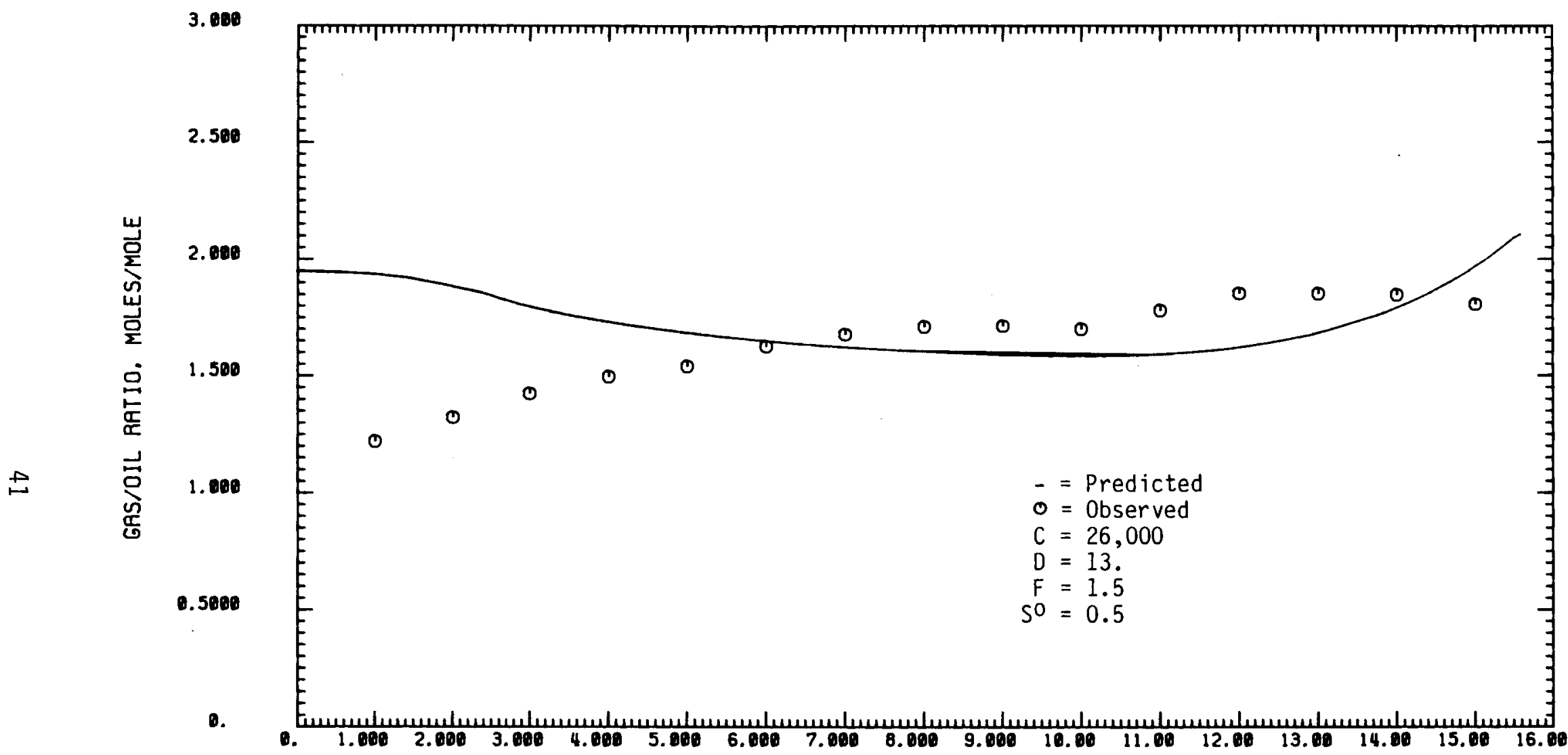

TIME: $20,55 \cdot 04$ DATE $26-$ AUG -80

TIME, YERRS

FIGURE 16. Predicted and Observed GOR, Set 4 ( $z$ Minimized for 15.6 Years) 
EMPIRE ABO POOL - BASED ON P AND WT. P FOR 15.6 YERRS.

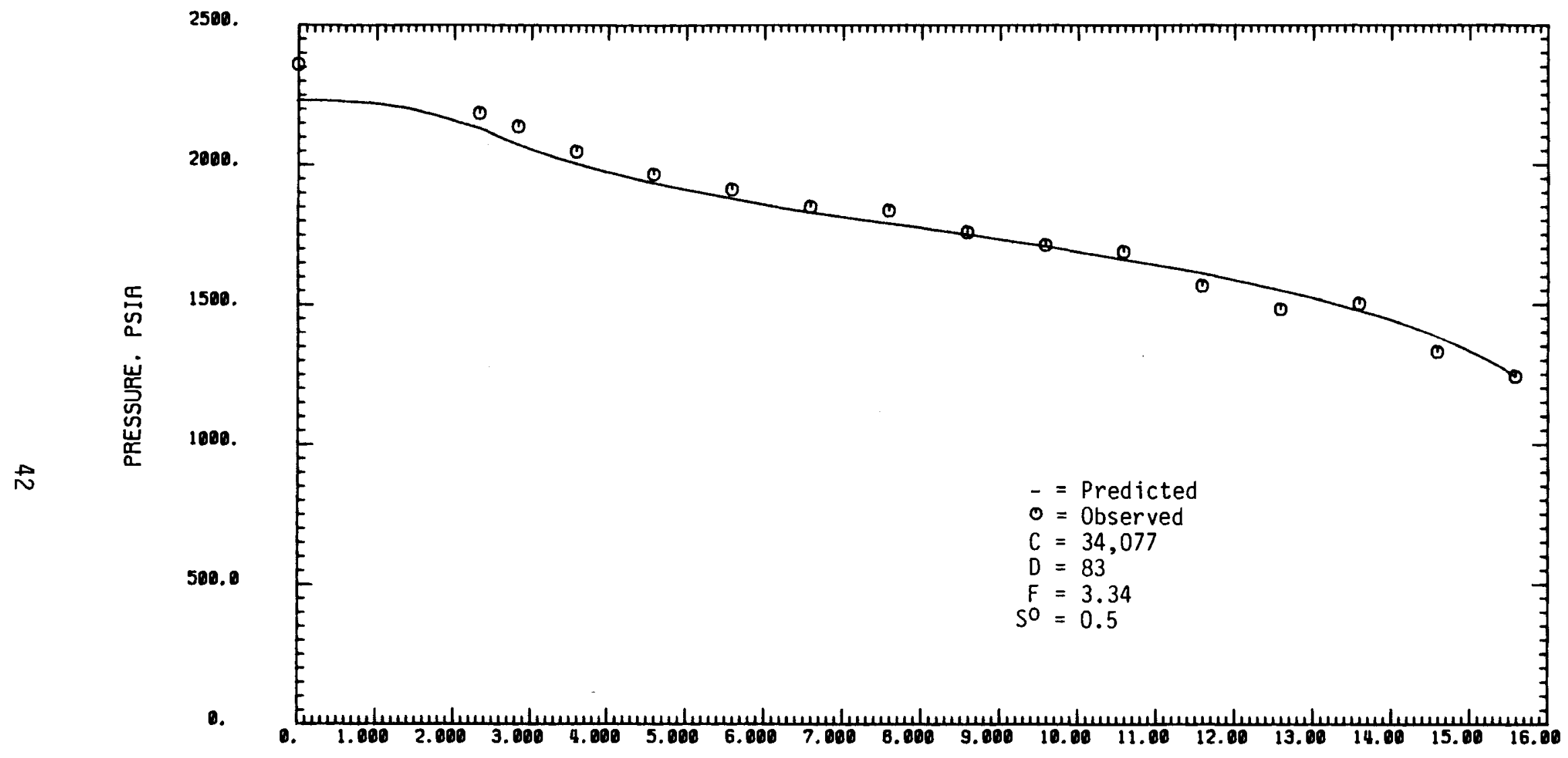

TIME $=20 \cdot 31 \cdot 36$ DATE $=26-$ AUG -80

TIME, YERRS

FIGURE 17. Predicted and Observed Pressure, Set 4 ( $x$ and y Minimized for 15.6 Years) 
EMPIRE ABO POOL - BASED ON P AND WT. P FOR 15.6 YEARS.

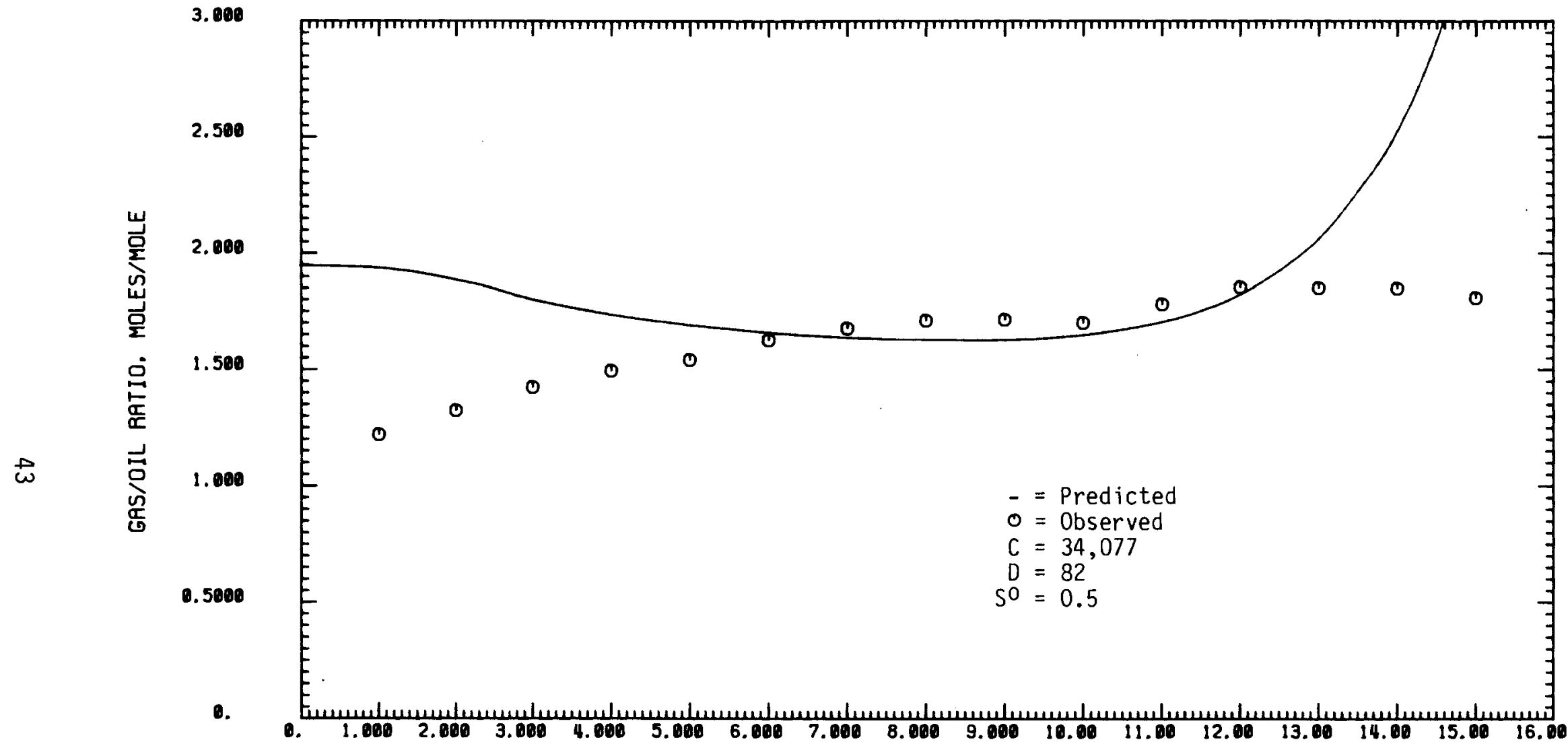

TIME : $20 \cdot 53 \cdot 33$ DATE $=26 \cdot$ RUG -80

TIME. YEARS

FIGURE 18. Predicted and Observed GOR, Set 4 ( $x$ and $y$ Minimized for 15.6 Years) 
initial value used for $G$. When the parameters are estimated by minimizing $x$ and $y$, the fit is not nearly as good. The overshoot occurs early and increases rapidly.

\section{HAWKINS (WOODBINE) FIELD}

The Hawkins field is located in the Woodbine basin of Texas, approximately 100 miles east of Dallas. The field is comprised of an Eastern and a Western segment. The Western segment contains approximately $80 \%$ of the field's oil reserve (King et al. 1976) and is separate from the Eastern segment (Wendlandt et al. 1946). The present simulation has been performed on the Western segment only. The data for performing the simulation are fairly complete and have been gathered from reports by King et al. 1976, Bell et al. 1951, and Wendlandt et a1. 1946. Based on the data contained in these reports, it has been possible to calculate reasonable values for all of the model input parameters except $a, b, D, F$, and $S^{0}$ (Table 3 ). The oil rate used during the reservoir simulation is shown in Figure 19.

The initial simulations on this reservoir were unsuccessful. The initial gas derivative $\dot{N}_{F G C}^{0}$ was negative, which conflicts with the model assumption that initially there is no free gas or gas-cap gas. Substituting the initial conditions data into Equation (17) indicated that $N_{L}^{0}, T^{0}, V_{L}^{0}$, or $\mathrm{p}^{0}$ would need to be adjusted by up to $45 \%$ to avoid $\dot{N}_{F G C}^{0}$ being negative.

$$
F_{F G C}=1.444 \nless 1
$$

This was felt to be an unacceptably large adjustment to the model parameters. Upon discovery in 1940, the reservoir had a substantial gas cap. The data in Table 3 indicate that initially the amount of gas-cap gas was equal to approximately one-half of the reservoir liquid, on a mole basis. Such a condition obviously does not meet the model assumption of no free gas or gas-cap gas, and is believed to be the cause of the negative $\dot{N}_{F G C}^{0}$ problem. The model was temporarily modified to allow the initialization of $N_{F G C}^{0}$. 
TABLE 3. Hawkins Field Input Data

\begin{tabular}{cl} 
Parameter & \multicolumn{1}{c}{ Value } \\
\cline { 1 - 2 }$a$ & est. $(a)$ \\
$b$ & est. $(a)$ \\
$C$ & $3.556 \cdot 10^{6}$ \\
$D$ & est. $(a)$ \\
$F$ & est. $(a)$ \\
$G$ & 1.016 \\
$N_{F G C}^{O}$ & $4.081 \cdot 10^{9}$ \\
$N_{b}^{O}$ & $8.764 \cdot 10^{9}$ \\
$P^{O}$ & 1985 \\
$r_{O I L}^{O}$ & $N A(b)$ \\
$S^{O}$ & est. $(a)$ \\
$T^{O}$ & 345 \\
$V_{L}^{O}$ & $3.12210^{10}$ \\
$V_{R}$ & 1.223 \\
$\Delta 0 I L$ & $N A(b)$ \\
Model & $N A(b)$
\end{tabular}

(a) These values estimated statistically

(b) Not applicable

While the modification has allowed the simulation of reservoirs with an existing gas-cap at discovery, it has also created difficulties in predicting the GOR. These difficulties probably arise because the assumption $N_{F G C}^{0}=$ 0 is used elsewhere in the model. Specifically, the equation that determines whether the gas is in the oil zone (free gas) or in the gas-cap zone can't handle a non-zero value for $N_{F G C}^{0}$. The equation that determines the fraction of gas-cap gas to free gas is as follows:

$$
N_{G C} / N_{F G}=S_{E} /\left(1-S_{E}\right)
$$


HAWKINS FIELD - OIL PRODUCTION RATE.

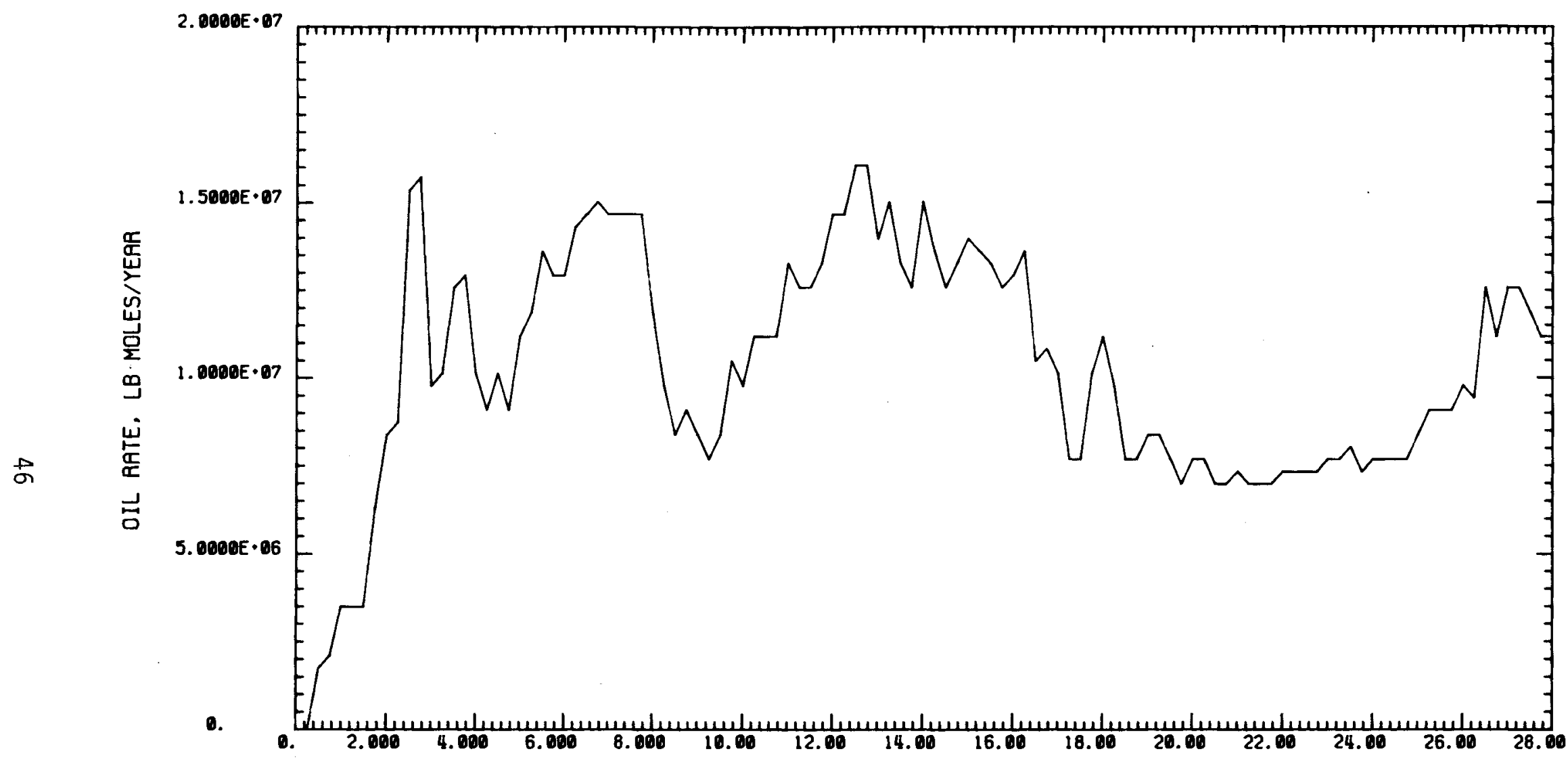

TIME $=20 \cdot 18: 11$ DATE $=27-$ AUG -80

TIME, YERRS

FIGURE 19. Hawkins Field - 0 il Production Rate 
where

$$
S_{E}=S^{0} e^{(-D / \theta)}
$$

It is apparent that at time $(\theta)$ equal to zero, $S_{E}$ will be zero, implying that there is no gas in the gas-cap. This is unrealistic for reservoirs that have an existing gas-cap when discovered. Upon discovery, these reservoirs are probably near equilibrium conditions. Consequently, it is expected that most of the free gas will have migrated to the gas-cap (except for pockets of gas trapped in the reservoir medium). Initially, at least, and relative to $N_{G C}$, $N_{F G}$ is probably quite smal1. Equation (30) forces all of the free gas to remain initially in the oil zone, however, resulting in unrealistic values for the relative permeability ratio $K_{R}$ [see Equations (13) and (14)], which influences the production of free gas from the reservoir and thereby influences the predicted GOR. The values estimated for $a, b, D$, and $S^{0}$ are unlikely to be physically realistic for these reservoirs, especially when the observed GOR is used to estimate these parameters. It is felt that relatively minor changes to the VARGOW model would correct this problem and significantly enhance the generality of the model. A possible modification may be to initialize the amount of gas-cap gas $N_{G C}^{0}$ and change the equation for $S_{E}$ as follows:

$$
S_{E}=S_{1}^{0} e^{-D / \theta}+S_{2}^{0} e^{-\theta / D}
$$

where

$$
\begin{aligned}
& s_{1}^{0}=s_{2}^{0}=s^{0} \text { if } N_{G C}^{0}>0 \\
& s_{1}^{0}=s^{0}, s_{2}^{0}=0 \text { if } N_{G C}^{0}=0
\end{aligned}
$$


This causes the segregation of gas-cap gas and free gas to be at the equilibrium value $S^{0}$ at discovery and as time goes to infinity for reservoirs with an initial gas-cap. Time did not permit investigation of this solution; hence, the following parameter estimations were performed by simply initializing $N_{F G C}^{0}$ to the appropriate value computed for the reservoir.

Since the results when $y$ is minimized for the Empire Abo Pool are essentially the same as the results when $x$ is minimized, only the minimization of $x$ and $z$ has been used for the Hawkins Field Reservoir. The parameters have been estimated by minimizing either $x$ or $z$ for the first 21 years of reservoir data. Therefore, the first 21 years serve as a check on the interpolative capabilities of the model, while the remaining 7 years of data demonstrate the extrapolative capabilities of the model.

The results from the parameter estimation when $z$ is minimized are shown in Figures 20 and 21 . The parameter values which minimize $z$ are:

$$
\begin{aligned}
& a=-3 \\
& b=5.5 \\
& D=17.5 \\
& F=5 \\
& S^{0}=0.375
\end{aligned}
$$

The value of $z$ for this set of parameters is 0.08 . Figure 20 shows that the set results in a poor prediction of the observed pressure, while figure 21 indicates a fairly good prediction of the GOR through the history match period. The deviation from the observed GOR starts to become relatively large about 3 years into the extrapolation.

When the parameters are estimated by minimizing $x$, the following values are obtained: 
HAWKINS FIELD - BASED ON GOR FOR 21 YEARS.

2889.

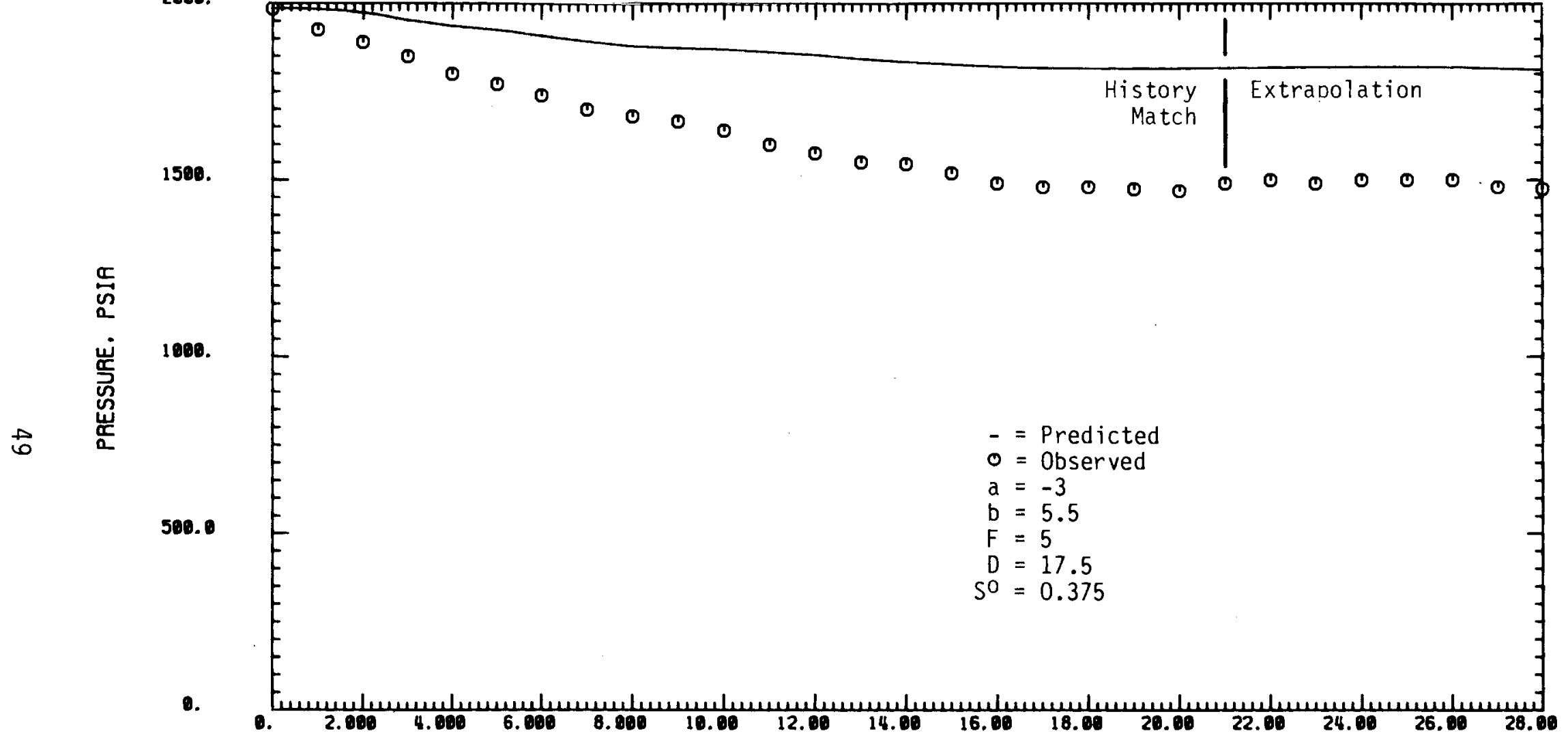

TIME $=20 \cdot 38114$ DATE $=27-$ RUG -80

TIME, YEARS

FIGURE 20. Predicted and Observed Pressure (z Minimized for First 21 Years) 
HAWKINS FIELD - BASED ON GOR FOR 21 YEARS.

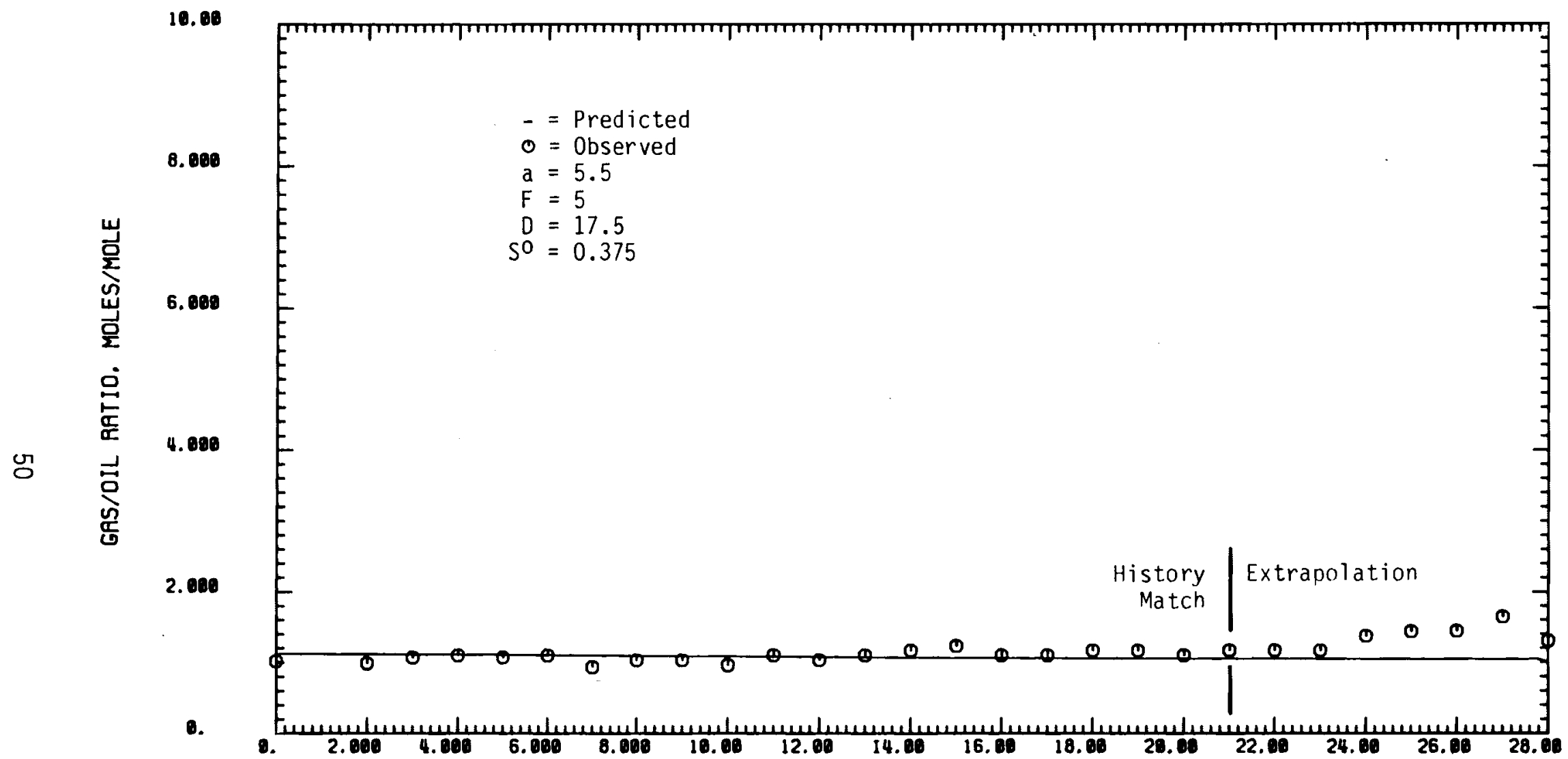

TIME $=20 \cdot 56: 37$ DATE $=27-$ AUG -80

TIME, YEARS

FIGURE 21. Predicted and Observed GOR (z Minimized for First 21 Years) 


$$
\begin{aligned}
a & =-2 \\
b & =7 \\
D & =15 \\
3 & \leq F \leq 7 \\
S^{0} & =0.5
\end{aligned}
$$

The value of $x$ for this set ranges from a high of 47.1 psi when $F$ equals 5 to a low of 43.2 psi when $F$ equals 7 . When $F$ equals $3, x$ has a value of 43.9 psi. Figures 22 and 23 are the observed and predicted pressure and GOR when $F=7$, while Figures 24 and 25 are the observed and predicted pressure and GOR when $F$ equals 3. When $F$ equals 3 , the history match and the extrapolation are good (Figure 22). When $F$ equals 7 , the history match is somewhat better, since the value of $x$ is smaller; however, the extrapolation is not as good. Unfortunately, this is the combination of parameters that would be selected if the parameter estimation is based purely on a minimization of $x$. The predicted GOR doesn't match the observed data (Figures 23 and 25). As mentioned previously, this probably occurs because the model is not intended to model reservoirs that initially have a gas cap.

\section{GAS-CAP DRIVE RESERVOIR}

The actual location and name of the gas-cap drive reservoir used for the following simulation is unknown. It is presumed that the reservoir is located somewhere in Texas since the authors of the reports, from which data were taken, work for Humble $0 i 1$ and Refining Company, Houston, Texas (Kirby et al. 1957 and Stone et a1. 1961). Time constraints did not permit the completion of the formal parameter estimation on this reservoir. Therefore, the results are preliminary in nature.

The input data used for the simulation are listed in Table 4, and the $0 i 1$ production rate is shown in Figure 26. As in the Hawkins Field simulation, this reservoir had an initial gas cap; hence, the simulation has been performed in essentially the same manner as Hawkins Field. The effect of initializing $N_{F G C}^{0}$ is the same as discussed for Hawkins Field. The data contained in the source reports allowed the specification of all the parameters except $D$ and $S^{0}$. 
HAWKINS FIELD - BASED ON P FOR 21 YEARS.

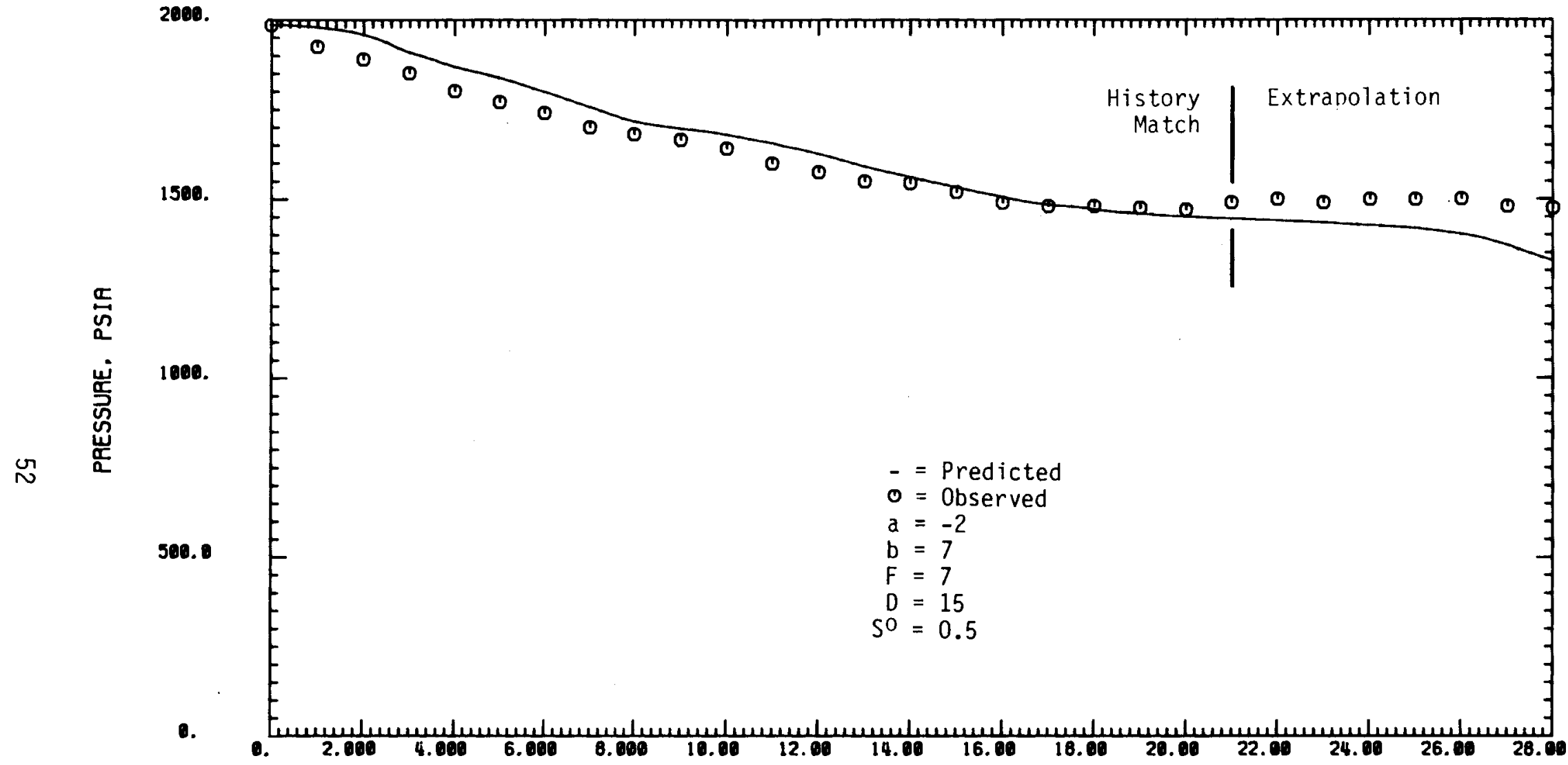

TIME = 28:37:53 DATE: 27-RUG-80

TIME, YEARS

FIGURE 22. Predicted and Observed Pressure, $F=3$ ( $x$ Minimized for First 21 Years) 
HAWKINS FIELD - BASED ON P FOR 21 YEARS.

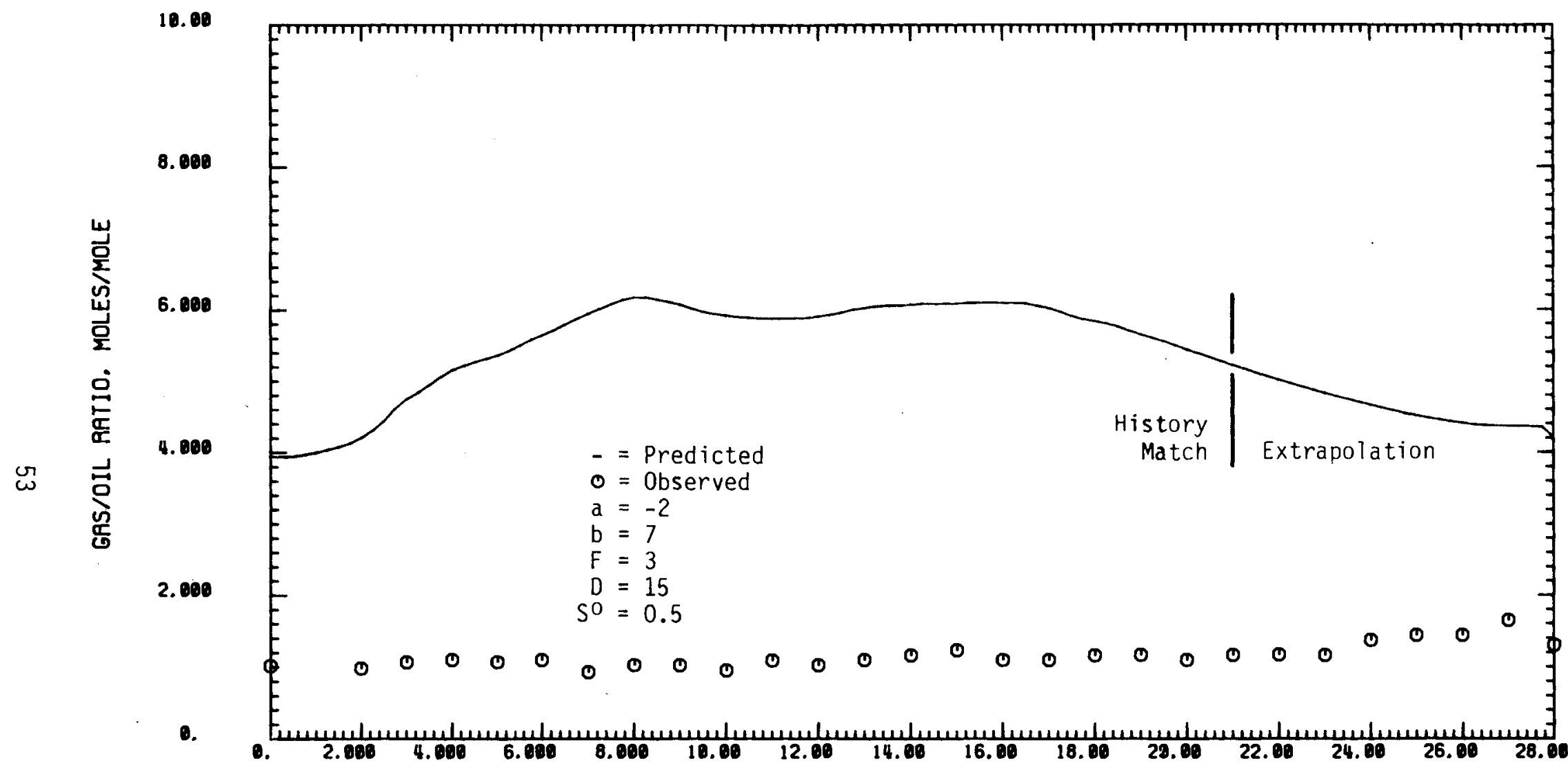

TIME: $28,55,57$ DATE $=27-$ AUG -80

TIME, YEAPS

FIGURE 23. Predicted and Observed GOR, $F=3$ ( $x$ Minimized for First 21 Years) 
HAWKINS FIELD - BASED ON P FOR 21 YEARS.

2800.

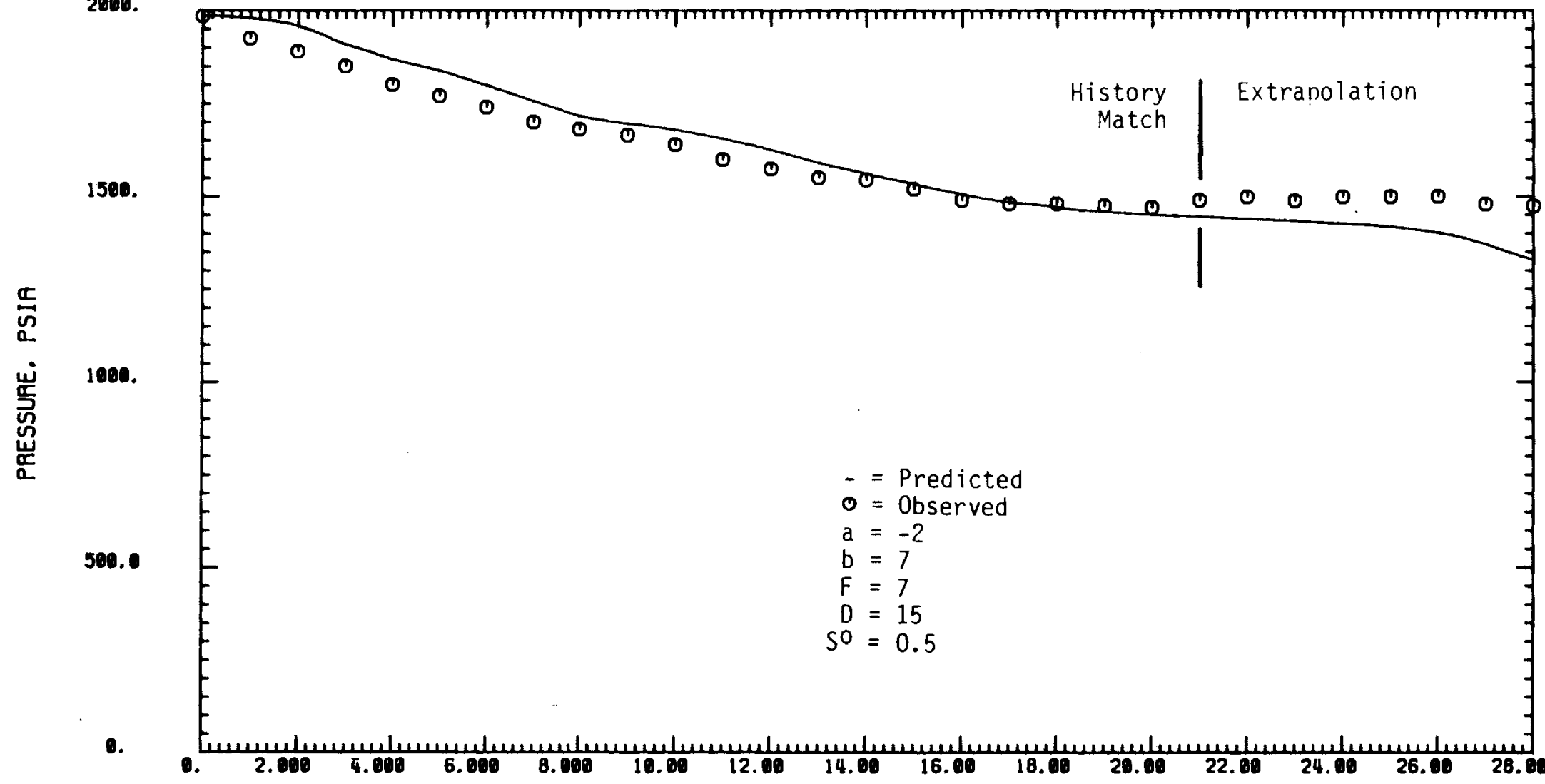

IIHE = 29:37:53 DATE = 27-9UG-80

TIME. YEARS

FIGURE 24. Predicted and Observed Pressure, $F=7$ ( $x$ Minimized for First 21 Years) 
HAWKINS FIELD - BASED ON P FOR 21 YEARS.

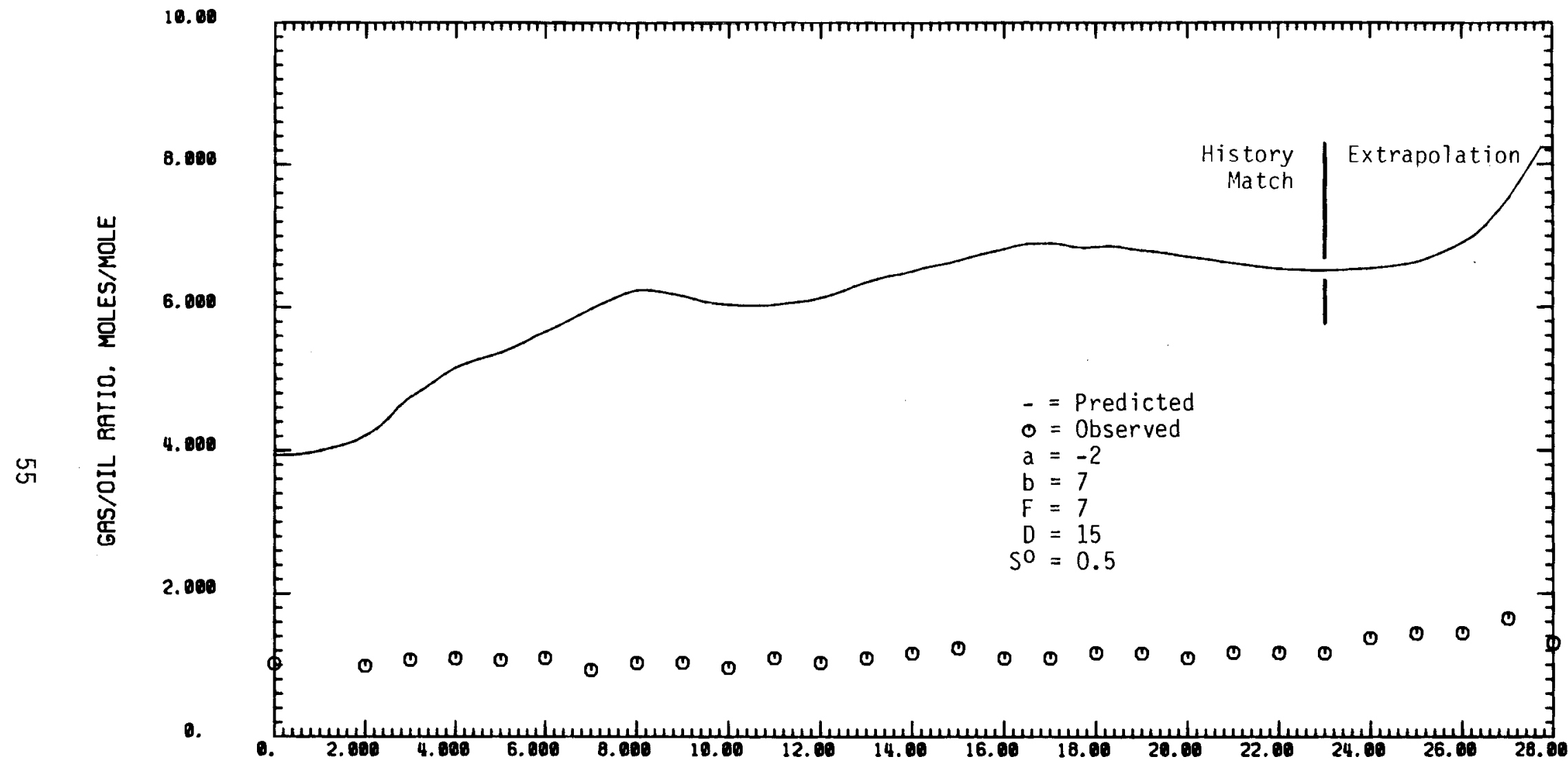

TIME $=20,56 \cdot 17$ DATE $=27-$ AUG -80

TIME, YERRS

FIGURE 25. Predicted and Observed GOR, $F=7$ ( $x$ Minimized for First 21 Years) 
GAS-CAP RESERVOIR - OIL PRODUCTION RATE.

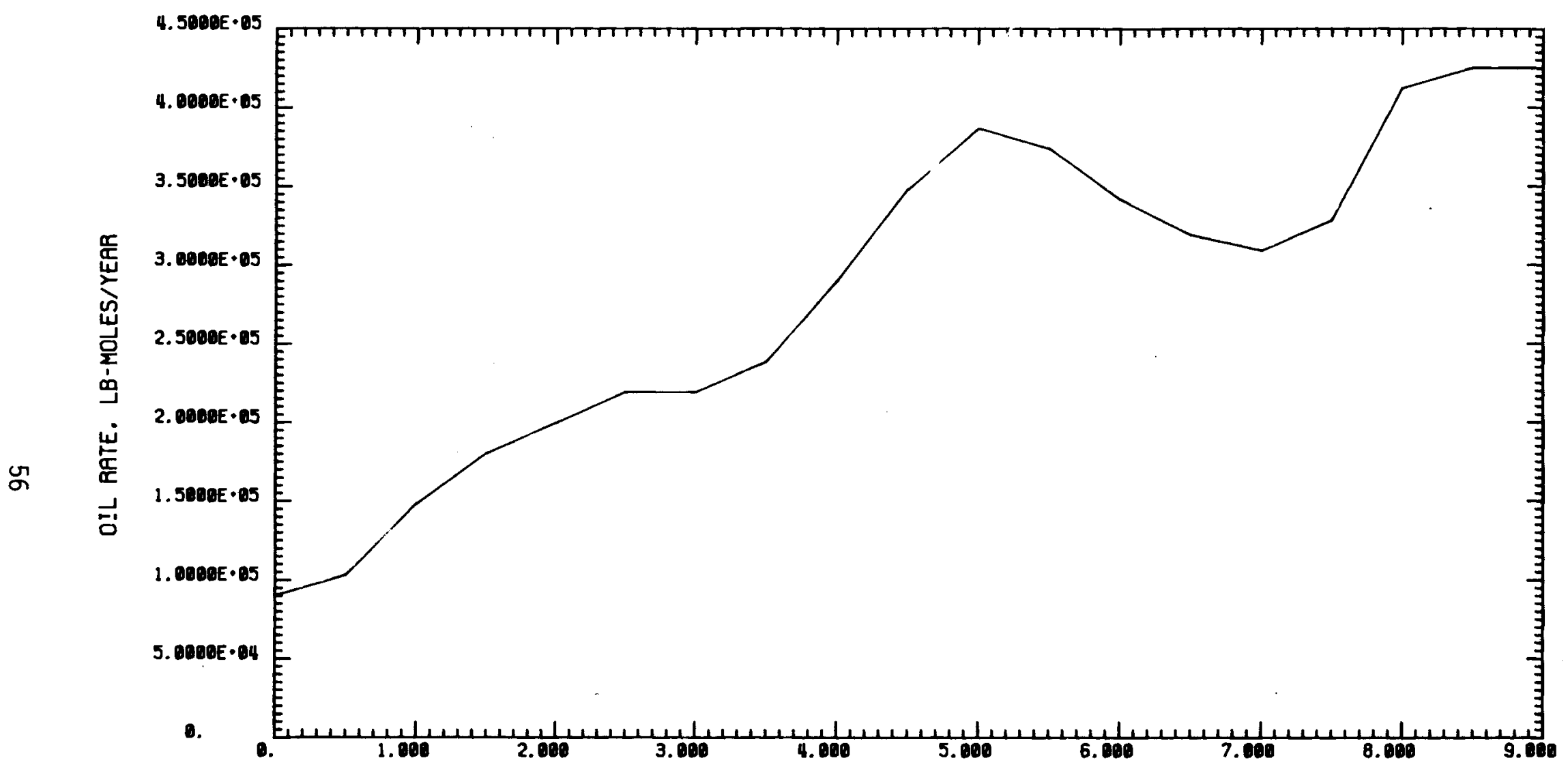

TIYE $=20: 02: 25$ DATE $=27-$ AUG -80

TIME, YERRS

FIGURE 26. Gas-Cap Drive Reservoir - $0 i 1$ Production Rate 
TABLE 4. Gas-Cap Drive Reservoir Input Data

\begin{tabular}{|c|c|}
\hline Parameter & Value \\
\hline a & -1.481 \\
\hline b & 8.011 \\
\hline c & 0 \\
\hline D & est. (a) \\
\hline $\mathrm{F}$ & $0($ since $C=0)$ \\
\hline G & 0.9803 \\
\hline $\mathrm{N}_{\mathrm{FGC}}^{0}$ & $1.98 \cdot 10^{8}$ \\
\hline$N_{1}^{60 C}$ & $4.202 \cdot 10^{8}$ \\
\hline$p^{6}$ & 2715 \\
\hline$r_{0 I L}^{0}$ & $N A^{(b)}$ \\
\hline$s^{\sigma^{1 L}}$ & est. ${ }^{(a)}$ \\
\hline$T^{0}$ & 356 \\
\hline$V_{L}^{0}$ & $9.142 \cdot 10^{8}$ \\
\hline$v_{R}$ & $\begin{array}{l}1.355 \\
\text { (b) }\end{array}$ \\
\hline $\begin{array}{l}\Delta 0 I L \\
\text { Mode } 1\end{array}$ & ${ }_{N A}(b)$ \\
\hline
\end{tabular}

(a) These values estimated statistically (b) Not applicable

The parameters for this reservoir have been estimated by running the VARGOW mode 1 with 21 combinations of $D$ and $S^{\circ}$. The value of $D$ ranged between 0 and 18.75, and $S^{\circ}$ ranged between 0 and 1 . The terms $x$ and $z$ were examined for each of the 21 combinations. The combination that resulted in the lowest value of $x$ was:

$$
\begin{aligned}
D & =0 \\
S^{0} & =0.4
\end{aligned}
$$


For this combination, $x$ had a value of $43 \mathrm{psi}$. The results for this combination (Figures 27 and 28 ) are not entirely satisfactory: the predicted pressure is reasonable, but the predicted GOR is not acceptable. None of the 21 combinations resulted in a small value for $z$. The value of $z$ ranged from 10 to 280 . Obviously, none of the combinations would have resulted in a reasonable match to the GOR data.

Based on the results from Hawkins Field, the term a was allowed to be -3 . The results were computed with $a=-3, D=0$ and $S^{\circ}=0.4$ (Figures 29 and 30). The match to the observed pressure is not as good as was achieved in Figure 27, but it is still reasonably close. The predicted GOR looks much better, however, as shown in Figure 30 .

Better results on this kind of reservoir can probably be obtained once the VARGOW model has been suitably modified to handle an initial amount of gas-cap gas. 
GAS-CAP RESERVOIR

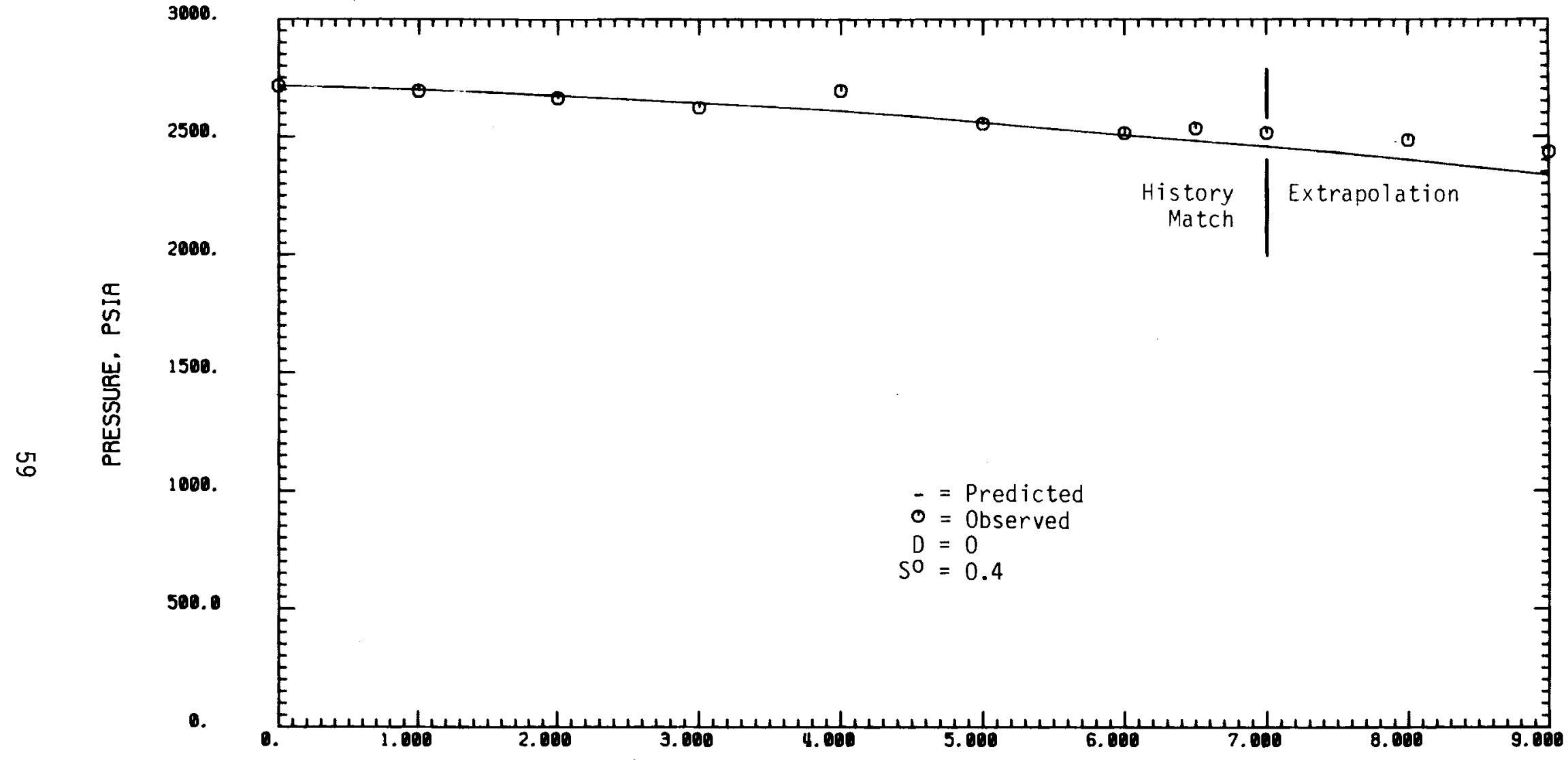

TIME $=20.03 .59$ DATE $=27-$ AUG -80

TIME, YEARS

FIGURE 27. Predicted and Observed Pressure (x Minimized for First 7 Years) 
GAS-CAP RESERVOIR

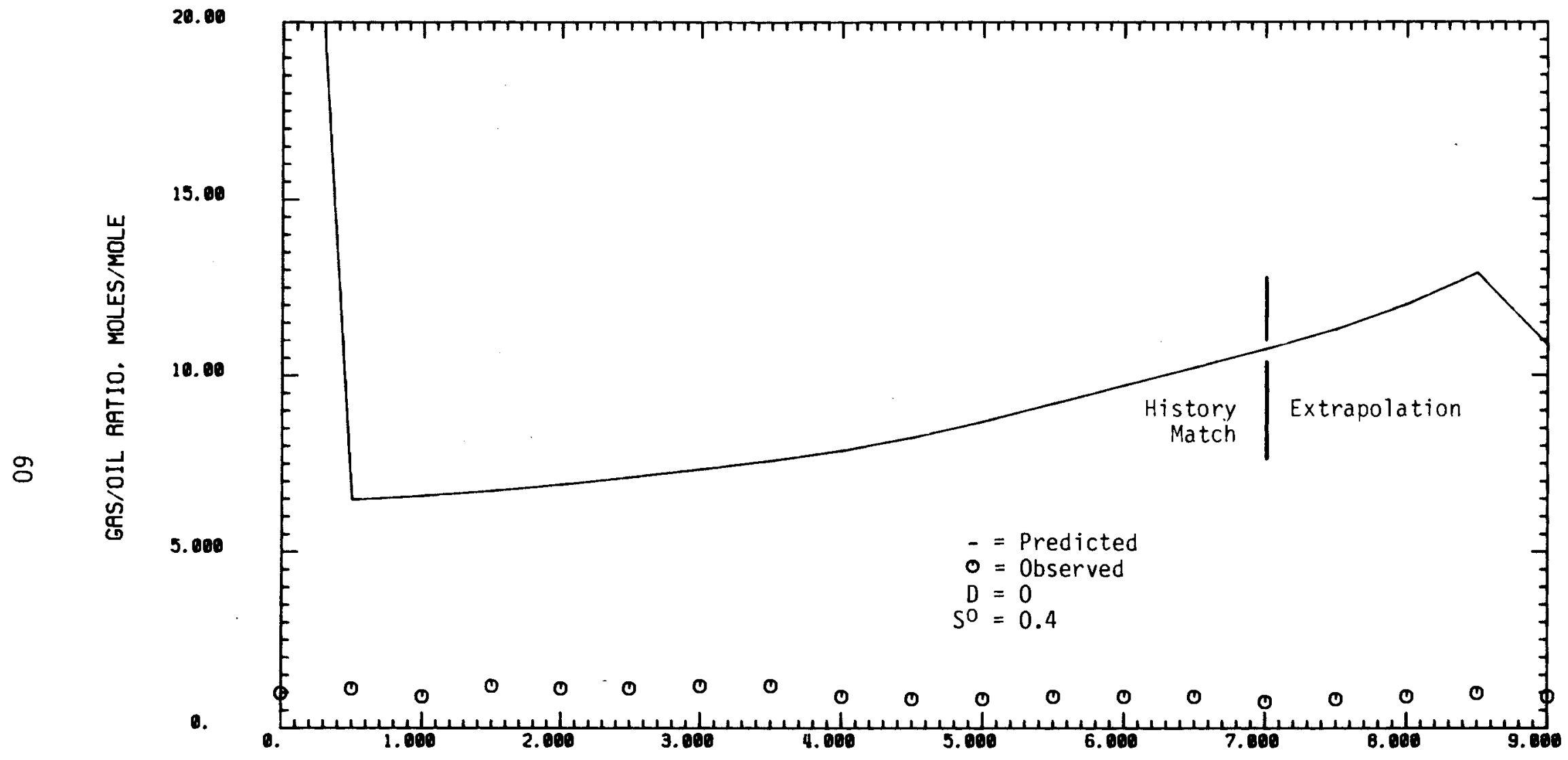

TIME= 20, 05,12 DATE= 27-AUG-80

TIME, YEARS

FIGURE 28. Predicted and Observed GOR ( $x$ Minimized for First 7 Years) 
GAS-CAP RESERVOIR

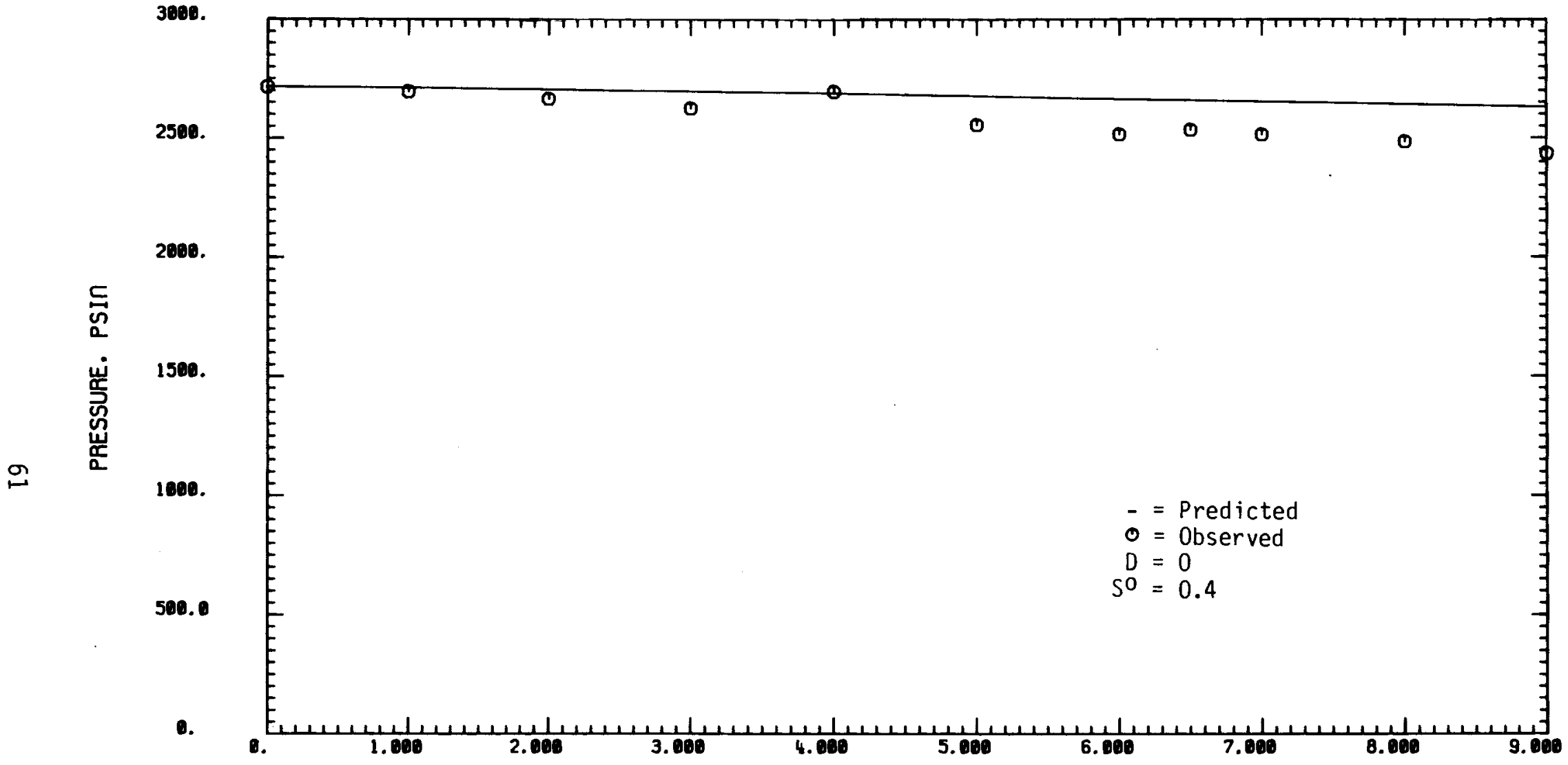

TIME $=21 \cdot 34 \cdot 09$ DATE $=27-$ AUG -80

TIME, YEARS

FIGURE 29. Predicted and Observed Pressure, $\mathrm{a}=-3$ 
GAS-CAP RESERVOIR

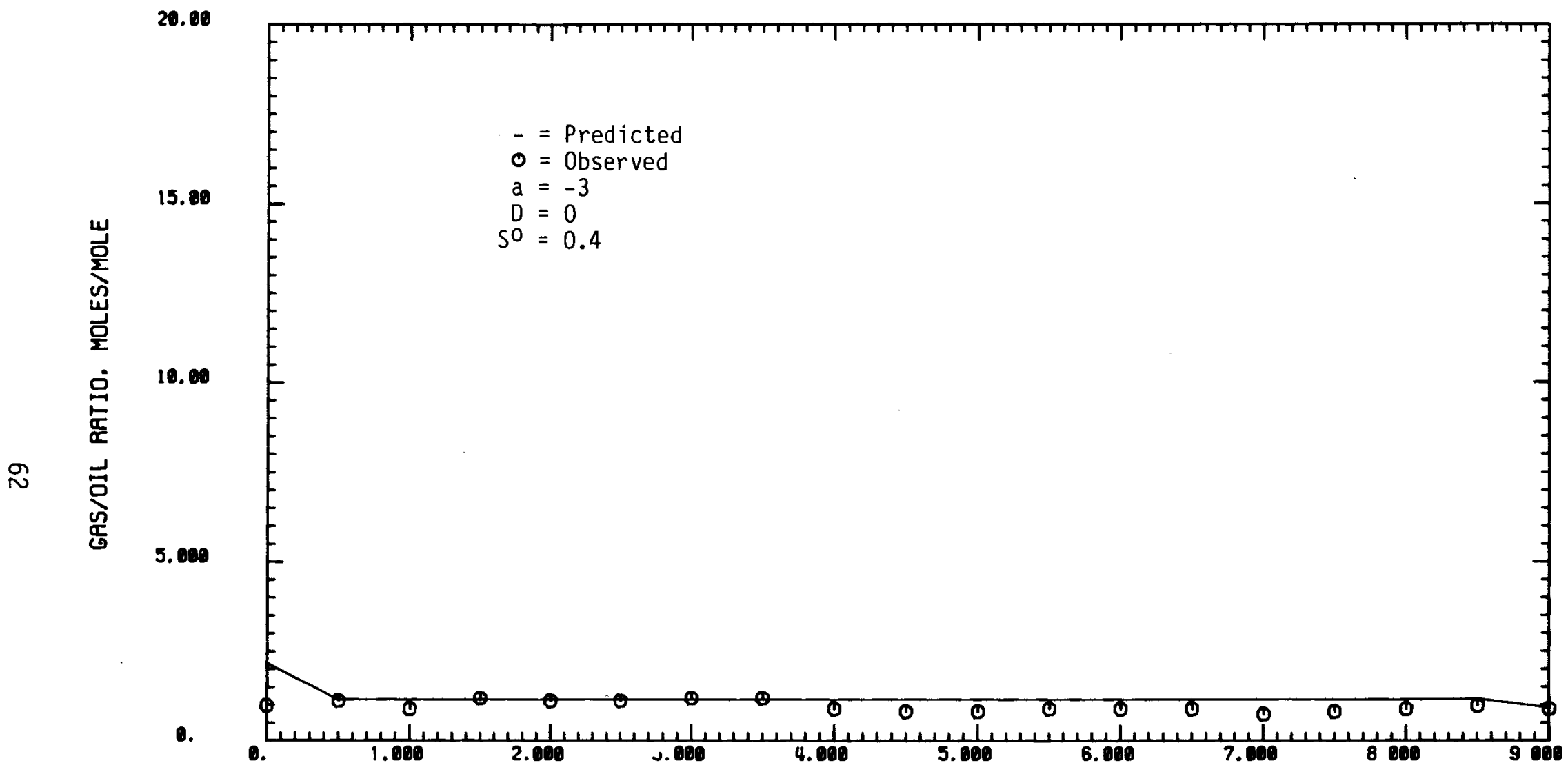

TIME = 21:31:15 DATE = 27-RUG-80

TIME, YEARS

FIGURE 30. Predicted and Observed GOR, $a=-3$ 


\section{VALIDATION STATUS}

The VARGOW reservoir model has been used to successfully simulate three reservoirs. For all three reservoirs, it has been possible to simulate the observed pressures in both an interpolative and an extrapolative mode. Simulating the GOR has not been as successful, although reasonable matches with the observed data at the end of the history match period have been achieved. It has also been possible to extrapolate GOR's for a short period of time beyond the history match period.

At this time, it appears that the difficulty in achieving suitable matches to the observed GOR data occurs for two reasons. For the Empire Abo pool, there are discrepancies in the observed data which have resulted in parameter estimates that may not be realistic. The other two reservoirs, Hawkins Field and a gas-cap drive reservoir, had gas-caps when they were discovered. Since this condition does not agree with the model assumptions, unrealistic GOR's have been predicted. These problems are minor. Slight revision of the model will enable it to handle reservoirs that initially have gas caps.

For all of the reservoirs simulated, the parameters that could be determined from the available reservoir data have been fixed. The remaining parameters have been estimated statistically using data on the observed pressure and GOR. We obtained a set of parameters that minimizes the absolute pressure discrepancy and a set of parameters that minimizes the absolute GOR discrepancy. For the reservoirs simulated, these parameter sets are not the same possibly because of previously discussed problems in simulating the GOR's.

In summary, the VARGOW model has been applied to three reservoirs. It has been possible to obtain predicted results that agree with the observed data. Typically, the pressure data can be matched quite we11, while the predicted GOR's don't match the observed data satisfactorily. It is clear that the VARGOW model can simulate important features of these reservoirs. Certain modifications are necessary to improve the ability of the VARGOW model to simulate these and other reservoirs. 


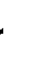




\section{REFERENCES}

Allen, W. W., H. P. Herriot, R. O. Stiehler. 1969. "History and Performance Prediction of UMM Farud Field, Libya," Journal of Petroleum Technology. May: 570-578.

Annual Report. 1958-1978. New Mexico $0 i 1$ and Gas Engineering Committee. Vol. 1, Southeast New Mexico and Vol. II, Northwest New Mexico.

Annual Report of the $0 i l$ and Gas Division. 1978. The Railroad Commission of Texas, State of Texas.

Arps, J. J., T. G. Roberts. 1955. "The Effect of the Relative Permeability Ratio, the 0 il Gravity, and the Solution Gas-0il Ratio on the Primary Recovery from a Depletion Type Reservoir," Petroleum Transaction, AIME, $204: 120-127$.

Be11, J. S. and J. M. Shepherd. 1951. "Pressure Behavior in the Woodbine Sand." Petroleum Transactions, AIME. 192:19-28.

Buchanan, R. 1979. "AUK Field Development: A Case History Illustrating the Need for a Flexible Plan," Journal of Petroleum Technology. Oct: 1305-1312.

Christianson, S. H. 1977. "Performance and Unitization of the Empire Abo Pool." Paper presented at the 1977 Permian Basin $0 i 1$ and Gas Recovery Conference of the Society of Petroleum Engineers of AIME, March 10-11, 1977, Midland, TX.

Clinton, G. W., J. Ruiz. 1968. "Performance of Payou Basal Eocene Block A Reservoir," Journal of Petroleum Technology, Jan: 31-35.

Craft, B. C. and M. F. Hawkins. 1959. Applied Petroleum Reservoir Engineering. Prentice-Hall, Inc., EngTewood CTiffs, NJ.

Criss, C. R. 1953. "History and Performance of the Coldwater Oil Field, Michigan," Journal of Petroleum Technology. Paper presented at the Petroleum Branch Fall Meeting in Dallas, Texas, October 18-21, 1958.

Haddenhorst, F. A. 1968. "Development History of Bell Creek Field, Powder River County, Montana," Journal of Petroleum Technology, Aug: 787-793.

Killough, J. E. and H. P. Foster, Jr. 1979. "Reservoir Simulation of the Empire Abo: The Use of Pseudos in a Multilayered System." Society of Petroleum Engineers Journal. pp. 279-288. 
King, R. L. and W. J. Lee. 1976. "An Engineering Study of the Hawkins (Woodbine) Field." J. of Petroleum Technology.

Kirby, J. E., Jr., H. E. Stamm III, and L. B. Schnitz. 1957. "Calculation of the Depletion History and Future Performance of a Gas-Cap-Drive Reservoir." Petroleum Transactions, AIME. 210:218-226.

Littlefield, M., L. L. Gray, A. C. Godbold. 1948. "A Reservoir Study of the West Edmond Hunton Pool, Oklahoma," Trans., AIME, 174:131-155.

Lohrenz, J. and E. A. Monash. 1979. "Ultimate Recovery, Rate of Withdrawal, and Maximum Efficient Rate (MER) for 0il Reservoirs." In Symposium Proceedings, Maximum Efficient Rate (MER) for Petroleum Reservoirs in the Outer Continental Shelf, ed. J. W. McFarland, pp. 20-66.

Lowe, R. M. 1967. "Performance Predictions of the Marg Tex 0il Reservoir Using Unsteady-State Calculations," Society of Petroleum Engineers Paper No. 1496 presented at the SPE 4lst Annual Fall Meeting, Dallas, Texas, October 2-5, 1966.

Myers, R. H. 1976. Response Surface Methodology. Virginia Polytechnic Institute and State University, Blacksburg, Virginia.

Stone, H. L. and A. 0. Garder, Jr. 1961. "Analys is of Gas-Cap or Dissolved-Gas Drive Reservoirs." Paper presented at the 35th Annual Fall Meeting of Society of Petroleum Engineers, October 2-5, 1961, Denver, CO.

U.S. Geological Survey, Systems Analysis and Development Section. 1976. A Basic Reservoir Per Se Mathematical Model for Determining Ultimate Recovery Functions for a Variable Withdrawal Rate of a Gas-0iT-Water (VAR/GOW) System. SAD Section Report No. 77-10, U.S. Geological Survey, Conservation Division, Lakewood, CO.

Willingham, R. W., C. D. Howa 1d. 1965. "Case History of the Tens leep Reservoir, Torchlight Field, Wyoming," Journal of Petroleum Technology, Oct: $1159-1163$.

Wendlandt, E. A., T. H. Shelby, Jr., and J. S. Be11. 1946. "Hawkins Field, Wood County, Texas." Bullet in of the American Association of Petroleum Geologists. $30(11): 18 \overline{30-1856 .}$ 
APPENDIX A

DERIVATION OF THE INITIAL GAS DERIVATIVE CRITERIA 


\section{APPENDIX A}

\section{DERIVATION OF THE INITIAL GAS DERIVATIVE CRITERIA}

Reference: U.S. Geological Survey, SAD Section Report No. 77-10. Note: Equation numbers in [ ] refer to the equation numbers in the source report.

The initial gas derivative is given by:

[107] $\quad \dot{N}_{F G C}=\frac{b_{1}(\alpha \gamma-\beta \psi)-b_{2} \gamma+b_{3} \beta}{W}$

where

[89] $\quad b_{1}=-r_{\text {TOTAL }}-\frac{C F(1+n)\left(P^{0}-P\right)}{\alpha+\zeta n}$

$[90] \quad b_{2}=-C(1+F)\left(P^{0}-P\right)$

[91] $\quad b_{3}=-\frac{C F(\psi+n)\left(P^{0}-P\right)}{\alpha+\zeta n}-\frac{\psi+\frac{K_{R} v^{0} \phi}{\zeta}}{1+\frac{K_{R} v^{0}}{\zeta}} r_{\text {TOTAL }}$

[83] $\alpha=v^{0} \phi$

[85] $\quad \beta=v^{0} \phi^{\prime} N_{L}+\zeta^{\prime} N_{F G C}$ 


$$
\begin{aligned}
{[88] } & \gamma=\psi^{\prime} N_{L} \\
{[111] } & \psi=\frac{G P}{P^{0}+G P} \\
{[103] } & W=\beta(1-\psi)+\gamma(\alpha-\zeta)
\end{aligned}
$$

and

$$
\begin{aligned}
r_{T O T A L} & =r_{O I L}+r_{D G}+r_{F G} \\
n & =N_{F G} / N_{L} \\
{[110] \quad \zeta } & =R T^{0} / P \\
{[16] \quad K_{R} } & =10^{(a+b \sigma)} \\
v^{0} & =\frac{v_{L}^{0}}{N_{L}^{0}} \\
\phi & =\frac{1}{v_{r}}+\left(1-\frac{1}{v_{r}}\right) \frac{P}{P^{0}} \\
\sigma & =\frac{v_{F G}}{v_{F G}+v_{L}}
\end{aligned}
$$

The remaining variables have been defined in the nomenclature section. 
Since we are interested in deriving a criterion for the initial gas derivative, analyze equation (Al) at time equal to zero.

$$
\dot{N}_{F G C}^{0}=\frac{b_{1}^{0}\left(\alpha^{0} \gamma^{0}-\beta^{0} \psi^{0}\right)-b_{2}^{0} \gamma^{0}+b_{3}^{0} \beta^{0}}{W^{0}}
$$

where

$$
\begin{aligned}
& b_{1}^{0}=-r_{\text {TOTAL }}^{0} \\
& b_{2}^{0}=0 \\
& b_{3}^{0}=-r_{\text {TOTAL }}^{0} \frac{\left(\psi^{0}+k_{R}^{0} \frac{V_{L}^{0} \phi^{0}}{N_{L}^{0} \zeta^{0}}\right)}{\left(1+k_{R}^{0} \frac{V_{L}^{0} \phi^{0}}{N_{L}^{0} \zeta^{0}}\right)} \\
& \alpha^{0}=\frac{V_{L}^{0}}{N_{L}^{0}} \\
& \beta^{0}=\frac{V_{L}^{0}}{p^{0}\left(1-\frac{1}{v_{r}}\right)} \quad \text { assuming } N_{F G C}^{0}=0 \\
& \gamma^{0}=\frac{p^{0}(1+G)_{L}^{0}}{p^{2}}
\end{aligned}
$$




$$
\begin{aligned}
& \psi^{0}=\frac{G}{1+G} \\
& W^{0}=\beta^{0}\left(1-\psi^{0}\right)+\gamma^{0}\left(\alpha^{0}-\zeta^{0}\right) \\
& \zeta^{0}=\frac{R T^{0}}{P^{0}} \\
& K_{R}^{0}=10^{a} \text { since } \sigma^{0}=0 \text { if } V_{F G}^{0} \text { is assumed to be zero. }
\end{aligned}
$$

Now,

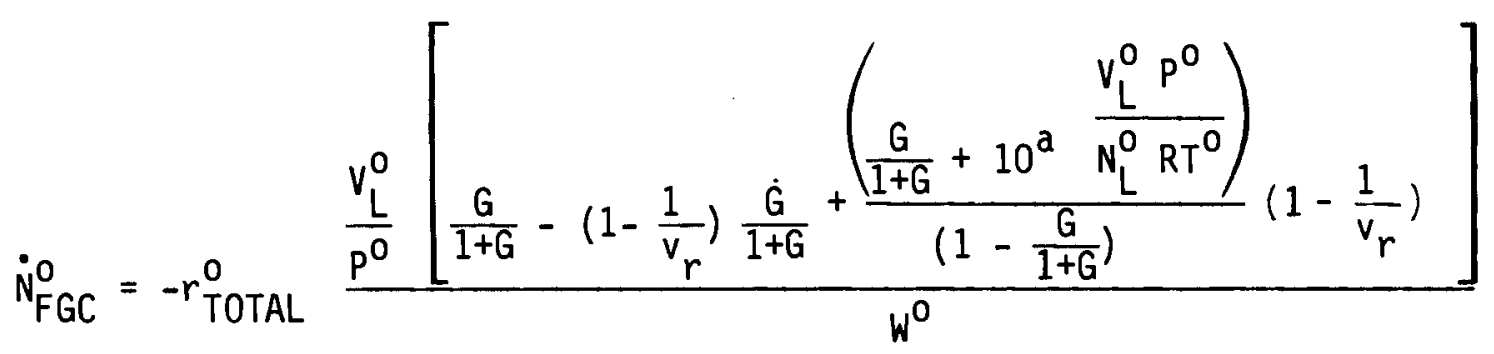

Since $r_{\text {TOTAL, }}^{0} V_{L}^{0}, P^{0}, N_{L}^{0}, T^{0}, R$, and $G$ are always greater than zero and $v_{r}$ is always greater than one, it can be determined that the numerator in Equation (A28) is always negative. Therefore, if a negative initial gas derivative is to be avoided, $W^{0}$ must also be negative. This means that the following inequality must hold for $\dot{\mathrm{N}}_{\mathrm{FGC}}^{0}$ to be positive:

$$
F_{F G C}<1
$$

where 


$$
F_{F G C}=\frac{V_{L}^{0} P^{0}}{N_{L}^{0} R T^{0}}\left[\frac{(1+G)^{2}}{G}\left(1-\frac{G}{1+G}\right)\left(1-\frac{1}{V_{r}}\right)+1\right]
$$


- 
APPENDIX B

RESERVOIR DATA SUMMARY 
APPENDIX B

\section{RESERVOIR DATA SUMMARY}

Certain reservoir data are necessary for operation and validation of the variable gas-oil-water (VARGOW) reservoir model. These data are divided into three groups: initial reservoir conditions, reservoir fluid characteristics, and performance history data. The initial conditions such as reservoir pressure, temperature, and gas in solution provide a starting point for the numerical solutions. Reservoir fluid characteristics such as the oil's specific gravity and chemical composition are necessary for the assignment of certain model parameters. Performance history data are used to evaluate the model predictions of pressure and production patterns.

The VARGOW model is based on 17 assumptions. Five of the assumptions can be directly evaluated for a given reservoir. This allows an assessment of the suitability of each reservoir data set for model operation to be made. Resulting information and the data types available are tabulated in Section 5.

The reservoir data for the Empire Abo pool in New Mexico have been found to be the most complete and should allow for good model operation and validation. The other data sets reviewed are not as complete. A gas-cap drive reservoir in Texas provided sufficient data for model operation with the exception of the oil's molecular weight or chemical composition. Data for the Hawkins (Woodbine) field in Texas were lacking chemical and relative permeability characteristics.

It is expected that during the remainder of the year, the VARGOW model will be applied to the Empire Abo pool and to the Hawkins (Woodbine) Field. In addition, the model will be tested on the gas-cap drive reservoir in Texas if the remaining required data can be located. It may be difficult to obtain these data, since the source document is nearly 20 years $01 d$, and the report did not mention the pool by name. 


\section{INTRODUCTION}

This report is a summary of available oil reservoir data of eleven pools reviewed for use in validating the variable gas-oil-water (VARGOW) reservoir model. The report is organized into six major sections. Following the conclusions, required reservoir data are given in Section 3 . This is a list of the initial conditions, reservoir fluid characteristics, and performance history data necessary for a complete data set. Following the list, we discuss the types of data usually available. The model assumptions are listed and discussed in Section 4. The data summary of Section 5 is made up of three tables. The first two show the types of data found for each reservoir reviewed, including specific items for initial conditions, fluid reservoir data, performance history, and the years of data available without enhanced recovery. Also included is a column for the rating of agreement of the reservoir with model assumptions. The third table indicates which assumptions were matched by each of the seven best reservoirs reviewed. These reservoirs are reviewed in detail in Section 6 with respect to their individual data sets.

\section{CONCLUSIONS}

The reservoir data reviewed to date have revealed much information for use in operation and validation of the variable gas-oil-water (VARGOW) reservoir model. Additional data sources are continually being sought to improve on the quality and quantity of data used for these activities. In particular, data from the New Mexico Annual Report (1958-1978) have added much detail to the performance history data of one reservoir in particular, the Empire Abo Field. This reservoir provides the most complete data set.

Several conclusions were made in the report:

- Reservoir field case histories usually provide sufficient data on initial conditions on which to base computer simulations.

- If available at all, information on a reservoir's relative permeabi1ity, water influx, and fluid characteristics is not always presented in a desirable form. 
- The relative permeability of the $0 i l$ and gas versus gas or liquid saturation is a function of the reservoir material. It is possible, then, to approximate this function for reservoirs on which data are not available. A number of relative permeability relationships for different types of reservoir rocks have been identified (Arps, 1955). A plot of this information on semi-logarithmic paper will give the constants needed for model operation.

- Chemical analysis or molecular weight of the stock tank oil is required for unit conversion. Several input parameters have molebased units, thus creating a great need for the chemical information.

- Field case histories usually present performance data in smoothed curves, which are not as desirable as data reported monthly (found in the recently located annual reports of the state of New Mexico).

- Data on the amounts of gas-cap gas, free gas and reservoir liquid remaining in the reservoir versus time would aid in model validation. This information was not found for any reservoir. Reservoir pressure history seems to be the only model "solution" variable readily available for model validation purposes. For certain reservoirs, however, we can check the validity of simulations using information on the time varying gas/oil ratio or on the gas and oil production.

- Five of the 17 assumptions employed in the VARGOW model can be used to evaluate a reservoir data set for its suitability in model operation and validation. The remainder are accepted as a means of simplifying the modeling process.

- The Empire Abo field case history and the information in the New Mexico annual reports provide the most complete data set for use in model operation and validation. The gas-cap drive reservoir and Hawkins field data are the next best, although chemical analysis information would greatly increase their usefulness. These three reservoirs will be used for model validation purposes. Difficulty in obtaining the additional data for the gas-cap drive reservoir is expected, since the source document is nearly 20 years old and the 
reservoir is not named. The balance of the reservoirs reviewed lack certain other data as shown in Tables 1 and 2. The data missing include water production history, water influx rates, and oil formation volume factors.

\section{RESERVOIR DATA}

The variable gas-oil-water (VARGOW) reservoir model ${ }^{(a)}$ must be operated and verified with actual oil reservoir data. An initial period of historical data is required to do interpolative model testing and to estimate certain model parameters. Extrapolative model testing can then be done to evaluate the model's predictive capabilities.

The data have been divided into three groups as follows: initial reservoir conditions to start numerical solutions, reservoir fluid characteristics for model operation, and performance history data for model output evaluation.

The required data on the initial reservoir conditions are:

- reservoir discovery pressure

- gas-oil ratio or gas in solution

- 0 il in place

- $0 i 1$ formation volume factor

- relative permeability of the oil and gas in the reservoir media as a function of gas or liquid saturation

- reservoir temperature

- initial oil production rate

- water influx rate versus the aquifer-reservoir differential pressure.

Certain reservoir fluid characteristics must be known for model operation, and for computing the initial oil production rate and reservoir liquid present

(a) Information obtained from a December 8, 1976 memorandum to the Chief of the Conservation Division, U.S. Geological Survey, from Systems Analysis and Development Section Staff. USGS, Lakewood, Colorado. Subject: SAD Section Report No. 77-10. 
on a mole basis. Also, the gas-0il ratio or gas in solution has volume units which must be converted to moles of gas per mole of $0 i 1$ as required by the mode1. The necessary data are:

- specific gravity of the $0 i 1$

- chemical analysis of the reservoir liquid

- chemical analysis of the casinghead gas.

Performance history data required to evaluate and verify model capabilities are:

- pressure history

- 0 il production history

- gas production or gas-oil ratio history

- history of the amount of gas existing as free gas and in the gas cap

- history of the amount of liquid (0il plus dissolved gas) remaining in the reservoir.

Most of these data are usually given in the field case history of a reservoir, which includes the initial values of reservoir pressure, temperature, gas/oil ratio or gas in solution, oil in place, the oil-formation-volumefactor, and oil production rate. Relative permeability and water influx data are presented in various ways, some more useful than others. These modes are discussed in the following two paragraphs.

The best form of relative permeability data for model operation purposes is a graph (on semi-logarithmic paper) of the ratio of the relative permeability of gas to that of oil versus gas saturation. This form was only found for the Payoa Basil Reservoir (Clinton 1967). The VARGOW model requires as input the slope and intercept of the best-fitting line to the data. Christianson (1977) presents the Empire Abo reservoir data in the form of relative permeability versus oil saturation. Stone (1961) shows two curves for a gas-cap driven reservoir: one pertaining to gas relative permeability and another pertaining to oil relative permeability, each versus liquid saturation (100\% minus oil or liquid saturation percent equals gas saturation percent). Since the relative permeability data are a function of the reservoir material, it is 
possible to approximate the curve for reservoirs without these data if the types of reservoir media are known. A number of relative permeability relationships for different types of reservoir rocks have been published (Arps $1955)$.

Water influx data were not found in the most desirable form in most cases. A constant (developed in the Schilthuis model) is needed for the VARGOW model to describe the water influx rate as a function of the differential aquiferreservoir pressure. This constant is given for the Hawkins Field (King 1976) and Marg Tex Reservoir (Lowe 1967) only. The gas-cap driven reservoir (Stone 1961) and the Umm Karud Field (Allen 1969) are noted as having no water drive that would allow the constant to be set at zero. The balance of the reservoir case histories reviewed give no water influx constants, although some accounts mentioned that an effective or limited water drive exists. The exception is the Empire Abo data (Christianson, 1977) which include a numerically estimated water influx rate over the life of the field.

Reservoir fluid characteristics are used primarily to make unit conversions to fit the VARGOW model's input format. The oil's specific gravity is easily found, although chemical analyses of the reservoir fluids are not readily available. This unavailability is unfortunate because the molecular weight of the stock tank $0 i 1$ is required to convert the units of certain parameters to mole-based units (e.g., to turn initial reservoir liquid into moles, oil production history into moles per year, and gas-oil ratio into moles of gas per mole of oil). To obtain chemical data for the Empire Abo Field, an employee of the Arco $0 i 1$ and Gas Company was consulted.

Performance history data cover such areas as reservoir pressure; 0il, gas and water production; the amount of gas-cap and free gas present in the reservoir; and the amount of liquid remaining. Smoothed curves of pressure and oil production histories are found without difficulty in the field case histories. Gas and water production curves are not consistently available. Annual production reports for Texas and New Mexico were recently located and should supply more useful data for model operation and validation. The types of information found in the New Mexico report are monthly values for oil, water, 
and gas production rates and cumulative amounts by pool, well, and county. The Texas report gives yearly values for reservoir oil and casinghead gas produced.

In the field, it is difficult or impossible to measure the amounts of gascap and free gas, and reservoir liquid that remain versus time. No calculated or measured values are given in any of the reservoir case histories.

\section{MODEL ASSUMPTIONS}

To assess the suitability of using a given set of reservoir data to verify the model, it must be determined how well the assumptions of the VARGOW reservoir model match the reservoir. The assumptions are as follows: (a)

1. The reservoir is homogeneous with respect to pressure.

2. The gas is ideal.

3. The water influx rate is proportional to the aquifer-reservoir pressure difference (follows the Schilthuis model).

4. The reservoir is a two-component system of $0 i 1$ and gas, and there is no $0 i 1$ in the gas phase ("black oil" assumption).

5. The $0 i 1$ and gas withdrawal rates are defined as functions of pressure and/or time.

6. The volumetric ratio of gas and oil entrapped behind the invading water to the volume of water is constant.

7. The gas and oil is entrapped behind the invading water at the current reservoir pressure and has no effect on the reservoir after entrapment.

8. The reservoir is isothermal.

9. The reservoir is not adiabatic.

(a) Information obtained from a December 8, 1976 memorandum to the Chief of the Conservation Division, U.S. Geological Survey, from Systems Analys is and Development Section Staff. USGS, Lakewood, Colorado. Subject: SAD Section Report No. 77-10. 
10. The reservoir is initially at the bubble point.

11. The gas cap, which is time dependent, forms from the reservoir gas in the oil zone and migrates to the "top" of the reservoir.

12. The liquid phase volume is linear with pressure between the original bubble point volume and the stock tank volume.

13. The relative permeability ratio forms a straight line with gas saturation on semilogarithmic paper.

14. The amount of gas and oil trapped at any time by the invading water is directly proportional to the amount present at that time.

15. Production of gas and oil ceases when the pressure becomes some low pressure or the volume becomes some low volume, or the withdrawal rate becomes some low rate, whichever occurs first.

16. The phase equilibrium ratio between dissolved gas and oil is directly proportional to the pressure.

17. There is no enhanced recovery.

It is assumed that the reservoir is homogeneous with respect to pressure and temperature. Slightly inhomogeneous reservoirs, therefore, should be characterized by average values. A very inhomogeneous reservoir might be better handled by a multi-dimensional grid model.

The gas is assumed to be ideal and to migrate from the oil zone to the top of the reservoir to form the gas cap. The "black oil" assumption holds that there is no oil in the gas phase, and that the reservoir is a two-component system. The volumetric ratio of oil and gas entrapped by the invading water is assumed to be constant. It is assumed that the amount trapped is directly proportional to the amount present, and that entrapment occurs at the current reservoir pressure, causing no effects thereafter. The reservoir is assumed to be nonadiabatic. The liquid phase volume is assumed to be linear with pressure, and the phase equilibrium ratio of dissolved gas to oil is assumed to be directly proportional to pressure. All of these assumptions cannot be readily evaluated for a reservoir and are accepted here as a means of simplifying the modeling process. 
The assumptions numbered 3, 5, 10, 13 and 17 are most easily employed for the evaluation of the suitability of a reservoir for model operation and validation. A rating system has been devised to check these five assumptions with actual reservoir conditions. If four or five assumptions hold true, the reservoir data set is rated good. Two or three matched assumptions constitute a fair rating and less than two is poor. The results of this evaluation are shown for seven reservoirs in Table 3 in Section 5.

\section{DATA SUMMARY}

Field case histories found in the literature were reviewed for oil reservoir data. Eleven of these are included in this data summary showing the types of information given for each. Table B.1 covers initial-condition data, and Table B.2 includes reservoir fluid characteristics and performance history data. Years of performance data available without enhanced recovery are also listed in Table B.2. Table B.3 indicates the assumptions that hold true for each of the seven best reservoirs reviewed. These seven, discussed separately in Section 6, are considered the best because of the amount of data available and the agreement of the reservoir with model assumptions. The remainder of the eleven reservoirs reviewed were rated poor relative to the first seven with respect to evaluation of data and assumptions. 
TABLE B.1. Data Summary - Initial Conditions

\begin{tabular}{|c|c|c|c|c|c|c|c|c|c|c|c|}
\hline & Reservoir & $\begin{array}{l}\text { Reservoir } \\
\text { Pressure } \\
\end{array}$ & $\begin{array}{l}\text { Gas-oil } \\
\text { Ratio } \\
\text { or } \\
\text { Gas in } \\
\text { Solution }\end{array}$ & $\begin{array}{l}0 i 1 \text { in } \\
\text { Place }\end{array}$ & $\begin{array}{c}\text { Dil } \\
\text { Formation } \\
\text { Volume } \\
\text { Factor } \\
\end{array}$ & $\begin{array}{c}\text { Relative } \\
\text { Permeability } \\
\text { Versus } \\
\text { Gas or Liquid } \\
\text { Saturation } \\
\end{array}$ & $\begin{array}{l}\text { Reservoir } \\
\text { Temper ature } \\
\end{array}$ & $\begin{array}{l}\text { Initial 0il } \\
\text { Production } \\
\text { Rate } \\
\end{array}$ & $\begin{array}{l}\text { Constant } \\
\text { Given for } \\
\text { Water Influx } \\
\text { Versus } \\
\text { Differential } \\
\text { Pressure } \\
\end{array}$ & $\begin{array}{r}\text { Agreement } \\
\text { with Model } \\
\text { Assumptions } \\
\end{array}$ & $\begin{aligned} G & =\text { good } \\
F & =f a \text { ir } \\
P & =\text { poor }\end{aligned}$ \\
\hline & $\begin{array}{l}\text { 1. Empire Abo Field, New Mexico } \\
\text { (Christianson, 1977) }\end{array}$ & $x$ & $x$ & $x$ & $x$ & $x$ & $x$ & $x$ & $x(1)$ & G & \\
\hline & $\begin{array}{l}\text { 2. Gas-Cap Drive Reservoir, Texas } \\
\text { (Stone, 1961) }\end{array}$ & $x$ & $x$ & $x$ & $x$ & $x$ & $x$ & $x$ & $x(2)$ & G & \\
\hline & $\begin{array}{l}\text { 3. Hawkins (Woodbine) Field, Texas } \\
\text { (King, 1976) }\end{array}$ & $x$ & $x$ & $x(3)$ & $x$ & & $x(4)$ & $x$ & $x$ & G & \\
\hline & $\begin{array}{l}\text { 4. West Edmond 0il Field, Ok lahoma } \\
(\text { Littlefield, 1947) }\end{array}$ & $x$ & $x$ & $x$ & & & $x(4)$ & $x$ & & $F$ & \\
\hline & $\begin{array}{l}\text { 5. Marg Tex 0il Reservoir, Louisiana } \\
\text { (Lowe, 1967) }\end{array}$ & $x$ & $x$ & $x$ & $x$ & & $x$ & $x$ & $x$ & $\mathrm{~F}$ & \\
\hline & $\begin{array}{l}\text { 6. Payoa Basal Reservoir, Columbia } \\
\text { (Clinton, 1967) }\end{array}$ & $x$ & $x$ & $x$ & $x$ & $x$ & $x$ & $x$ & & $\mathrm{~F}$ & \\
\hline 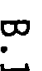 & $\begin{array}{l}\text { 7. Coldwater 0il Field, Michigan } \\
\text { (Criss, 1953) }\end{array}$ & $x$ & $x$ & & $x$ & & $x$ & $x$ & & $\mathrm{~F}$ & \\
\hline 0 & $\begin{array}{l}\text { 8. Auk Field, North Sea } \\
\text { (Buchanan, 1979) }\end{array}$ & $x$ & $x$ & $x$ & & & $x$ & $x$ & & p & \\
\hline & $\begin{array}{l}\text { 9. Bell Creek Field, Montana } \\
\text { (Hadenhorst, 1968) }\end{array}$ & $x(5)$ & $x$ & $x(3)$ & $x$ & & $x$ & $x$ & & $p$ & \\
\hline & $\begin{array}{l}\text { 10. Tens leep Reservoir, Wyoming } \\
(\text { Will ingham, 1965) }\end{array}$ & $x$ & $x$ & $x$ & $x(6)$ & & $x$ & $x$ & & $p$ & \\
\hline & $\begin{array}{l}\text { 11. Umm Farud } F \text { ield, Libya } \\
\text { (A)len, 1969) }\end{array}$ & $x$ & $x$ & $x$ & $x$ & & $x$ & $x$ & $x(2)$ & $p$ & \\
\hline & \multicolumn{11}{|l|}{$\begin{array}{l}\text { (1) Estimated from pressure history wi } \\
\text { (2) There is no water drive. } \\
\text { (3) Calculated from geometry and poros } \\
\text { (5) Inferred from reservoir depth. } \\
\text { (5) Giver at bubble point pressure. }\end{array}$} \\
\hline
\end{tabular}




\section{TABLE B.2. Data Summary - Reservoir Fluid Characteristics and Performance History}

\begin{tabular}{|c|c|c|c|c|c|c|c|c|c|c|c|}
\hline & Reservoir & $\begin{array}{l}\text { Oil } \\
\text { Specific } \\
\text { Gravity } \\
\end{array}$ & $\begin{array}{l}\text { Chemical } \\
\text { Analys is of } \\
\text { Reservoir } \\
\text { Liquid } \\
\end{array}$ & $\begin{array}{l}\text { Chemical } \\
\text { Analys is } \\
\text { of Casing- } \\
\text { head Gas } \\
\end{array}$ & $\begin{array}{l}\text { Pressure } \\
\text { History }\end{array}$ & $\begin{array}{l}\text { Oil } \\
\text { Production } \\
\text { History } \\
\end{array}$ & $\begin{array}{c}\text { Gas } \\
\text { Production } \\
\text { or Gas Ratio } \\
\text { History } \\
\end{array}$ & $\begin{array}{l}\text { Water } \\
\text { Production } \\
\text { History } \\
\end{array}$ & $\begin{array}{c}\text { Gas Cap } \\
\text { and Free } \\
\text { Gas Amount } \\
\text { vs. Time } \\
\end{array}$ & $\begin{array}{l}\text { Reservoir } \\
\text { Liquid } \\
\text { Amount } \\
\text { vs. Time. } \\
\end{array}$ & $\begin{array}{l}\text { Years } \\
\text { of Data } \\
\text { Without } \\
\text { Enhanced } \\
\text { Recovery } \\
\end{array}$ \\
\hline & $\begin{array}{l}\text { 1. Empire Abo Field, New Mexico } \\
\text { (Christianson, 1977) }\end{array}$ & $x$ & $x(1)$ & $x(1)$ & $x$ & $x$ & $x$ & $x$ & & & 16 \\
\hline & $\begin{array}{l}\text { 2. Gas-Cap Drive Reservoir, Texas } \\
\text { (Stone, 1961) }\end{array}$ & $x$ & & & $x(2)$ & $x$ & $x(2)$ & & & & 8 \\
\hline & $\begin{array}{l}\text { 3. Hawkins (Woodbine) Field, Texas } \\
\text { (K ing, 1976) }\end{array}$ & $x$ & & & $x$ & $x$ & $x$ & $x$ & & & 29 \\
\hline & $\begin{array}{l}\text { 4. West Edmond 0il Field, Ok lahoma } \\
\text { (Littlefield, 1947) }\end{array}$ & $x$ & & & $x$ & $x$ & $x$ & $x$ & & & 3 \\
\hline & $\begin{array}{l}\text { 5. Marg Tex 0il Reservoir, Lou isiana } \\
\text { (Lowe, 1967) }\end{array}$ & $x$ & & & $x$ & $x$ & & $x$ & & & 15 \\
\hline & $\begin{array}{l}\text { 6. Payoa Basal Reservoir, Columbia } \\
\text { (Clinton, 1967) }\end{array}$ & $x$ & & & $x$ & $x$ & $x$ & & & & 2 \\
\hline 泀 & $\begin{array}{l}\text { 7. Coldwater 0il Field, Michigan } \\
\text { (Criss, 1953) }\end{array}$ & $x$ & & $x$ & $x$ & $x$ & & $x$ & & & 3 \\
\hline & $\begin{array}{l}\text { 8. Auk Field, North Sea } \\
\text { (Buchanan, 1979) }\end{array}$ & $x$ & & & $x$ & $x$ & & $x$ & & & 2 \\
\hline & $\begin{array}{l}\text { 9. Bell Creek Field, Montana } \\
\text { (Hadenhorst, 1968) }\end{array}$ & $x$ & & $x$ & $x(3)$ & $x$ & $x$ & & & & 2 \\
\hline & $\begin{array}{l}\text { 10. Tensleep Reservoir, Wyoming } \\
(\text { Willingham, 1965) }\end{array}$ & $x$ & & & $x$ & $x$ & & & & & 10 \\
\hline & $\begin{array}{l}\text { 11. Umm Farud Field, Libya } \\
(\text { Allen, 1969) }\end{array}$ & & & & $x(2)$ & $x$ & & & & & 2 \\
\hline & $\begin{array}{l}\text { (1) Information obtained from } A \text {. W. Jo } \\
\text { (2) Values given as a function of anot } \\
\text { (3) Inferred from pressures given at a }\end{array}$ & $\begin{array}{l}\text { ohnston of } \\
\text { ther value } \\
\text { a shallowe }\end{array}$ & $\begin{array}{l}\text { Arco } 0 i 1 \text { an } \\
\text { with known } \\
\text { r depth }\end{array}$ & $\begin{array}{l}\text { Compd } \\
\text { funct }\end{array}$ & ald & 15 , & 1980 & & & & \\
\hline
\end{tabular}


TABLE B.3. Reservoir Agreement with Model Assumptions

\begin{tabular}{|c|c|c|c|c|c|c|}
\hline Reservoir & $\begin{array}{l}\text { Water Influx } \\
\text { Proportional } \\
\text { to Pressure } \\
\text { Differential } \\
\end{array}$ & $\begin{array}{c}\text { 0il, Gas } \\
\text { Withdrawals } \\
\text { Given Versus } \\
\text { Pressure or Time } \\
\end{array}$ & $\begin{array}{c}\text { Initial Pressure }= \\
\text { Bubble Point Pressure }\end{array}$ & $\begin{array}{c}\text { Relative } \\
\text { Permeability } \\
\text { Given Versus } \\
\text { Saturation } \\
\end{array}$ & $\begin{array}{l}\text { No Enhanced } \\
\text { Recovery }(1) \\
\end{array}$ & Rating \\
\hline $\begin{array}{l}\text { 2. Gas-Cap Drive Reservoir, Texas } \\
\text { (Stone, 1961) }\end{array}$ & $x(2)$ & $x$ & $x$ & $x$ & $x$ & good \\
\hline $\begin{array}{l}\text { 4. West Edmond 0il Field, Ok lahoma } \\
\text { (Littlefield, 1947) }\end{array}$ & & $x$ & $x(4)$ & & $x$ & fair \\
\hline $\begin{array}{l}\text { 5. Marg Tex 0il Reservoir, Louisiana } \\
\text { (Lowe, 1967) }\end{array}$ & $x$ & $x(3)$ & & & $x$ & fair \\
\hline $\begin{array}{l}\text { 6. Payoa Basal Reservoir, Columbia } \\
\text { (Clinton, 1967) }\end{array}$ & & $x$ & & $x$ & $x$ & fair \\
\hline
\end{tabular}

(1) This means that there is performance data available without enhanced recovery (See table 2 , last column for number of years).

(2) It is stated that there is no water drive: $C=0$.

(3) Only the oil production history is given.

(4) The initial reservoir pressure is slightly above the bubble point pressure. 


\section{RESERVOIR DISCUSSIONS}

The first three reservoirs listed in the data summary are rated highest with respect to agreement with model assumptions. The next four are rated fair. Each of these pools will be reviewed below for its agreement with assumptions, available data, and usefulness in model validation.

\subsection{Empire Abo Field}

The Empire Abo pool fits quite well into the group of assumptions used by the variable gas-oil-water reservoir model (Christianson, 1977). Although no water influx data are given, Christianson (1977) has estimated a value for total influx rate over the life of the reservoir. His numerical model studies showed that this rate was necessary to sustain actual reservoir pressures. The water influx constant may then be estimated by assuming that the influx rate occurred at an average reservoir pressure and that no water influx occurred at the initial reservoir pressure.

Christianson (1977) shows pressure and oil, gas, and water production on a small graph versus the years in production, beginning in 1958. The recently located New Mexico annual report gives production data for each month beginning in 1958 and bottom hole pressures for each year, beginning in 1960 . The annual report data are more desirable than the smooth curves given in the field case history.

The Empire Abo reservoir discovery pressure is very close to the bubble point pressure, as assumed by the VARGOW model. The relative permeability ratio of $0 i 1$ and gas is presented by Christianson (1977) as a function of oil saturation, which is a desirable form for model input purposes. 0 il recovery was not enhanced for 16 years of performance, thus providing substantial data for model validation.

Gas-cap gas, free gas, and reservoir liquid remaining in the reservoir versus time were not given in the field case history of Empire Abo or any of the pools reviewed. To date, the chemical composition of the reservoir liquid and the casinghead gas has been established for the Empire Abo field only. This information is highly desirable because it eliminates the need for 
statistical estimation of certain model parameters. Overal1, the Empire Abo reservoir lends the most information for model validation purposes.

\subsection{Gas-Cap Drive Reservoir}

An unidentified gas-cap driven reservoir, most likely in Texas, is addressed in an article discussing a numerical method of predicting reservoir behavior (Stone 1961). Compliance with model assumptions is good, as shown in Table 3 of the data summary. There is no active water drive, which means that the water influx constant required by the model is set at zero. The oil production rate is given in a smoothed curve of data versus time in years. Bottom hole and gas-cap pressures are shown as smoothed functions of cumulative oil production. A table of fluid properties lists solubility (gas/oil ratio) versus pressure to allow rough calculation of the gas production history. The original and saturation pressures are the same. Relative permeabilities of oil and gas are shown as functions of liquid saturation. Eight years of performance data are available and no enhanced recovery is mentioned.

Water production data and chemical analysis information are not given, although the remainder of the required data is available. Aside from not listing the molecular weight of the oil, this data group should be fairly adequate for model operation purposes.

\subsection{Hawkins (Woodbine) Field}

The Hawkins Field is located in the Woodbine basin of Texas (King 1976). A rating of good is given to this reservoir for its agreement with model assumptions. The water influx rate, shown as a function of differential pressure, is approximated as a straight line which provides influx constants for model input. 0il production, gas/oil ratio, and the pressure and percent of water produced are given as smoothed functions of time. Original and saturation pressures are very close. Although no relative permeability or chemical analysis information was available for this data group, there are 29 years of performance data shown without enhanced recovery. The remainder of the necessary data is available for use in model operation and validation. 


\subsection{West Edmond 0 il Field}

The West Edmond pool is located in Central Oklahoma (Littlefield 1946). The reservoir agrees fairly well with model assumptions, although some data are missing. Water invasion is considered very small. No water influx rate information is given except for a total water influx estimate. 0il, gas, and water production and reservoir pressure are given as smoothed functions of time. Initially, the reservoir was slightly undersaturated. No enhanced recovery is mentioned for the few years of performance data available when the field case history was written.

In addition to a paucity of relative permeability and chemical analysis data, data on the oil formation volume factor are missing. The data group is therefore less desirable for model operation than the previous ones mentioned.

\subsection{Marg Tex 0il Reservoir}

The Marg Tex oil reservoir in Louisiana is highly undersaturated (Lowe 1967). This opposes the VARGOW model assumption that the initial reservoir pressure is at the bubble point. Yearly values of cumulative $0 i l$ and water production are given, but not for gas. The field case history is lacking in relative permeability and chemical composition information, although a water influx constant is given. The 15 years of performance data available are without enhanced recovery. A rating of fair is given to the Marg Tex reservoir.

\subsection{Payoa Basal Reservoir}

A case history of the Payoa field Eocene reservoir in Colombia gives no water influx or water production information (Clinton 1967). A small gas cap existed initially in this undersaturated reservoir. Relative permeability versus gas saturation is given for the pool. Chemical analys is data were not available in this field case history, and only two years of performance are shown prior to enhanced recovery by gas injection. Performance histories of the Payoa field are shown as smoothed curves of pressure, gas/oil ratio, oil production and accumulated oil versus time. This data group is rated fair. 


\subsection{Coldwater 0il Field}

The Coldwater reservoir in Michigan has a natural water drive, although no influx rates are given. Smoothed data are given for reservoir pressure, water production, and daily and cumulative oil production. Chemical analys is is given only for the casinghead gas. Original oil in place and relative permeability data are missing in this data set. Overall, the Coldwater data are only fair with respect to suitability for model validation. 
PNL -3478

UC-92

\section{DISTRIBUTION LIST}

No. of

Copies

OFFSITE

A. A. Churm

DOE Patent Division

9800 S. Cass Avenue

Argonne, IL 60439

B. Walker

U.S. Department of the Interior Geological Survey

EGS-Mail Stop 620

Reston, VA 22092

167 DOE Technical Information Center

H. Toml inson

U.S. Department of the Interior Geological Survey

EGS-Mail Stop 620

Reston, VA 22092

J. Gregory

U.S. Department of the Interior Geological Survey

EGS-Mail Stop 620

Reston, VA 22092

D. Kash

U.S. Department of the Interior Geological Survey

EGS-Mail Stop 620

Reston, VA 22092

25 Dr. J. Lohrenz

U.S. Department of the Interior Geological Survey

Conservation Division

Mail Stop 608

Box 25046, Denver Federal Center

Denver, CO 80225
No. of

Copies

25 E. Monash

U.S. Department of the Interior Geological Survey

Conservation Division

Mail Stop 608

Box 25046, Denver Federal Center

Denver, CO 80225

H. Oden

U.S. Department of the Interior

Geological Survey

EGS-Mai1 Stop 620

Reston, VA 22092

Dr. D. Voss

12240 SE 60th

Bellevue, WA 98006

ONSITE

DOE Richland Operations Office

H. E. Ransom

17 Pacific Northwest Laboratory

E. M. Arnold

W. M. Bowen

S. M. Brown

D. B. Cear lock

P. J. Gutknecht

D. W. Mayer (5)

Publishing Coordination (2)

Technical Information (5) 
